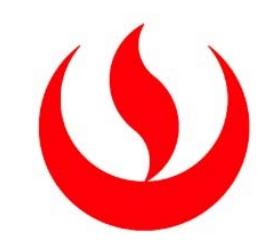

UNIVERSIDAD PERUANA DE CIENCIAS APLICADAS

ESCUELA DE POSTGRADO

PROGRAMA DE MAESTRÍA EN ADMINISTRACIÓN DE EMPRESAS

Plan de negocio para la implementación de un servicio tutorial online para

escolares

\title{
TRABAJO DE INVESTIGACIÓN
}

Para optar el grado académico de Maestro en Administración de Empresas

\section{AUTORES}

Cavero Díaz, Elisa Isabel (0000-0003-1406-1763)

Meincken, Sánchez-Moreno, Julie (0000-0001-6640-6853)

Vidurrizaga Costa, Rosario Marcela (0000-0003-1692-4737)

\section{ASESOR}

Alania Vera, Ricardo Humberto (0000-0001-9528-5798)

Lima, 16 de abril de 2019 


\section{DEDICATORIA}

A nuestras familias que nos inspiran cada día a ser mejores: Carlos, Fabrizio, Marcelo

David, Santiago, Cayetana, Américo, Olga, Ian y Sandy. 


\section{AGRADECIMIENTOS}

Queremos agradecer a nuestro asesor, Ricardo Alania, por su motivación y dedicación para nuestro proyecto. Asimismo a los profesores del MBA para titulados del Máster UPC que nos aportaron con su visión estratégica para negocios y así poder convertirnos en mejores profesionales. Al apoyo de David Mendoza, que nos orientó con su perspectiva empresarial. Y por último a nuestras familias por la paciencia durante esta maestría. 


\section{RESUMEN}

El presente plan de negocio muestra la oportunidad y viabilidad de Klaz: un nuevo servicio de tutoría online en tiempo real, para escolares de segundo grado de primaria a onceavo grado de secundaria de colegios de NSE AB, donde el alumno/a podrá acceder a clases del curso en el que tenga dificultades o para algún tema específico, interactuando con profesores capacitados y empáticos, a través de un dispositivo móvil, tablet, laptop o PC. Asimismo, este servicio permitirá a los padres de familia, monitorear la clase y recibir reportes de avances. La cobertura en una primera etapa será Lima metropolitana y a corto plazo se ampliará a colegios de NSE B- y C, y a mediano plazo a nivel nacional.

Para analizar la viabilidad de su ejecución se llevó a cabo una investigación de mercado, la cual evidenció las desventajas del servicio de tutoría presencial actual frente a lo cual Klaz se presenta como una propuesta innovadora que responde al nuevo escenario de generaciones nativo digitales. También permitió proyectar el mercado potencial, estimando que el $30 \%$ de los estudiantes necesitan refuerzo escolar.

Es por ello que desarrollaremos una plataforma digital, que permita la interacción en forma amigable entre profesor y estudiante y así facilitar la enseñanzaaprendizaje, respondiendo a las tendencias digitales y educativas.

Para la ejecución de este proyecto se requerirá de una inversión inicial de $\mathrm{S} / 100,000$ y posteriores aportes de S/70,000 y S/100,000. Financiado íntegramente por las accionistas. El punto de equilibrio se alcanzará en el primer trimestre del segundo año de operaciones.

Palabras clave: Tutoría; online; escolares; profesor; particular. 


\begin{abstract}
This business plan shows the opportunity and feasibility of Klaz: a new online tutoring service in real time, for second grade in elementary schools to eleventh grade in high schools with $\mathrm{AB}$ socioeconomic status, where the student can access tutoring classes the classes of the course in which he or she has difficulties or a specific topic, interacting with trained and empathetic teachers, through a mobile device, tablet, laptop or PC. In addition, this service will allow parents to monitor the class and receive progress reports. The first stage will cover metropolitan Lima and in short-term it will expand to socioeconomic status B- and C schools, and in medium-term will be extended nationwide.
\end{abstract}

A market research was carried out to analyze the feasibility of its execution, which demonstrated the disadvantages of current face-to-face tutoring service, against which Klaz is presented as an innovative proposal that responds to the new scenario of digital native generation. It also allowed to project the potential market, estimating that $30 \%$ of students need tutoring.

That is why we will develop a digital platform that allows a friendly interaction between teacher and student and thus facilitate teaching and learning, responding to digital and educational trends.

The implementation of this project will require an initial investment of $S / 100,000$ and subsequent contributions of $S / 70,000$ and $S / 100,000$. fully funded by the shareholders. Breakeven will be reached on 1Q of Year 2.

Keywords: tutoring; on-line; students; private teacher. 


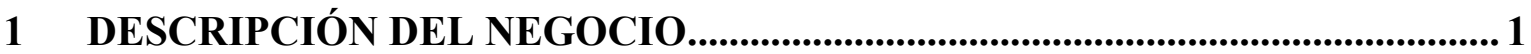

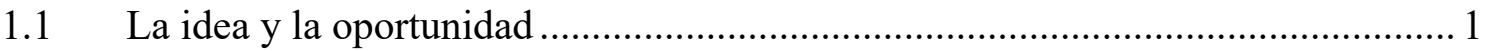

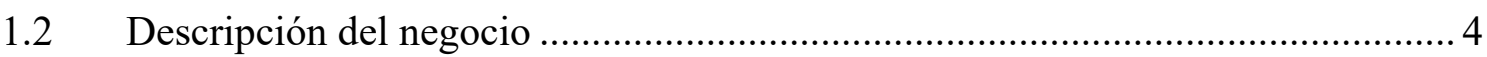

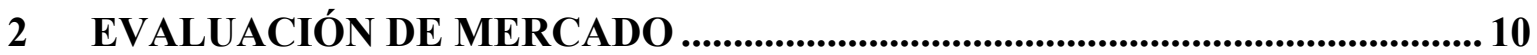

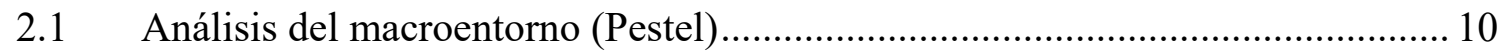

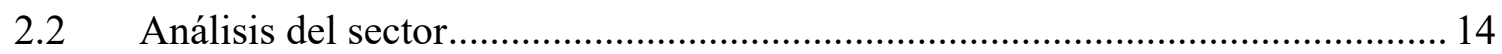

2.2.1 Análisis del micro entorno: Las cinco fuerzas de Porter............................ 14

2.2.2 Investigación del mercado objetivo ......................................................... 17

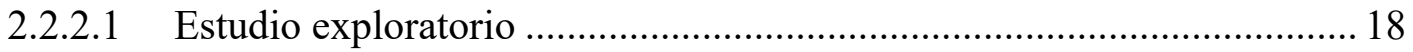

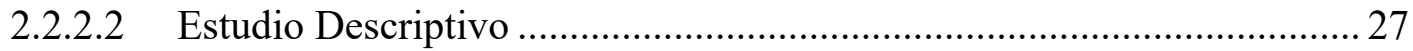

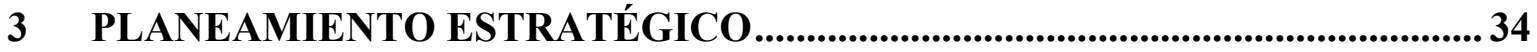

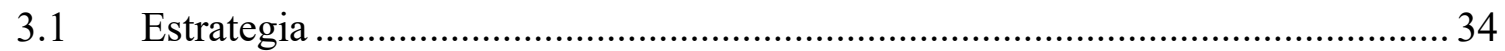

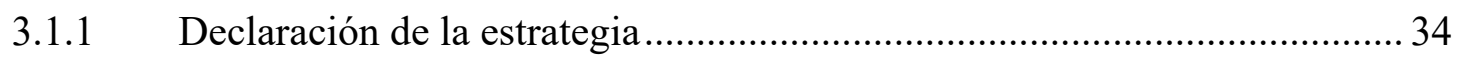

3.2 Misión y visión del negocio, valores y grupos de interés.................................... 34

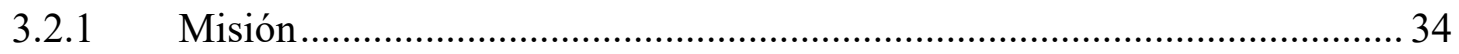

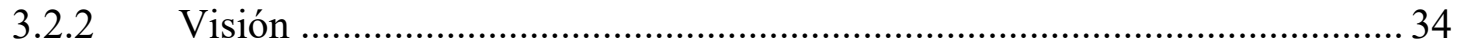

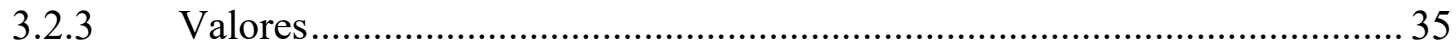

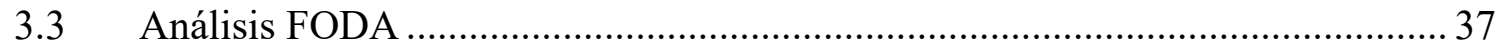

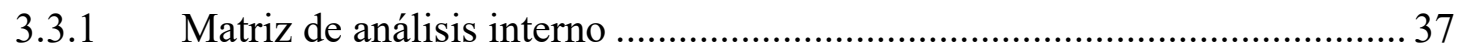

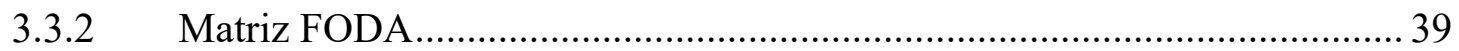

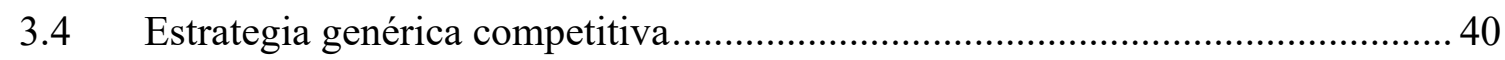

3.5 Objetivos estratégicos y específicos ............................................................. 41

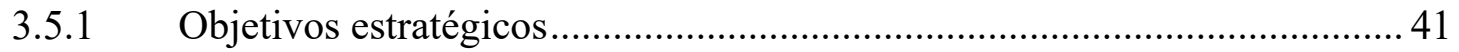

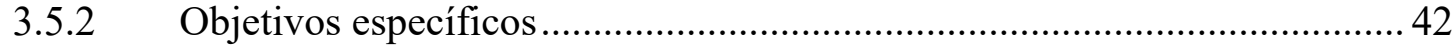

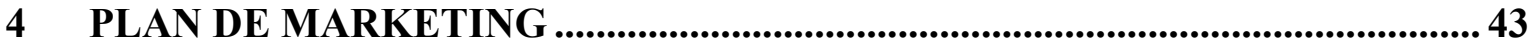

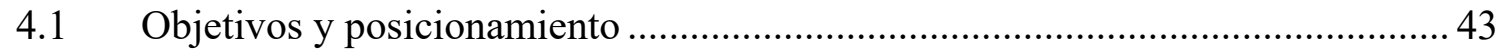

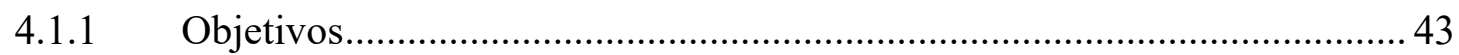

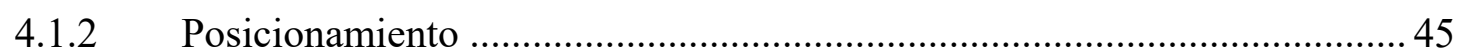

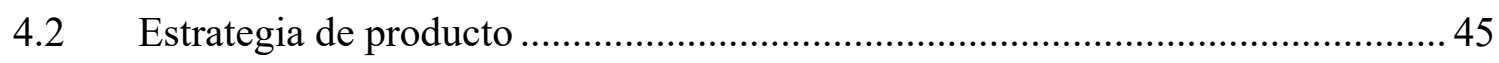




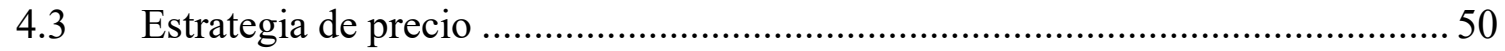

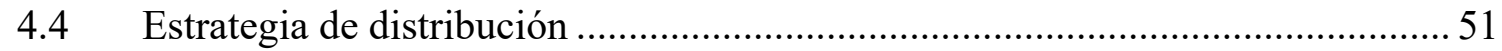

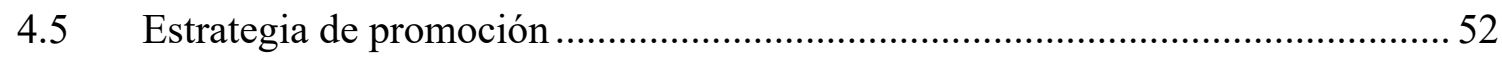

4.5.1 Segmentación y target de comunicación .................................................. 52

4.5.2 Personalidad de la marca ......................................................................... 54

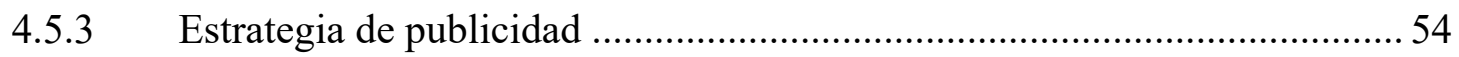

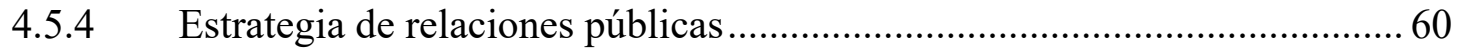

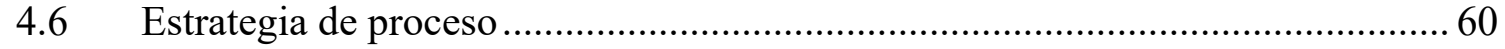

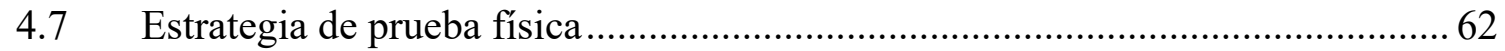

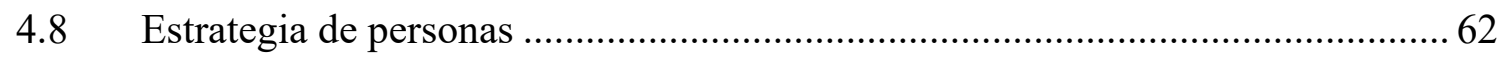

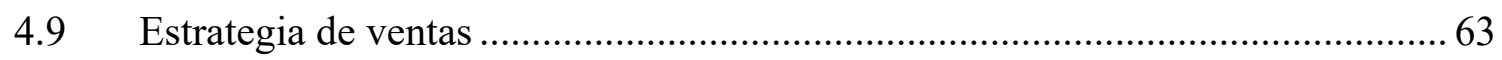

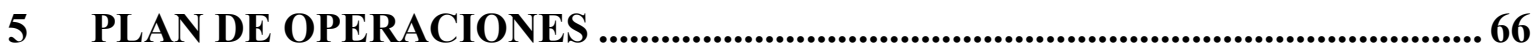

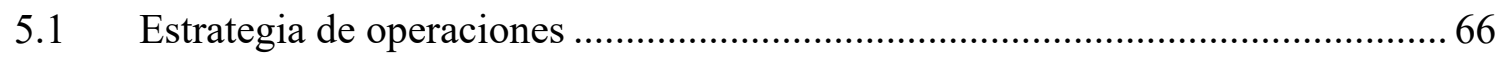

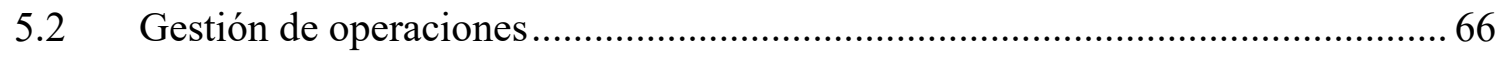

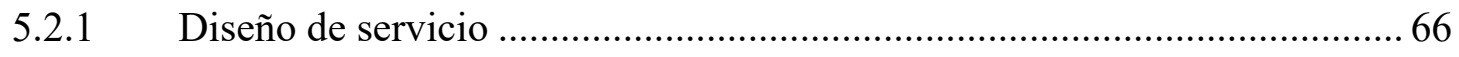

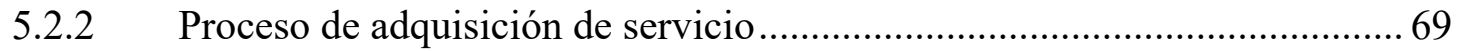

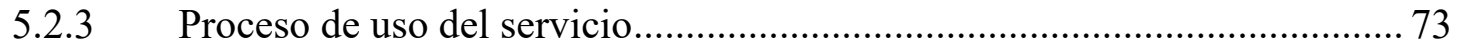

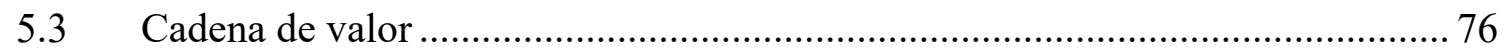

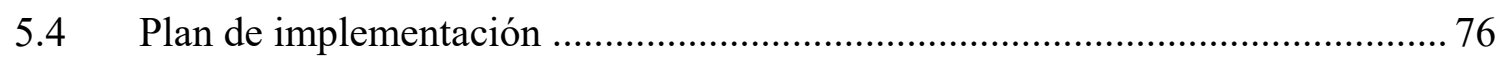

6 ORGANIZACIÓN Y PLAN DE RECURSOS HUMANOS................................. 80

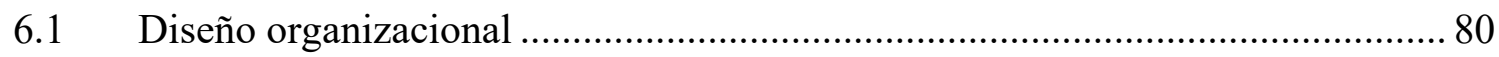

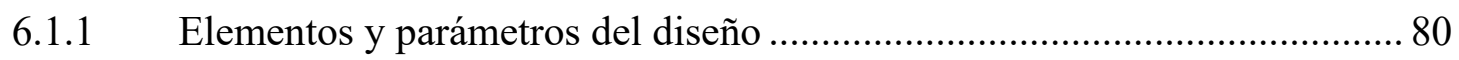

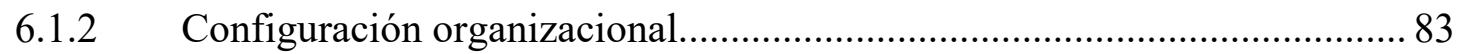

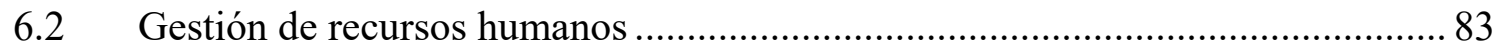

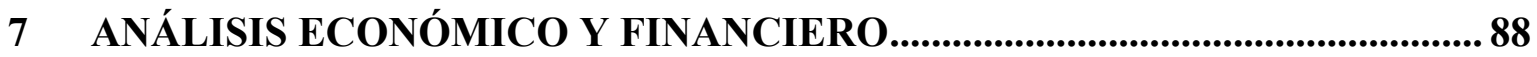

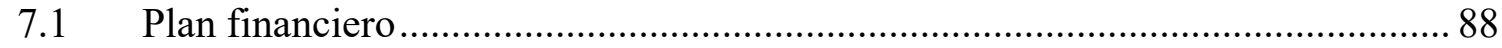

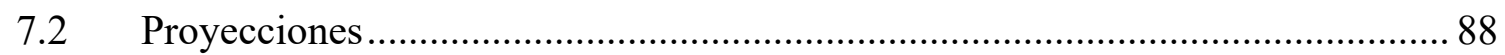

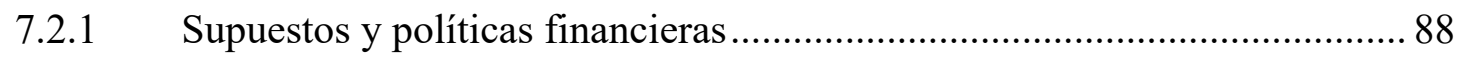

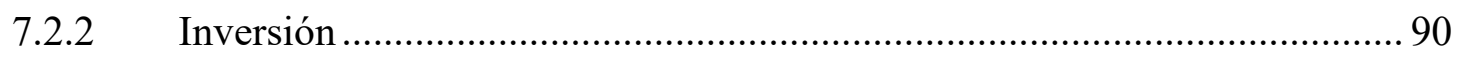

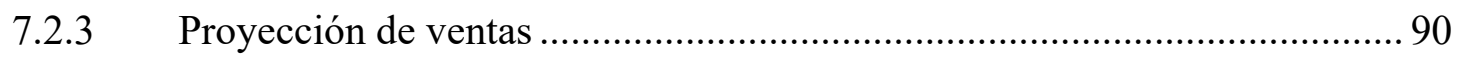

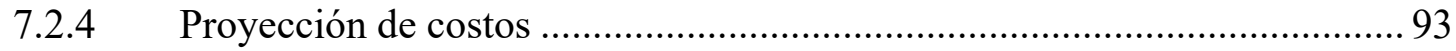




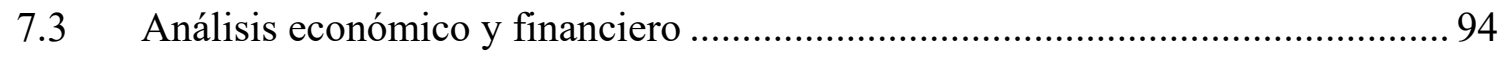

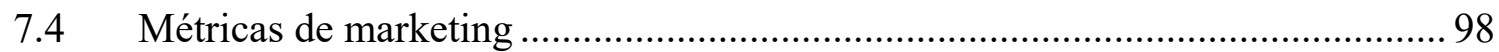

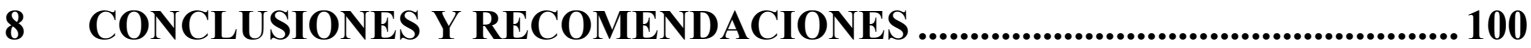

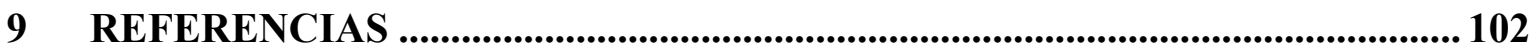

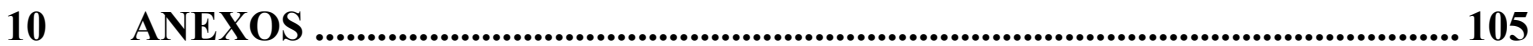




\section{ÍNDICE DE TABLAS}

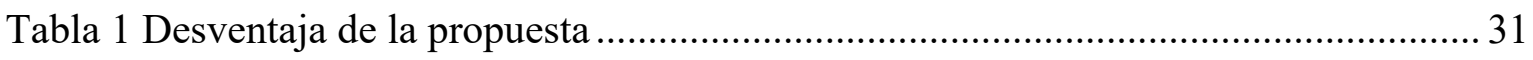

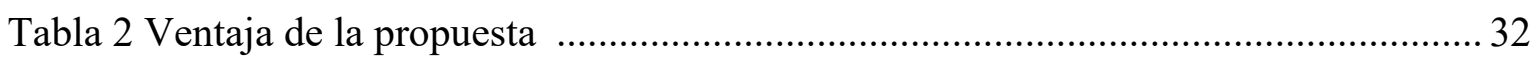

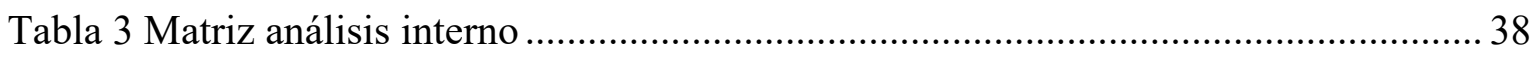

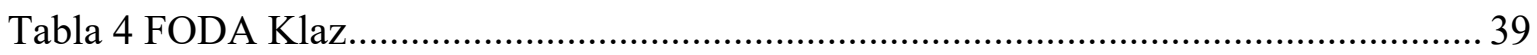

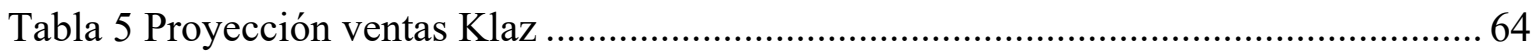

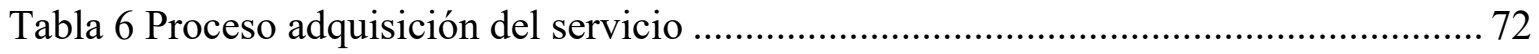

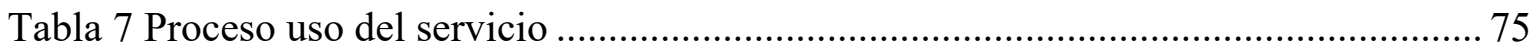

Tabla 8 Cronograma de implementación de plataforma digital ...................................... 78

Tabla 9 Cronograma de implementacion de operaciones............................................... 79

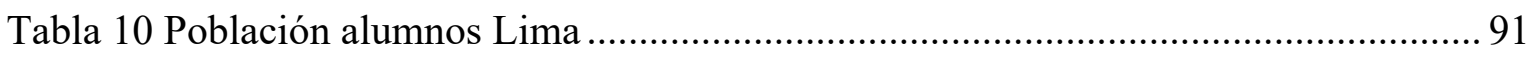

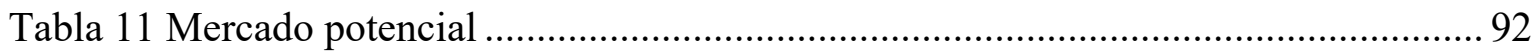

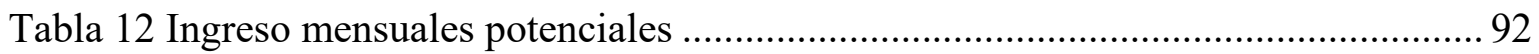

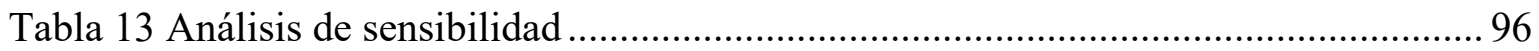

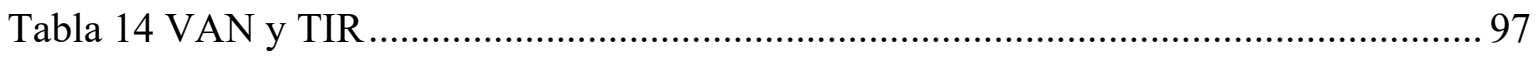

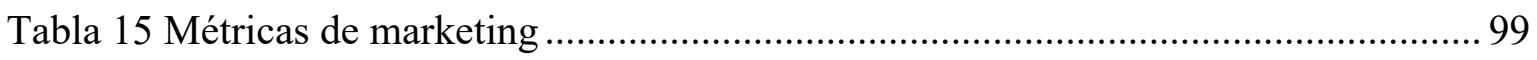




\section{ÍNDICE DE FIGURAS}

Figura 1. Rendimiento académico en países de América latina.

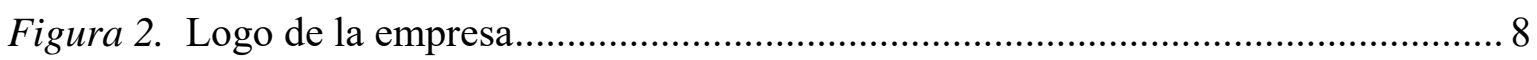

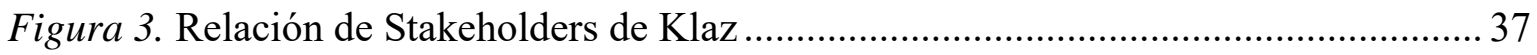

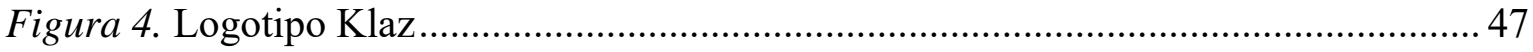

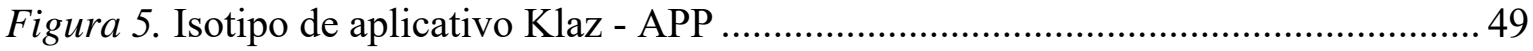

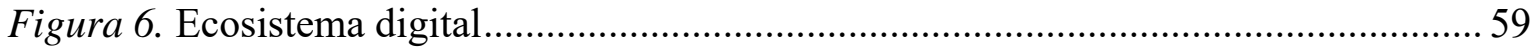

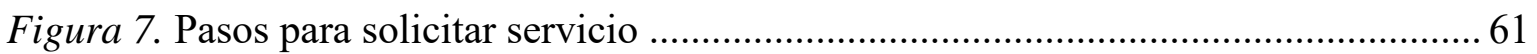

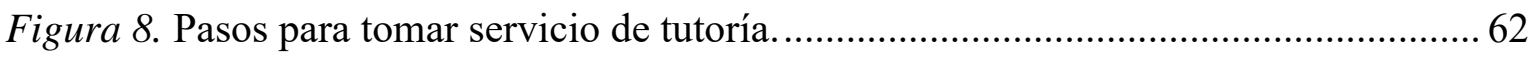

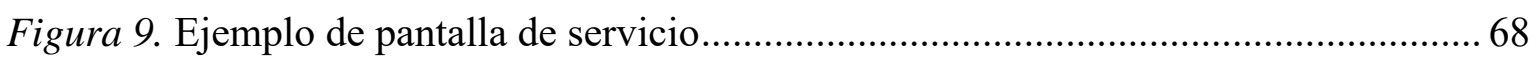

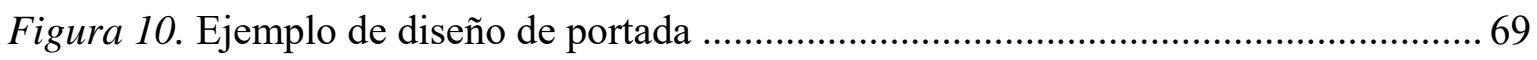

Figura 11. Ejemplo pantallazo de video demo Klaz ........................................................ 70

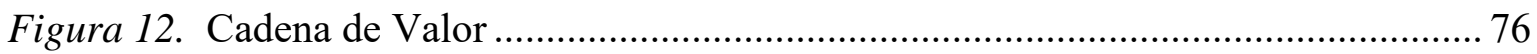

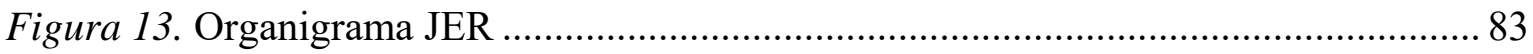




\section{DESCRIPCIÓN DEL NEGOCIO}

1.1 La idea y la oportunidad

La educación, es un soporte muy importante con el que cuenta un país para poder alcanzar su desarrollo, tanto desde el punto de vista económico como social. Sin embargo, en nuestro país, la educación carece de un nivel de calidad óptimo, ello se evidencia en el Informe del Programa Internacional para la Evaluación de Estudiantes o Informe PISA de la Organización para la Cooperación y el Desarrollo Económico (OCDE), organismo que tiene como misión promover políticas que mejoren el bienestar económico y social de las personas alrededor del mundo. La evaluación PISA, se aplica cada tres años en diversos países, y busca medir el rendimiento académico de los alumnos en matemáticas, ciencia y lectura. Este informe indica que nuestro país tiene el más alto porcentaje de estudiantes de 15 años que no alcanzan el nivel básico, establecido por la OCDE. Es así que en su ranking publicado el 2016, ubican al Perú como aquel de peor rendimiento escolar en América latina.

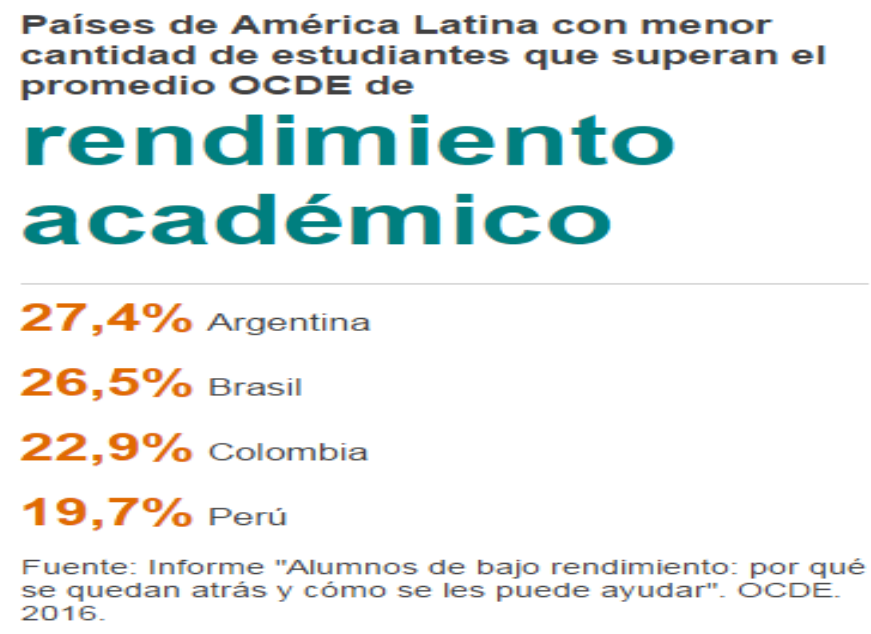

Figura 1. Rendimiento académico en países de América latina.

Otro aspecto a tener en cuenta es el modelo educativo actual, dado que muchas veces en las clases presenciales se dificulta personalizar la enseñanza, la información se distribuye a todos los alumnos por igual, por lo que dependiendo del alumno, unos se adelantan y otros se atrasan en su aprendizaje. 
Esta brecha entre enseñanza y aprendizaje se incrementa año tras año, debido a que aumentan las exigencias académicas $\mathrm{y}$, al no contar los estudiantes con una base sólida de conocimientos sobre determinadas materias, su desempeño académico se ve afectado.

Es por esta razón, que muchos padres de familia buscan disminuir o revertir esta brecha con el apoyo de tutorías a domicilio, las cuales se hacen cada vez más recurrentes y demandadas.

De acuerdo a lo manifestado por Ximena Rodríguez, gerente y consultora educativa de Tutor Doctor, en una entrevista para el portal PQS la voz de los emprendedores, sección economía (2018), el mercado de tutorías en Perú viene creciendo en 40 por ciento anualmente.

Sin embargo, debemos tener en cuenta que este tipo de servicio es excluyente geográficamente, ya que se dificulta su cobertura a todos los distritos de Lima y provincias del Perú.

Por otro lado, dicho servicio se ve directamente afectado por dos variables importantes, la primera es el tráfico en la ciudad de Lima. En el caso específico de los profesores que brindan las tutorías en forma presencial, se ven muy afectados al invertir un tiempo valioso movilizándose de un domicilio al siguiente, incrementando además sus gastos en gasolina, taxi o transporte público. Así mismo, esta variable afecta a los padres que trabajan fuera de sus domicilios, haciendo que el retorno a sus hogares sea cada día más tarde, y muchas veces no puedan estar presentes en el momento en que el escolar recibe la tutoría.

La segunda variable que afecta el servicio de tutorías a domicilio, es la percepción de alto riesgo en la seguridad personal, al permitir que una persona extraña ingrese a los hogares para interactuar a solas con los escolares. 
Teniendo en cuenta estas variables, es allí donde la educación virtual puede apoyar en la enseñanza - aprendizaje, pues se adapta al tiempo y necesidades de estudiantes y profesores.

La educación virtual, es un proceso educativo que se brinda en el ciberespacio, donde el objetivo es facilitar el manejo de la información y permitir aplicar nuevos métodos pedagógicos para desarrollar aprendizajes importantes. Está centrado en el estudiante y en su participación activa.

De igual manera, tiene como componente a las tecnologías de la información y la comunicación -las TIC- que brindan herramientas de aprendizaje más atractivas y motivadoras que las tradicionales.

La diferencia principal que se da entre educación virtual y presencial son los medios utilizados para la comunicación entre los protagonistas del proceso educativo. El principal beneficio es la flexibilidad en el manejo del tiempo y espacio. Roger, Loaiza Alvarez (2002), define educación virtual como: "Es una paradigma educativa que compone la interacción de los cuatro variables: el maestro y el alumno; la tecnología y el medio ambiente".

De igual manera, es importante reconocer que hoy en día hay un nuevo escenario, donde las nuevas generaciones son nativos digitales que disfrutan la interacción con la tecnología y, donde las tecnologías de la información y comunicación (TIC) para el sector educación, van adquiriendo un papel protagónico. Es por ello, que investigando casos de éxito, encontramos varios países que ya están usando las TIC para uso educativo.

De acuerdo al informe TIC y Educación, la experiencia de los mejores: Corea, Finlandia y Singapur (2012); estudio realizado por Grupo Educativo para Santillana con apoyo y asesoramiento del Banco Interamericano de Desarrollo (BID), estos países destacan por el alto nivel de aprendizaje que tienen sus estudiantes, posicionándose en los últimos años en los primeros puestos de los resultados de 
PISA. Dichos países se han convertido en los líderes educativos, por la preparación de sus profesores, por el uso educativo de las TIC, y por tener como política prioritaria, contribuir al desarrollo e innovación de la educación. De hecho, han sido los primeros en adaptarse a las nuevas necesidades de la sociedad del conocimiento, integrando tecnología y aprendizaje, desarrollando infraestructura, sistemas de evaluación, seguimiento, formación de profesores, cambio pedagógico y programas de estudio, obteniendo excelentes resultados.

En nuestro país, existe un crecimiento sostenido de módulos de educación online, principalmente de idiomas o cursos especializados. Por ejemplo en las universidades peruanas, se consideran cursos blended como parte de las mallas curriculares, y en los colegios se trabaja usando las TIC para determinados cursos. Si bien se ha avanzado en el uso de las TIC, aún hay mucho por desarrollar.

Es por ello que, encontrando una necesidad en los padres de familia/estudiantes y conocedores de la importancia del uso de la TIC en educación, nuestra propuesta busca brindar un servicio innovador, que fusione el tema educación, seguridad, practicidad y tecnología, brindando solución a las necesidades de los padres de familia, estudiantes y profesores que se dedican a las tutorías, usando un nuevo canal.

En este escenario, hemos decidido incursionar en el creciente negocio de tutorías personalizadas. Desarrollaremos la implementación y comercialización, de un servicio de tutoría online en tiempo real, para escolares de segundo grado de primaria a onceavo grado de secundaria de colegios de NSE AB; en una primera etapa será Lima metropolitana y a corto plazo se ampliará a más colegios de NSE B- y C, y a mediano plazo a nivel nacional.

\subsection{Descripción y nombre del negocio}

Nuestro proyecto está dirigido a niños y adolescentes pertenecientes a la generación Alpha (8 a 13 años) y a la generación Z (14 a 18 años). De acuerdo al estudio 
poblacional de IPSOS (2018), de los 32’162,184 de peruanos, el 10.84\% (3’487,096) corresponde al grupo de edad comprendido entre 8 a 13 años y, el 9\% (2’894,144) al grupo de edad entre 14 a 18 años.

Estas generaciones no conciben vivir sin internet, no conocieron la vida antes de las redes sociales, por ello procesan más rápido la información digital. Los nuevos modos de aprendizaje online (Massive Online Open Courses - MOOC, tabletas, aplicaciones educativas, etc.) son más adecuados para ellos pues tienen un estilo de vida centrado en la tecnología. Sienten gran atracción por la información visual debido a su familiaridad con los dispositivos digitales y su facilidad para llevar a cabo diversas actividades simultáneamente. Además, diversos estudios señalan que los estudiantes virtuales tienden a ser auto-motivados, auto-disciplinados y autodirigidos.

Por otro lado, los profesores también están incluyendo cambios en la forma de entender el aprendizaje, a través de los entornos virtuales, optimizando el proceso educativo.

El docente obtiene diversos modos de interactuar con los alumnos para planificar una tarea, ejecutarla y evaluar el aprendizaje, con un sentido de interactividad, pues el usuario se vincula a toda una comunidad online. Es por eso que los docentes deben transmitir esa sensación de comunidad, trabajo en equipo y que los estudiantes se hagan cargo de su propio proceso educativo con el apoyo de la tecnología.

De acuerdo a diversos autores, los métodos de educación virtual más importantes son: Método Sincrónico; tanto el emisor como el receptor del mensaje en el proceso de comunicación, deben estar presentes en el mismo tiempo. Este método facilita la socialización, de esta manera el alumno (a) que estudia en la modalidad virtual no se siente aislado. Los medios que se emplean para este método son: videoconferencias con pizarra interactiva, audio o imágenes como NetMeeting de internet, chat de voz y audio y, grupos virtuales. 
Asimismo tenemos el método Asincrónico; donde se emiten mensajes sin la necesidad que estén presentes emisor y receptor al mismo tiempo, por lo que el acceso es en forma diferida. Necesita un lugar físico para el servidor y es muy usado en la educación a distancia. Los medios que emplean son, email, foros de discusión, dominios web, textos, gráficos animados, audio, presentaciones interactivas y video, etc. Por último, el método B-Learning, es una combinación de asincrónico y sincrónico. La enseñanza y aprendizaje de la educación virtual se hace más efectiva. Es más flexible, porque no impone horarios y más efectivo que las estrategias autodidactas de educación a distancia.

Por otro lado, debemos tener en claro la diferencia entre educación virtual y educación a distancia. La educación a distancia pone a disposición de los estudiantes toda la información y tiene un tutor que guía y solicita el desarrollo de actividades para el curso, corrige evaluaciones, necesita de un contacto permanente con el alumno (a), pero los dos tienen libertad para definir los tiempos en los que llevarán a cabo las actividades, sin embargo se hace difícil trabajar en equipo.

La educación virtual, por su parte, necesita de todo lo anterior, pero en tiempos coordinados. Necesita contar con una plataforma que permita la interacción al mismo tiempo entre profesor y alumno (a). Es así que por ejemplo la universidad colombiana Javeriana está utilizando programas y plataformas como las Habbo o Second Life.

Teniendo en cuenta estas descripciones, nuestro proyecto se basará en el método sincrónico, pues brindaremos tutorías online donde la interacción entre profesor y estudiante será en tiempo real.

Es así, que nuestro proyecto, buscará atender la demanda de tutorías escolares que año tras año va en aumento, pero de una manera innovadora, brindando a través de 
la tecnología experiencias individuales de aprendizaje en forma práctica, amigable y además de forma segura, ya que no requiere que nadie ingrese físicamente a los domicilios de los estudiantes.

De igual manera, debemos tener presente que a medida que aumenta el ciclo de vida de los escolares, aumentará la frecuencia del uso de internet, por tanto deseamos que desde ya direccionen el uso de la tecnología, no sólo para momentos de distracción (Play Station, Nintendo, Xbox, etc.) sino que estén conscientes que puede ser sumamente útil para realizar sus estudios, en cualquier momento y lugar. Este servicio busca adaptarse a la disposición del estudiante tanto en horarios, lugar de la tutoría como en el ritmo de aprendizaje. Como dice Salman Khan, fundador de « The Khan academy ", lo que importa no es la manera en que se le enseña a un niño, sino que aprenda de la manera en que le resulte más fácil (Oppenheimer 2015).

La educación virtual es incluyente, pues es un compromiso entre tiempo y aprendizaje, no discrimina ubicación geográfica del alumno ni del profesor o profesora, se evita distractores como los desplazamientos físicos, así se ahorra tiempo y dinero.

Nuestro modelo de negocio busca conectar a dos grupos de clientes, por un lado a estudiantes que presenten dificultad en algún curso y por otro lado, a personas que se dediquen a la enseñanza (tutores), para ello se diseñará y desarrollará una aplicación web y móvil que permita esta conexión, de forma amigable y rápida, respondiendo a las tendencias digitales y educativas.

Esta aplicación permitirá brindar un servicio de tutoría, donde el alumno/a podrá acceder a clases online del curso en el que tenga dificultades o, para algún tema específico, interactuando en tiempo real, con profesores capacitados y empáticos, a través de un dispositivo móvil, tablet, laptop o PC. Así mismo, este servicio permitirá a los padres de familia, monitorear la clase en tiempo real a través de otro dispositivo o a través de reportes enviados por el profesor. Nuestra aplicación contará con una metodología diseñada especialmente para este tipo de interacción digital, 
fortaleciendo el proceso de aprendizaje para mejorar competencia lectora, competencia matemática, competencia científica y competencia en el idioma inglés.

La marca de nuestro negocio será Klaz. Buscamos que al decir su nombre, se sepa rápidamente de qué trata el negocio y cuál es el beneficio directo que ofrece a los consumidores. Además se ha pensado en ser usada como verbos y que deje margen a la creación de nuevo lenguaje como por ejemplo Google con "googlear".

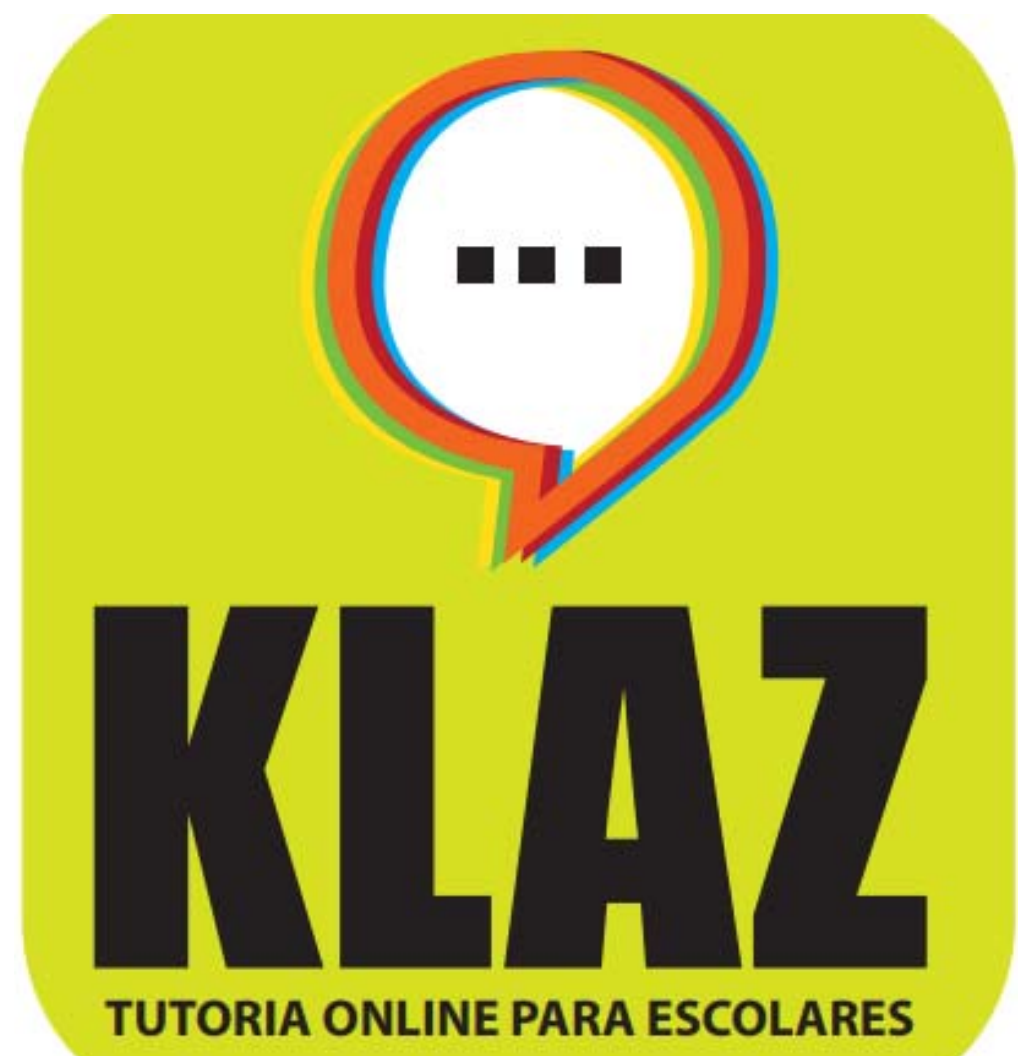

Figura 2. Logo de la empresa

Fuente: Elaboración de diseñadora para Klaz.

Por otro lado, para que nuestro servicio satisfaga totalmente a nuestra comunidad virtual, y potenciemos sus beneficios, dentro de la plataforma de Klaz, se incluirá un formato que debe ser llenado por los padres de familia, donde nos permitirá conocer qué expectativas tienen del servicio, así como el desenvolvimiento académico del su hijo (a), y por qué requiere de nuestros tutores. De ser necesario también se contactará 
a profesores del colegio de procedencia del estudiante, para alinear estrategias y que nuestros alumnos (as) logren un impacto favorable en su desempeño escolar.

Asimismo, por el lado de los tutores, nuestra capacitación incluye un video tutorial de la metodología de enseñanza, de uso de la plataforma, herramientas, lineamientos generales del servicio, procedimientos en cuanto a temas éticos y morales, preguntas frecuentes, responsabilidades, etc.

En cuanto a la selección de tutores por parte de los alumnos, nuestra plataforma contará con una lista que permitirá seleccionar al profesor/a, de acuerdo al perfil mostrado, el cual indicará sus estudios y experiencia; así como también su valoración y comentarios realizados por los usuarios.

De acuerdo a las necesidades del alumno (a), y privilegiando la función docente y el valor agregado que puedan dar en función de algún conocimiento complementario, dividiremos a los profesores en tres perfiles: estudiantes universitarios, docentes de colegios particulares/nacionales $\mathrm{y}$, docentes de colegios particulares que puedan asumir otro idioma en el dictado y cursos de bachillerato internacional (IB).

Las clases podrán tener una duración entre 1 a 2 horas y, al final de cada sesión se enviará un reporte a los padres. El pago será online por débito o crédito, de acuerdo a la tarifa del perfil del profesor seleccionado. 


\section{EVALUACIÓN DE MERCADO}

\subsection{Análisis del macro entorno (PESTEL)}

La evaluación del impacto Político, Económico, Social, Tecnológico, Ecológico y Legal permite apreciar que la mayoría de los factores son favorables para el desarrollo potencial del plan de negocio planteado.

\section{Político}

La dinámica de la política en el Perú, se mantiene dentro de la estabilidad democrática, a pesar de los escándalos de corrupción de los poderes del estado que generan desconfianza hacia las autoridades. El presidente Vizcarra, cuenta con amplia aprobación popular terminando el 2018 con 66\%. (Encuesta Nacional Urbano Rural, IPSOS Perú). No se aprecia impacto hacia este proyecto desde este factor político.

Por otro lado, el presupuesto del Sector Público para el año 2019 establece a la educación como uno de los 6 sectores principales incrementando su inversión en $6.9 \%$ versus el año anterior. (Proyecto de Ley de Presupuesto del Sector Público para el año fiscal 2019, Ministerio de Economía y Finanzas, MEF). Esta asignación de presupuesto transmite un mensaje de valoración de la importancia de la educación lo cual es favorable para el proyecto aun cuando se refiere al sector público.

En cuanto a las políticas de impuestos por recibo por servicios por honorarios, la tasa de retención es del 8\%, lo cual no se considera en el empleo informal de profesores a domicilio. En una empresa formal como la del presente proyecto, el pago de honorarios sería bajo este régimen, con convenios que consideren como responsabilidad del profesor, el incluir esta retención cuando los ingresos anuales son mayores a 7 UIT. Este factor puede ser percibido como desfavorable para el ingreso salarial neto de los profesores. La compensación sería en la mayor cantidad de horas de clases que se pueden brindar. 


\section{Económico}

Luego del ruido político a finales del 2018 y comienzos del 2019, se considera que la economía peruana empieza a repuntar tras la transición de gobierno. Para Jaime Reusche, vicepresidente de Moodys, la calidad de crecimiento económico del 2018 es mejor que la de los 2 años anteriores (América Economía, octubre 2018). Por su parte, Citibank estima que el Perú crecerá en 4\%, el cual será el mayor de la región (Semana Económica, 12 diciembre 2018). Esta condición es favorable.

En cuanto al desempleo en Lima Metropolitana, este se ubicó en 6.2\% en el trimestre juliosetiembre 2018 siendo la tasa más baja de trimestres comparables de los últimos tres años (Informe técnico situación del mercado laboral en Lima Metropolitana, Instituto Nacional de Estadística e Informática, INEI Octubre 2018). Si bien hay una mejora en el empleo formal, la cifra sigue siendo alta lo cual es favorable para la disponibilidad de potenciales profesores, Además, las tutorías virtuales son consideradas principalmente como ingreso adicional.

\section{Social}

De acuerdo a la consultora IPSOS, la tasa de crecimiento anual de población del Perú en el 2018 es de $1.01 \%$, lo que es menor que años anteriores El número promedio anual de nacimientos ha ido retrocediendo, de acuerdo a datos del INEI y para el 2018, el promedio es de 2.2 hijos por mujer mientras que hace 50 años era de 6. Para el quinquenio 2020-2025, se proyecta una tasa de fecundidad aún menor de 2.1. Este decrecimiento es desfavorable para nuestro proyecto a largo plazo.

El nivel de seguridad ciudadana es una de las mayores preocupaciones de los limeños. La sensación de inseguridad se presenta también al interior de los hogares mediante diversos delitos como robos, violencia contra la mujer y hostigamiento sexual. El Perú presenta altas tasas de agresiones sexuales contra menores dentro del entorno familiar, lo que se traduce en una preocupación por el ingreso de adultos, sean conocidos o no, al hogar, para interactuar 
con los niños y niñas. El servicio tutorial online, presenta una mayor percepción de seguridad en ese sentido aunque no es garantía de $100 \%$ seguro, por lo tanto, este factor es favorable.

En cuanto a tendencias de la educación, observamos que en el Perú crece la aspiración de contar con estudios universitarios. Menos del 28\% de los estudiantes de educación superior se inclina hacia la formación profesional técnica, mientras que más del $72 \%$ va a la opción universitaria. (Yamada \& Martínez, 2016). De otro lado, las universidades más prestigiosas ofrecen la modalidad de ingreso preferente para los alumnos de colegios acreditados según convenio. La exigencia por ejemplo para la Universidad de Lima es de pertenecer al tercio superior de tercero a quinto de secundaria o medio superior de primero a quinto de secundaria. En el caso de la UPC, el requisito es tercio superior de tercero a quinto o promedio mínimo de 15 . Estos formatos de ingreso implican tener buenos promedios en secundaria lo cual es favorable al proyecto.

Otra tendencia es la necesidad de contar con un segundo idioma, el cual es de preferencia el inglés. El segundo idioma es incluso requisito para graduarse en universidades, maestrías y algunos institutos. Esta necesidad impacta en la selección de colegios por parte de los padres y el otorgar contenidos de cursos en otro idioma por parte de los colegios. Este factor es favorable pues incrementa la necesidad de apoyo escolar en otro idioma.

A pesar del crecimiento digital en diversas áreas sociales, aún existen barreras culturales a través de un bajo rechazo hacia su uso en servicios que tradicionalmente se han dado de manera presencial como es el apoyo de profesores a domicilio. Se podrá evidenciar el bajo rechazo al analizar los resultados de la encuesta.

\section{Tecnología}

El crecimiento de entornos digitales se da a alta velocidad en casi todos los aspectos de la vida de las personas. Los niños de hoy son nativos digitales donde la influencia de las redes sociales y uso de aplicaciones en general es de suprema relevancia. Existen los llamados vloggers o youtubers menores de 10 años con más seguidores que programas de televisión 
por lo que son considerados influencers de alto impacto, como Ryan Toys Review, de 7 años, que es un niño que gano US\$ 22 millones en YouTube en el 2018.

Los niños tienen acceso a una serie de aplicativos educativos amigables enfocados principalmente en matemáticas, inglés y ciencias como Smartick, para matemática; Duolingo para inglés y, Arloon Anatomy para ciencias. La plataforma YouTube contiene videos tutoriales para variados temas de acceso gratuito.

En cuanto al uso de entornos digitales como complemento educativo dentro del aula de clase, este crece día a día en los colegios de Lima y del mundo. Muchas de las tareas escolares también deben ser "colgadas" en la intranet de sus centros educativos en lugar de llevarlos hechos en los tradicionales cuadernos. Ya a nivel de educación superior, la incidencia de entornos virtuales es mayor con cursos Blended y softwares como LanSchool y Sianet para monitorear la actividad de los estudiantes en las computadoras bloqueando distractores.

Visto todo esto, el factor tecnológico es altamente favorable para el proyecto.

\section{Ecología/medio ambiente}

El uso digital impacta positivamente en el medio ambiente al utilizar menos papel, factor altamente valorado por los niños y jóvenes. Es favorable.

\section{Legal}

Tratándose de servicios profesionales se establecen contratos de locación de servicios donde los profesores acuerdan la verificación de sus datos, respetar el reglamento y valores de la empresa así como confidencialidad de información de los estudiantes. Este factor es favorable pues fortalece la confianza de los padres en la contratación de este servicio.

En conclusión, la situación del macro entorno favorece potencialmente el desarrollo del servicio de tutoría online para escolares, donde los aspectos de mayor impacto positivo son los factores sociales, en particular las necesidades de seguridad y tendencias de la educación y, los factores tecnológicos. 


\subsection{Análisis del sector}

\subsubsection{Análisis del micro entorno: Las cinco fuerzas de Porter}

La empresa debe analizar la estructura del mercado y considerar las consecuencias para el negocio en un mediano y largo plazo. Es por ello, que las decisiones estratégicas que tomemos impactarán en nuestros clientes (escolares y sus padres), profesores, proveedores y competidores.

\section{Amenaza de entrada de nuevos competidores}

La amenaza de ingreso de nuevos competidores será alta si las barreras de ingreso resultan fáciles de quebrar. Actualmente se lanzan al mercado start ups de negocios digitales que se reproducen rápidamente; es por ello, que la empresa debe considerar barreras en cuanto a diferenciación del servicio y costos cambiantes por ser la primera en participar en este tipo de negocio online dentro del país.

La diferenciación se llevará a cabo por ser la primera plataforma online de tutoría virtual en tiempo real donde se atenderán las distintas necesidades de los escolares mediante una metodología pedagógica diseñada adhoc. Se contará con una amplia cobertura de profesores capacitados y empáticos, que puedan atender las diversas solicitudes con disponibilidad horaria flexible, manteniendo de esta manera, la practicidad y comodidad de conectarte donde quieras y cuando quieras. Klaz se convertirá en una lovemark que marque la pauta en cuanto a tutorías virtuales.

Barreras de ingreso

Además de la diferenciación, los requisitos de capital de trabajo, son importantes para este sector.

Se requiere de una plataforma multidevice que contenga una interactive blackboard para poder ofrecer el servicio de tutorías online. Para el diseño y desarrollo de la plataforma, se requiere una serie de especificaciones técnicas además de contar con aplicación web y móvil. Toma aproximadamente entre 6 a 8 meses incluyendo pruebas beta de lanzamiento. 
Otra barrera importante es la del capital humano, es decir, los profesores. El reclutamiento y selección debe ser minucioso puesto que se debe validar los antecedentes, títulos y CV. Asimismo se brindará una capacitación acerca de la metodología de Klaz a utilizar y la misión y valores de la empresa.

Hoy no se cuenta con ninguna empresa local que ofrezca el mismo servicio, sin embargo, se puede concluir que dada la tendencia tecnológica de los negocios de ofrecer servicios con plataformas digitales, la amenaza de entrada de nuevos competidores es alta dentro del sector.

\section{Rivalidad entre competidores}

Considerando que no existe en la actualidad un servicio tal cual el planteado en el presente negocio, estamos considerando como competidores directos, a los profesores que brindan clases particulares a domicilio.

Dentro de cada colegio, los mismos profesores, una vez culminada su labor, ofrecen clases particulares sea en su casa o a domicilio. Asimismo los ex alumnos de los diversos colegios y jóvenes universitarios ofrecen clases particulares a un precio más económico. Cabe destacar, que un factor importante y clave es la recomendación y/o boca a boca del profesor para las clases a domicilio.

De igual manera, se puede resaltar a la franquicia Tutor Doctor, cuyos servicios se gestionan a través de su página web para poder reservar un profesor a domicilio.

Dentro del sector de tutorías o clases particulares, consideramos que la rivalidad es baja, puesto que el sector se encuentra muy atomizado y, no existe un liderazgo importante de alguna empresa en el sector dado que existen muchos profesores que ofrecen este tipo de clases.

\section{Amenaza de productos sustitutos}

En este caso, estamos incluyendo las diversas modalidades de clases grupales como: grupos de estudio por recomendación o por páginas en redes sociales como facebook o whatsapp (Grupo Matefacil, Repaso U. San Marcos, Grupo de estudio 2021, entre otros). 
También podemos incluir a los mismos colegios, dado que algunos ofrecen un programa afterschool, nivelación de cursos en verano y programas escolares de asesorías.

De igual manera se consideran productos sustitutos a las academias como:

- MAB Afterschool: refuerzan académicamente a los escolares mediante una metodología adhoc ayudándolos a desarrollar una personalidad segura y autoestima.

- Nivel A: academia de grupos multidisciplinarios que refuerzan las diversas materias de colegios y preparan para ingresos a universidades.

- Matlab: academia especializada en matemáticas.

- Trilce: academia para refuerzo académico e ingreso a universidades.

- Pamer: academia preuniversitaria y escolar.

- Pitágoras: academia pre universitaria y refuerzo académico escolar.

También podemos incluir los diversos tutoriales en YouTube ya grabados (no en tiempo real), que se pueden consultar en cualquier momento o programas que pudieran ser relevantes para materias escolares.

Con respecto a la amenaza de sustitutos, la consideramos alta, debido a la diversidad de alternativas que pudieran sustituir las clases. Sin embargo, ninguna atiende las necesidades de los estudiantes de la manera investigada, es decir, en el horario deseado y con la practicidad, comodidad y seguridad que uno necesita dentro de un entorno digital.

\section{Poder de negociación de proveedores}

Los principales proveedores de Klaz, están relacionados con la infraestructura necesaria para operar el sistema tecnológico. Nuestro proveedor del software y plataforma digital, será la agencia Electo, quien se encargará del diseño, desarrollo y posterior mantenimiento de la plataforma y de todos los alcances funcionales y tecnológicos requeridos.

Hoy en día existe una variada oferta de proveedores que ofrecen plataformas en línea para este tipo de negocio, sin embargo, Electo nos garantiza la rapidez de respuesta y la eficiencia 
en su gestión del día a día que son clave para el óptimo funcionamiento y por ende brindar un servicio de calidad.

En este caso, el poder de negociación es bajo puesto que existen varias agencias expertas en diseño y desarrollo de plataformas; sin embargo, estamos considerando a Electo como socio estratégico para poder llegar a los crecimientos esperados y que puedan conocer a nuestro cliente a la perfección.

\section{Poder de negociación de los clientes.}

Dado que el servicio de tutoría es online, contamos con precios establecidos en función a la investigación de mercado realizada. Para ello hemos tomado en cuenta, la experiencia y grado de instrucción del docente, de tal manera que se pueda ofrecer un precio segmentado $\mathrm{y}$ adhoc al servicio brindado.

El poder de negociación del cliente es bajo, puesto que los precios se han fijado satisfaciendo los distintos niveles de precios del mercado y considerando un buen número de profesores que pueda cubrir las necesidades del estudiante.

Con este análisis, podemos evidenciar, que si bien existen algunas barreras altas, no es de temer puesto que es un negocio nuevo, basado en la tendencia digital nativa natural de los estudiantes de hoy, por lo tanto atenderíamos sus necesidades de acuerdo a su estilo de vida: centenials y alpha.

\subsubsection{Investigación del mercado objetivo}

Se diseñó una investigación de mercado exploratoria y descriptiva con el fin de poder obtener información para poder diseñar y formular la estrategia y modelo del negocio.

La investigación exploratoria, nos ayudó a definir el problema o tensión a investigar, en este caso, qué actitud (positiva o negativa) se tiene con respecto a las clases presenciales y online de tutoría así como las ventajas y/o desventajas (barreras) con respecto a este nuevo servicio online. Es una investigación más flexible, no estructurada mediante la cual se pudieron reunir datos cualitativos de entrevistas a mamás con hijos que cursaran el año escolar entre 2do grado de primaria y 5to grado de secundaria; de igual manera de entrevistas a profesores de colegios de NSE A/B y a directores de Instituciones reconocidas para poder explorar sus 
reacciones ante el concepto propuesto y de esta manera contar con información valiosa para el diseño del concepto y de los beneficios funcionales y emocionales.

La investigación de mercado descriptiva nos permitió especificar y describir situaciones concretas de mercado gracias a una encuesta previamente planeada y estructurada a 255 mamás o papás de escolares que cursan entre 2 do de primaria y 11 vo de secundaria y que asisten a colegios de NSE AB. Nos ayudó a dimensionar la oportunidad de mercado y además a evaluar cuantitativamente el nivel de aceptación de nuestra propuesta.

\subsubsection{Estudio exploratorio}

A través de entrevistas exploratorias, nos propusimos obtener información sobre el servicio tutorial presencial, y si era factible la implementación de un servicio tutorial online. Buscamos conocer las opiniones de tres grupos:

1. Padres de familia

2. Educadores - Especialistas

3. Docentes y universitarios que brindan clases particulares

A continuación el detalle de los resultados obtenidos:

Ficha técnica cualitativa del primer grupo: padres de familia

\begin{tabular}{|l|l|}
\hline Técnica utilizada & $\begin{array}{l}\text { Entrevista personal mediante aplicación de } \\
\text { un cuestionario. }\end{array}$ \\
\hline Grupo objetivo & $\begin{array}{l}\text { Padres de familia residentes en la ciudad de } \\
\text { Lima, cuya edad se encuentra entre 35 a 55 } \\
\text { años. }\end{array}$ \\
\hline Ejes seleccionado para representatividad & $\begin{array}{l}\text { Padres de familia de colegios privados que } \\
\text { pagan pensión desde S/2000 a S/5000 y } \\
\text { cuyos hijos cursan desde 1er grado a 11 vo } \\
\text { grado. }\end{array}$ \\
\hline Reclutamiento & Por contacto en base a una lista elaborada. \\
\hline Tamaño de la muestra original & 25 personas. \\
\hline Entrevistadores & Miembros del equipo. \\
\hline Periodo de trabajo de campo & Octubre-Noviembre 2018. \\
\hline
\end{tabular}

\section{Objetivo General}

Conocer si los padres de familia contratan a profesores particulares a domicilio cuando sus hijos tienen alguna materia para reforzar en el colegio, y en los casos en los que la respuesta fue afirmativa, se buscó confirmar si para el mismo objetivo contratarían a profesores que 
brinden las tutorías, pero en forma virtual. De igual manera, se buscó profundizar en el proceso de contratación de profesores particulares y obtener mayor información para el diseño conceptual de nuestra propuesta y poder desarrollar la encuesta. (ver anexo 1: guía entrevista exploratoria)

\section{Resultados:}

De acuerdo a lo manifestado por los padres de familia, el promedio de veces que contratan por semana a un profesor particular presencial es de 2 veces por semana, aumenta la frecuencia si es que tienen algún tema en específico como exámenes o trabajos.

En cuanto a la duración de las clases, la respuesta en su mayoría fue de 2 horas y a veces de 1 hora y media.

Sin tener en cuenta el colegio o zona de residencia encontramos que el pago que se le hace al profesor particular presencial varía desde: el más económico de $\mathrm{S} / 30.00$, rango medio $\mathrm{S} / 50-70$ y el más caro $\mathrm{S} / 80$, todos por hora.

Las áreas más demandadas para las clases son en el siguiente orden: matemática, comunicación, inglés y ciencias.

Dentro de las principales razones para contratar a un profesor, nos manifestaron, el reforzar un curso o tema en el que se tiene dudas. En segundo orden, temas puntuales como exámenes y/o tareas, y por último los que presentan deficiencia en un curso.

Los principales criterios para la contratación de profesor a domicilio serían: por recomendación, de preferencia que sea un profesor del colegio de sus hijos o ex alumno del mismo. Asimismo se busca que el profesor sea empático, con mucha paciencia y que sepa como conectar con el alumno.

Dentro de los principales problemas que encuentran los padres para contratar a los profesores están : el desconocimiento de la metodología del colegio de sus hijos, que no se conecte en forma adecuada con el estudiante, la impuntualidad o frecuente cambio de horario 
y, el no dominar el idioma en el que se debe dictar la clase. Por otro lado, sienten que deben restringirse a la disponibilidad del profesor.

La mayoría de entrevistados confirmó que sí les parecía atractiva la idea de contratar un servicio de tutoría online, ya que no tendrían a un extraño en casa, y además las clases estarían de acuerdo al horario del alumno y no restringidas a la disponibilidad del profesor. En cuanto al precio, pagarían lo mismo que un profesor a domicilio en la mayoría de los casos. Con respecto a los grados en los que se tomaría este servicio virtual, correspondería a partir de 2 do grado de primaria, puesto que los niños más pequeños de primer grado requerirían un acompañamiento físico.

\section{Debilidades percibidas en el servicio tutorial online}

Una de las principales preocupaciones de los padres con respecto al servicio es que los alumnos se puedan distraer y desconcentrase, o que su hijo(a) no le explique bien al profesor lo que necesitan estudiar. Por otro lado, otra preocupación fue la velocidad del internet que dificulte la conexión, que se cuelgue y que no se pueda brindar la clase.

\section{Ventajas:}

Las principales ventajas que encuentran en el servicio de tutoría virtual son la practicidad para conectarse y llevar la clase en el horario y lugar requerido por los estudiantes. Asimismo, consideran un acierto el usar la tecnología como herramienta de aprendizaje pues es la tendencia y los estudiantes son nativo digitales.

Consideran además a este servicio de tutoría virtual como no invasivo, pues nadie ingresa a los hogares, y así sienten seguridad de no tener un extraño en casa. De otro lado, los alumnos (as) podrán tomar las clases con comodidad y confort en el espacio que deseen y vestidos como quieran estar.

Los principales atributos que esperan encontrar los padres es que puedan obtener información sobre ranking y comentarios de profesores, medio de pago afiliado al sistema online, perfil del profesor, reporte vía email o whatsapp de la sesión, requerimiento de 
materiales previo al inicio de clases (previa solicitud) y notificación inmediata de solicitud de servicio.

\section{Conclusiones}

El servicio de tutorías a domicilio es muy demandado por los padres de familia, que buscan reforzar las materias que se les hace difícil a sus hijos, pero se deben regir a los horarios del profesor, que muchas veces llega tarde o no cuenta con disponibilidad. Asimismo, existe el gran temor de dejar ingresar a una persona extraña a casa. Es por ello, que un servicio de tutoría virtual es considerado como una propuesta innovadora que podría responder mejor a las necesidades de los estudiantes.

Ficha técnica cualitativa del segundo grupo: especialistas - educadores - directores

\begin{tabular}{|l|l|}
\hline Técnica utilizada & $\begin{array}{l}\text { Entrevista personal mediante aplicación de } \\
\text { un cuestionario. }\end{array}$ \\
\hline Grupo objetivo & Especialistas - educadores - directores \\
\hline Ejes seleccionado para representatividad & $\begin{array}{l}\text { Personas representativas del sector } \\
\text { educación. }\end{array}$ \\
\hline Reclutamiento & Por contacto \\
\hline Tamaño de la muestra original & 6 \\
\hline Entrevistadores & Miembros del equipo \\
\hline Periodo de trabajo de campo & Octubre-Diciembre 2018 \\
\hline
\end{tabular}

\section{Objetivo General}

Conocer la opinión de los especialistas sobre cómo los entornos virtuales generados por las tecnologías de información y comunicación (TIC) ayudan a optimizar el aprendizaje de los alumnos en los cursos de mayor dificultad, y si consideran atractivo aplicar un servicio tutorial virtual para alumnos en edad escolar.

\section{Resultados:}

De acuerdo con la experiencia del especialista en el sector educación, buscamos conocer cuál sería el curso de mayor dificultad, encontrando que los entrevistados señalaron al curso de matemática en primer lugar, seguido de inglés, comunicación y ciencias.

Se observa que los niños que tienen dificultad en matemática desde niños, cargan con esta dificultad a lo largo de toda su vida escolar. De igual manera, muchas veces los padres se 
acostumbran a que el niño tenga acompañamiento durante toda su vida escolar y no se preocupan de encontrar la causa raíz y buscar estrategias para que el niño continúe solo. Idealmente, el profesor debe poder determinar las bases que debe corregir o las deficiencias que el niño podría tener ya sea para ser trabajadas con él mismo o con otro especialista. Es natural que en ocasiones se requiera focalizar esfuerzos en pasar el curso por la falta de tiempo, y podrían dedicar otros momentos para trabajar en los fundamentos del curso.

Encontramos similitud en la opinión de nuestros entrevistados sobre las tecnologías de información y comunicación y su aporte en optimizar los aprendizajes de los alumnos. Manifiestan que los chicos son nativos digitales y que hoy en día, la mayoría utiliza la tecnología para fines recreativos. Es un área con mucho potencial por desarrollar pues se puede personalizar las herramientas mediante una interacción uno a uno.

La correcta utilización de las herramientas tecnológicas beneficiará a los alumnos en optimizar sus conocimientos. Hoy en día los recursos son más dinámicos, entretenidos, les interesa más y eso ayuda a que aprendan, son más reales porque son más cercanos a su día a día.

Actualmente en el Perú, se están utilizando las TIC en tutoriales para enseñar programas de computación, plataformas para el curso de matemáticas, ciencias y otros cursos. A partir de 5to grado se incrementa el uso de tecnología en las aulas, se utiliza Google Class, juegos en línea y, se interactúa en el aula virtual, donde encuentran ejercicios y tareas e investigaciones que deben desarrollar; también se utilizan foros para ciencias. En secundaria crean páginas web, programas, entre otros.

Por otro lado, ante la propuesta de la creación de un servicio tutorial después del colegio, para los alumnos que presentan dificultad en su aprendizaje, (sin ninguna complicación de fondo cognitivo), nuestros encuestados coincidieron en señalar que sí estaban de acuerdo, porque muchos niños requieren apoyo extraescolar por salones muy grandes o estilos de 
educación complejos para el alumno. Es natural que requieran un apoyo temporal, incluso se da en el modelo de Finlandia.

Asimismo, con el apoyo de las plataformas se puede reproducir la situación en clase, y apoyar en el punto específico que no comprendió el alumno. La interacción es de uno a uno por lo que el aprendizaje es mejor. Los entrevistados afirman que es lo que se viene en el futuro próximo y es totalmente natural. Actualmente se buscan profesores por internet aunque luego ellos vayan a domicilio a dictar las clases. La clase en línea sería lo adecuado para estos tiempos modernos en que se necesita este tipo de soporte. También se menciona que la búsqueda de información por internet es ya parte natural de todos nosotros, como por ejemplo se compra por internet todo.

En cuanto a la duración de la clase nos manifestaron que en niños menores, de 2 do a 4to grado, podría ser hasta de 50 minutos. A partir de 5 to grado entre una hora y hora y media. Sería recomendable que a los niños menores se les deje una tarea individual, pues en la repetición está el proceso de aprendizaje.

\section{Debilidades percibidas en el servicio}

El mal uso de la tecnología puede distraer a los alumnos, por lo que algunos alumnos no lograrían concentrarse durante la sesión y por ende no alcanzar los resultados esperados.

Además, se podría hacer un sobreuso del servicio, utilizándolo para todas las tareas del colegio. Es importante dejar bien en claro, que el servicio es de acompañamiento, para ayudar a mejorar el rendimiento y NO para hacerles sus deberes.

\section{Ventajas}

Dentro de las principales ventajas que encuentran en el servicio que pretendemos ofrecer, son que se contará con un aplicativo flexible, amigable y dinámico para su interacción. También que se contará con profesores de distintos colegios que podrán aplicar la metodología de los mismos en las clases. 
De igual manera, la propuesta es atractiva, puesto que es más práctica para los padres y estudiantes al conectarse desde cualquier lugar y momento. Por ejemplo desde sus academias deportivas, clases extracurriculares, entre otras.

Se puede también aprovechar la tecnología para enseñarles estrategias a los alumnos que puedan transferir en el colegio y en el examen, desarrollar hábitos de estudio y rutinas que mejoren el desempeño del alumno.

\section{Perfil del tutor}

En cuanto al perfil del tutor para el servicio que deseamos implementar, nos proponen que para primaria podría ser un tutor que domine todas las áreas, pero en secundaria se necesita que sean especialistas por áreas. En primaria puede ser un liderazgo más directivo, mientras que en secundaria debería ser más horizontal, que conecte con el alumno, que haya empatía. Los tutores deben ser capaces de encontrar el problema central y proponer estrategias. Para ambos niveles, debe tratarse de personas motivadoras (que sepan escuchar al alumno para apoyarlo en el punto específico que no entiende). Se debe formar vínculos entre profesor/alumno, para ello importante lograr empatía entre ambos para alcanzar resultados. El mejor profesor no es el que más sabe sino el que genera un "feeling" con el alumno, además que cuente con buen manejo de las herramientas tecnológicas. El profesor debe poder detectar las verdaderas necesidades de los alumnos y poder dar retroalimentación a los padres del status de sus hijos.

Los directores estiman que aproximadamente el 30\% de los estudiantes requiere apoyo con clases adicionales. Sin embargo, posteriormente en el estudio cuantitativo vimos que más del 55\% de los hijos de los encuestados toman clases particulares, lo que nos permitiría inferir que las clases se toman no solo en caso necesario para pasar, sino también para mejorar desempeño. 


\section{Conclusiones}

Dado el alto porcentaje de alumnos que asisten a asesorías tanto en nivel primaria como secundaria, sumado a la relevancia del uso de internet en la vida cotidiana, los especialistas en educación y directores consideran muy interesante y recomendable la propuesta.

Ficha técnica cualitativa del tercer grupo: docentes.

\begin{tabular}{|l|l|}
\hline Técnica utilizada & $\begin{array}{l}\text { Entrevista personal mediante aplicación de } \\
\text { un cuestionario. }\end{array}$ \\
\hline Grupo objetivo & $\begin{array}{l}\text { Personas dedicadas a la docencia o ex } \\
\text { alumnos y/o universitarios que dictan } \\
\text { clases particulares. }\end{array}$ \\
\hline Ejes seleccionado para representatividad & $\begin{array}{l}\text { Personas con y sin perfil docente que } \\
\text { enseñen a estudiantes de diversos niveles. }\end{array}$ \\
\hline Reclutamiento & Por contacto \\
\hline Tamaño de la muestra original & 4 \\
\hline Entrevistadores & Miembros del equipo \\
\hline Periodo de trabajo de campo & Octubre-Noviembre 2018 \\
\hline
\end{tabular}

Las personas entrevistadas, brindan servicio tutorial a domicilio y manifiestan que el tráfico es un factor que toman en cuenta para aceptar las clases, generalmente se mueven en un radio cercano a su domicilio y/o centro de trabajo.

La materia más demandada es matemática, pero también se requiere tutoría para comunicación, inglés y otros. El promedio de horas que dictan a cada niño es de 1 hora como mínimo y 2 como máximo.

Para verificar el avance de los alumnos emplean varias técnicas como exámenes, trabajos, y seguimiento de notas y tareas. El reporte del avance de los alumnos es dado a los padres de familia, principalmente a las madres quienes los contratan la mayor parte del tiempo. 
En cuanto a su opinión sobre un aplicativo para conectar profesores con alumnos para el dictado de clases particulares de manera online, la mayoría estuvo interesado en este servicio.

Las tarifas que cobran actualmente son variadas, depende del perfil del tutor, si es docente es mayor mientras que con los universitarios podría ser menor. Las tarifas fluctúan desde 35 a 80 soles. No conocen algún aplicativo que hoy en día brinde tutorías online.

\section{Ventajas}

La principal ventaja que destacan es el ahorro en tiempo, en materiales, y que se hablará en el idioma de los escolares, quienes dominan las herramientas tecnológicas. Con esta herramienta el tutor puede tener una mejor cobertura y disponibilidad para atender un mayor número de clases puesto que no incurriría en traslados, pudiendo dictar las clases desde cualquier lugar como su casa o entre horas desde la universidad o centro de trabajo.

\section{Desventajas}

Los docentes consideran que podría haber una posible distracción por parte del alumno al no tener un control presencial; de igual manera hay padres que se encuentran alejados de los beneficios de la tecnología.

Podría surgir dificultad para lograr empatía con el alumno al ser un canal nuevo virtual.

También manifestaron preocupación por no lograr la cobertura idónea para alcanzar sus ingresos actuales. Finalmente, se debe contar con una plataforma amigable y sencilla para poder interactuar fácilmente con los alumnos.

\section{Conclusiones}

El negocio lo consideran atractivo para los docentes, puesto que el servicio les ofrecería un ahorro considerable en traslados, y a su vez reduce el estrés por el tráfico cotidiano, con lo cual podrían abarcar un mayor número de tutorías. 


\subsubsection{Estudio Descriptivo}

Luego del estudio exploratorio se llevó a cabo el estudio cuantitativo aplicando los hallazgos detectados en las entrevistas cualitativas.

Ficha técnica estudio cuantitativo

\begin{tabular}{|l|l|}
\hline Objetivo de estudio & $\begin{array}{l}\text { Conocer los hábitos de uso hacia el servicio de profesores a domicilio y encontrar tendencias en cuanto } \\
\text { actitudes hacia este versus el servicio de tutoría online. }\end{array}$ \\
\hline Universo de estudio & $\begin{array}{l}\text { Madres o pades de escolares de 2do a 11vo grado, de niveles socioeconómicos A/B, que toman servicios de } \\
\text { profesores a domicilio. }\end{array}$ \\
\hline Cobertura & $\begin{array}{l}\text { Lima Metropolitana, distritos de: San Isidro, Surco, Miraflores, La Molina, San Miguel, San Borja, } \\
\text { Barranco. }\end{array}$ \\
\hline Tipo de investigación & Concluyente \\
\hline Metodología & Cuantitativa \\
\hline Muestra & $\begin{array}{l}141 \text { madres o padres respondiendo por 211 niños entre 2do y 11vo gra do de } 40 \text { colegios de los TOP 60 más } \\
\text { caros de Lima. }\end{array}$ \\
\hline Margen de error & El diseño y tamaño muestral permiten proyectar tendencias neutralizando el sesgo. \\
\hline Selección de la muestra & Se realizó una muestra no probabilística por conveniencia. \\
\hline Recolección de datos & Se realizaron encuestas por internet utiliando Google forms del 29 noviembre al 7 de diciembre 2018. \\
\hline Procesamiento & $\begin{array}{l}\text { Los resultados han agrupado las respuestas de 1 a 3 hijos, analizando por grados y sexo sin ser } \\
\text { representativos estadísticamente de la población total. }\end{array}$ \\
\hline
\end{tabular}

\section{Resultados}

Inicialmente se realizaron 255 encuestas para filtrar a los padres que sí contratan o han contratado los servicios de un profesor particular a domicilio. Se encontró que el 55.3\% respondió afirmativamente a esto, sin embargo, este dato es referencial por lo que no se estaría utilizando para la proyección de tamaño de mercado. Sin embrago, dado el tamaño de la muestra, sí lo consideramos como un dato de tendencia.

\section{Selección de colegios}

Se encuestaron a padres de familia de niños y niñas de 40 colegios $A B$ de Lima que afirmaron que contrataban o habían contratado profesor a domicilio en alguna oportunidad. 
Los colegios fueron variados incluyendo mixtos, de niños, de niñas, religiosos, laicos, bilingües en inglés, alemán, chino e italiano o, con inglés como segundo idioma; con y sin bachillerato internacional. Las pensiones de dichos colegios van entre $\mathrm{S} / 1,100$ y S/5,200.

\section{Razones para contratar profesor particular}

La razón principal por la que contratan o contratarían a un profesor particular es el de reforzar un curso para mejorar el rendimiento de sus hijos. En segundo lugar, la deficiencia en aprendizaje en un curso específico, es motivo para buscar ayuda. En tercer lugar se contratan profesores cuando se quiere lograr un objetivo específico como puede ser pasar un examen o realizar un proyecto especial. Finalmente, la cuarta razón es para reforzar un tema específico de un curso.

Claramente el apoyo que se considera más necesario es constante ya sea para mejorar el rendimiento del estudiante, el cual puede ser por prevención para no desaprobar o inseguridad del estudiante en repasar solo sus tareas. En segundo lugar se busca el refuerzo del curso dadas las dificultades que se evidencian en un curso en particular, generalmente matemáticas. Esta deficiencia en el aprendizaje se atribuye a diversas causas centradas en el estudiante o por la enseñanza en sí, según comentarios que se dieron en entrevistas de madres, profesores y directores.

\section{Problemas o dificultades que se haya tenido con un profesor particular}

E1 35\% de las respuestas acordó que la principal dificultad se debe a que el profesor no haya podido lograr una conexión con el estudiante durante la sesión de clase o no haber logrado una empatía lo cual impidió resultados. Un $23 \%$ afirmó que el no conocer la metodología del colegio fue un problema para que la clase sea satisfactoria y de igual manera otro $23 \%$ se refirió a la disponibilidad restringida del profesor que muchas veces debe dictarse la clase en horarios no apropiados para el alumno, por ejemplo en la noche tarde o habiendo regresado inmediatamente del colegio.

\section{Características de las clases particulares}

Un $72.3 \%$ afirma pagar más de $\mathrm{S} / 50$ soles, siendo el precio promedio $\mathrm{S} / 66.70$. La procedencia de colegios es indistinta en relación al pago de apoyo escolar. 
La materia en la que mayormente se tiene dificultad, independiente del grado, es matemáticas, y es el curso principal para la cual se contrata en muchos casos 2 horas de tutoría. En segundo lugar se toman profesores de idiomas, principalmente inglés, seguido por comunicación y ciencias.

El 52\% de niños tiene clases de una hora de duración, seguido con un 26\% de 1.5 horas y $22 \%$ para 2 horas.

La frecuencia de clases a la semana es de 1 a 2 veces a la semana en el $61 \%$ de los casos, $33.3 \%$ esporádicamente para casos puntuales y $5.7 \%$ para 3 veces a más por semana.

No hay ningún grado en especial donde siempre se requiera mayor apoyo de tutorías

La "recomendación" es el criterio más importante y fundamental para la elección del tutor, independientemente del colegio de origen. Por lo tanto, sugerimos poner énfasis en acumular testimoniales representativos de nuestros alumnos. En segundo lugar, y no menos importante, se ubica la opción de "empatía y paciencia" que debe tener el tutor con el objetivo de enganchar con el alumna (o). Es por eso que nuestra metodología debe apuntar a diseñar un discurso inicial que permita este enganche natural, podemos crear un discurso tipo storytelling del profesor, donde por ejemplo cuente los problemas escolares por los que atravesaba a la edad del escolar y cómo lo solucionó a través de compartiendo algunas estrategias.

\section{Tendencia a contratar servicio propuesto de tutoría virtual}

Ante la pregunta si estarían dispuestas a utilizar el servicio propuesto, a nivel general, en el $79 \%$ de los niños, sus madres afirman que sí estarían dispuestas a utilizarlo. La respuesta es afirmativa al $81 \%$ para el primer hijo, $75 \%$ para el segundo y baja a $73 \%$ para el 3 er hijo. Se 
infiere que a menor edad de los hijos la disposición a utilizar el servicio baja ligeramente llegando a un considerable $73 \%$ en el peor de los casos.

No se puede concluir que haya una relación directa en relación a las edades de los niños cuyas madres no optarían por el servicio aunque se puede apreciar una tendencia hacia los de grados iniciales sobre todo en el segundo y tercer hijo. Las edades de las respuestas negativas del "2do hijo" fueron mayormente entre 2do y 5to grado y del "3er hijo" fueron entre 2do y 4to grado, sin embargo dentro de las respuestas afirmativas también se incluyeron niños de estos niveles escolares.

También se dan casos en que las madres sí tomarían el servicio para un hijo y no para el otro independientemente de cuál de ellos es mayor. Las razones expuestas son principalmente relacionadas a la distracción de ese hijo.

\section{Principal razón por la que se contrataría a un profesor online}

De acuerdo con la encuesta, con un $41 \%$, la razón principal estaría dada por la disponibilidad para el momento en que justo se necesita la clase de acuerdo a los horarios del estudiante sin tener la necesidad de interrumpir o sacrificar otras actividades o tiempo. La segunda razón más importante con un $31 \%$, estaría dada por la comodidad y practicidad de poder tomar la clase en cualquier lugar que se necesite o en cualquier espacio de la casa sin tener que incomodar a los otros miembros de la familia o al mismo estudiante.

\section{Atributos deseados del servicio de tutoría online}

El principal atributo es el de contar con un reporte de avance de clase y de una evaluación del hijo culminada la clase, seguido del perfil del profesor y contar con el ranking y comentarios de los profesores. 


\section{Precio dispuesto a pagar por una hora de tutoría virtual}

El precio considerado a pagar sería más de 50 soles en el $53.5 \%$ de los encuestados, donde el rango de precio promedio mayor es entre 50 a 59 soles con un $27.5 \%$. Los precios son similares a los de tutoría presencial.

\section{Razones para no contratar el servicio online}

Ante la negativa de interés en contratar los servicios online, las justificaciones fueron en primer lugar (34\%) el no estar de acuerdo con tutorías online ya sea por no confiar en su efectividad o no gustarles "nada online". En segundo lugar (25\%) se menciona que los hijos son muy distraídos o con dificultad para concentrarse y, en último lugar la corta edad del niño/niña (16\%). En los casos restantes, se menciona la no necesidad de tutoría.

\section{Desventajas de la propuesta}

Las desventajas o dificultades que las mamás creen que sus hijos podrían tener con este servicio fueron:

Tabla 1

Desventaja de la propuesta

\begin{tabular}{|lc|}
\hline Que se pueda distraer o desconcentrar & $37 \%$ \\
Menor control del professor & $24 \%$ \\
Dificultad en la interacción con el profesor & $23 \%$ \\
Que el estudiante no pueda explicar el requerimiento con claridad & $\underline{16 \%}$ \\
& $100 \%$ \\
\hline
\end{tabular}

Fuente: Estudio cuantitativo plan de negocio, elaboración propia

Se observa que los temores van hacia la posible distracción de los estudiantes y la dificultad que el profesor podría tener para lograr liderar la clase. Por lo tanto la principal barrera es la percepción de no lograr la concentración del estudiante. En este sentido la estrategia debe 
asarse en la empatía que se logra con el alumno, haciendo que la clase sea amena y lograr la efectividad del aprendizaje de manera entretenida para que los niños tengan interés.

\section{Ventajas de la propuesta}

De otro, lado, las ventajas que las mamás creen que sus hijos podrían tener con este servicio fueron:

Tabla 2

Ventaja de la propuesta

\begin{tabular}{|lc|}
\hline Practicidad para conectarte en el horario y momento que necesites & $41 \%$ \\
Comodidad y confort al tomar la clase en el espacio que desees & $23 \%$ \\
Pago online & $13 \%$ \\
Seguridad de no tener un extraño en casa & $10 \%$ \\
No invasivo, no vienen a tu casa & $8 \%$ \\
Servicio Ad hoc porque son nativos digitales & $\underline{5 \%}$ \\
Total & $100 \%$ \\
\hline
\end{tabular}

Fuente: Estudio cuantitativo plan de negocio, elaboración propia

Considerando las respuestas para todos los hijos en edad escolar de padres de familia encuestados, ellos ven como ventaja del servicio tutorial online la practicidad de conectarte en el horario que se necesite en contraparte a uno de los problemas mencionados como desventajas de los profesores particulares a domicilio en el sentido de que el estudiante debe adaptarse a la disponibilidad de horario del profesor, lo que en muchos casos por darse a una hora no ideal para el estudiante, este tiene que dejar de asistir a otras actividades como por ejemplo las deportivas.

Otra ventaja importante es la comodidad de poder tomar la clase en el espacio que se desee dentro del hogar. Las clases se toman generalmente en los comedores de las casas o departamentos lo que trae como consecuencia diversas preocupaciones que involucran a toda la familia: que el lugar esté ordenado, que los demás familiares no hagan mucho ruido, la vestimenta de la madre y niño debe ser adecuada, atender al profesor al menos con agua. Al poder tener las clases online, estas se pueden tomar en cualquier lugar de la casa, incluso la habitación del niño donde si quiere estará vestido adecuadamente de la cintura para arriba y, 
en pijama si así lo desea, de la cintura para abajo. La familia puede estar vestida para "entre casa" y no hay preocupación del "cómo está la casa" y, en general, se puede continuar con la vida cotidiana de la familia. La repuesta "no invasivo/no vienen a tu casa" refuerza este punto.

En menor medida se menciona el tema de mayor seguridad y naturalidad del servicio dado que los niños son nativos digitales. Estas respuestas podrían sorprender pues se prioriza la comodidad por encima de otras cualidades del servicio, lo cual nos da insights para la propuesta de comunicación

En conclusión, el estudio cuantitativo nos indica un alto interés en tomar el servicio tutorial virtual propuesto y nos revela los atributos base para el diseño de la propuesta y la estrategia de comunicación. 


\section{PLANEAMIENTO ESTRATÉGICO}

\subsection{Estrategia}

\subsubsection{Declaración de la estrategia}

La declaración de la estrategia de Klaz se ha desarrollado considerando a la ventaja del servicio a través de la propuesta de valor para el cliente, su alcance y objetivos.

Klaz es un servicio de tutoría escolar online en tiempo real, con profesores que entienden y conectan de manera amigable con las necesidades individuales de aprendizaje de cada estudiante, permitiendo a los padres monitorear su progreso académico a través de una plataforma innovadora y práctica.

En cuanto al alcance, el servicio de Klaz se enfocará en escolares, primero de Lima metropolitana y, después del primer año, a nivel Perú, de 2do grado de primaria hasta 11vo grado de secundaria, de colegios de NSE AB.

El objetivo estratégico, es alcanzar una rentabilidad que se mantenga en crecimiento gracias a la lealtad y recomendación de clientes satisfechos por un servicio ágil, moderno, siempre actualizado y con profesores comprometidos.

De esta manera, Klaz cambiará la forma de tomar tutorías en el Perú, mediante un concepto innovador y disruptivo frente a la manera tradicional de clases particulares a domicilio con una metodología pedagógica exclusiva.

\subsection{Misión y visión del negocio, valores y grupos de interés}

\subsubsection{Misión}

Somos un servicio único de tutoría escolar que satisface las necesidades individuales académicas de cada usuario a través de una plataforma innovadora, amigable y práctica, conectando a estudiantes y tutores en cualquier momento y lugar.

\subsubsection{Visión}

Ser reconocidos como el servicio de tutoría online preferido y más buscado por escolares, padres y profesores en el Perú. 


\subsubsection{Valores}

Hemos considerado que los valores más importantes de la empresa son la empatía, la innovación, la integridad y la practicidad. Estos valores deben evidenciarse a través de cada acción que realizamos bajo la marca Klaz.

La empatía será transmitida y vivida haciendo las preguntas adecuadas para identificar y entender las necesidades de los estudiantes y sus padres por parte de los profesores y Klaz, a través de las plataformas tecnológicas como son la página web, redes sociales y contacto telefónico. Los escuchamos activamente creando un ambiente de colaboración amigable y luego, estas necesidades son atendidas apropiadamente. Asimismo, nos pondremos en los zapatos de los profesores apoyándolos para que tengan una experiencia agradable y de alto impacto en los estudiantes.

También consideramos altamente importante la innovación, dado que buscaremos constante mejora de los procesos tecnológicos y educativos (TIC), según las tendencias internacionales y nacionales.

La integridad estará siempre presente en las relaciones internas y externas siendo sinceros y respetuosos en todas las acciones y comunicaciones.

Finalmente, incluimos el valor practicidad, pues nos adaptamos al estilo de vida de los estudiantes, buscando su confort para que el enfoque sea en el aprendizaje.

\subsubsection{Grupos de interés o stakeholders}

Los stakeholders son los grupos de personas que pueden verse afectados de acuerdo a sus propios intereses, por las acciones y decisiones de nuestro proyecto. Dada la importancia de su influencia en el negocio y además que sin su participación la empresa no se podría sostener, hemos definido como stakeholders, a las socias inversionistas, empleados y tutores, clientes y proveedores. También son considerados stakeholders la competencia, universidades y colegios, instituciones gubernamentales y, organismos internacionales. 
Las socias inversionistas son 3 y buscan además de la rentabilidad del negocio, mantener su competitividad y prestigio.

En cuanto a los empleados, estos estarán conformados por personal administrativo que facilitará las labores de los profesores y de la empresa. De otro lado están los profesores, que son la columna vertebral de la compañía al ser el vehículo de entrega del servicio.

Los clientes estarán representados por los padres de familia quienes contratan el servicio, mientras que sus hijos serán los usuarios del servicio. Ambos evaluarán la calidad de Klaz.

Los proveedores estarán conformados por diversas empresas como son las de servicio tecnológico a nivel de diseño, desarrollo y mantenimiento. En este nivel contaremos con proveedores como App Store, Play Store, Firebase, Digital Ocean. Godaddy Punto.pe, Zibbler y Electo. También se contará con proveedores a nivel de servicio contable, consultoría legal, inmobiliaria y, de gestión humana para apoyo de evaluación y selección del personal.

En lo que se refiere a la competencia, en la actualidad no existe una empresa en el Perú, con el mismo formato de servicio de tutoría online en tiempo real, pero sí se brindan tutorías en formato presencial, a manera de clases a domicilio, academias y en los mismos colegios.

Los colegios y universidades son también stakeholders importantes; los colegios por ser una posible fuente de recomendación de profesores, recomendación de servicio y porque se pueden dar variaciones en las exigencias académicas y a nivel curricular, las que deben ser atendidas por nuestros docentes. Además, allí trabajan los profesores de nuestros usuarios. En cuanto a las universidades, llegar a estas es el objetivo de la mayoría de los escolares y el lograr altos promedios facilita su ingreso. Es por esto que estaremos actualizándonos con los nuevos procesos pedagógicos. 
Las instituciones gubernamentales están lideradas por el Ministerio de Educación (MINEDU) y, de acuerdo a sus normativas, se podría eventualmente tener alguna repercusión en la actividad de nuestro servicio. Es importante estar siempre atentos a los requerimientos y beneficios que imparte la entidad.

A nivel internacional existen diferentes asociaciones u organismos como por ejemplo Padres 2.0, que están vigilantes frente al riesgo del uso de las TIC a nivel de prevención, sensibilización, formación, mediación y asistencia psicológica y jurídica. Es importante estar al tanto de sus preocupaciones.

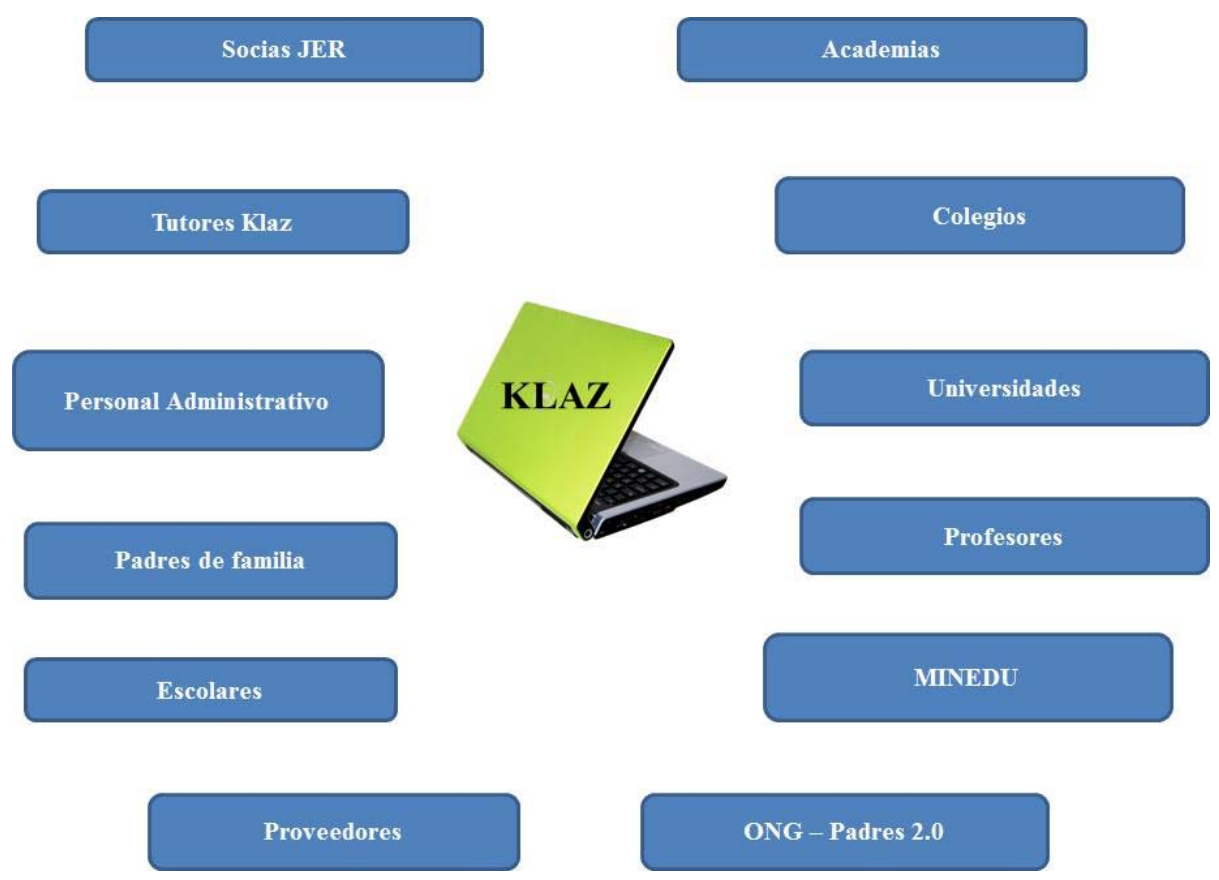

Figura 3. Relación de Stakeholders de Klaz

Fuente: Elaboración propia.

\subsection{Análisis FODA}

\subsubsection{Matriz de análisis interno}

Complementando el análisis PESTEL visto en el capítulo II, y de donde extraemos las oportunidades y las amenazas, presentamos la matriz de análisis interno para poder construir las fortalezas y las debilidades del FODA. 
Esta matriz de análisis interno considera las áreas de compras, operaciones, marketing y ventas, innovación y recursos humanos.

Tabla 3

Matriz de análisis interno

\begin{tabular}{|c|c|c|c|c|c|c|}
\hline & COMPRAS & OPERACIONES & MARKETING Y VENTAS & FINANZAS & INNOVACIÓN & RECURSOS HUMANOS \\
\hline FORTALEZAS & \begin{tabular}{|l|}
-Proveedores con \\
experiencia en diseño y \\
desarrollo de aplicaciones \\
educativas y \\
conocimiento del target.
\end{tabular} & $\begin{array}{l}\text {-Entorno web práctico y } \\
\text { amigable. } \\
\text { - Exclusiva metodología } \\
\text { pedagógica adhoc al } \\
\text { servicio virtual. } \\
\text { - Experiencia de socias en } \\
\text { enseñanza en entorno } \\
\text { innovador y alta exigencia } \\
\text { UPC. } \\
\text { - Experiencia de las socias } \\
\text { en servicio de tutoria para } \\
\text { escolares como usuarias y } \\
\text { madres. } \\
\text { - Disponibilidad de } \\
\text { profesores para óptima } \\
\text { cobertura de clases. } \\
\text { - Pago online }\end{array}$ & $\begin{array}{l}\text { - Expertise de socias en } \\
\text { marketing y ventas } \\
\text { - Continua } \\
\text { comunicación en } \\
\text { redes. }\end{array}$ & $\begin{array}{l}\text { - Capital disponible } \\
\text { para invertir en } \\
\text { proyecto. } \\
\text { - Aálisis cuantitativo } \\
\text { de proyecto por } \\
\text { expertise MBA } \\
\text {-Bajos costos de } \\
\text { inversión }\end{array}$ & $\begin{array}{l}\text { - Pioneros en mercado. } \\
\text { - Proactividad para } \\
\text { aplicar nuevas } \\
\text { tendencias. } \\
\text { - Expertise de socias en } \\
\text { Innovación }\end{array}$ & $\begin{array}{l}\text { Profesores evaluados y } \\
\text { seleccionados por } \\
\text { competencias. } \\
\text { - Profesores cuentan con } \\
\text { verificaciones y } \\
\text { evaluaciones de seguridad y } \\
\text { prevención riesgos. } \\
\text { - Docentes con } \\
\text { conocimiento de } \\
\text { metodologías de diversos } \\
\text { colegios. } \\
\text { - Profesores son evaluados } \\
\text { y recomendados } \\
\text { visiblemente en la } \\
\text { plataforma. }\end{array}$ \\
\hline DEBILIDADES & & - Servicio fácil de imitar. & & $\begin{array}{l}\text {-Complejo manejo de } \\
\text { tributación }\end{array}$ & & $\begin{array}{c}\text { - Posibible falta de lealtad de } \\
\text { los profesores hacia Klaz } \\
\text { (negociación por fuera) }\end{array}$ \\
\hline $\begin{array}{c}\text { FACTOR CRÍTICO DE } \\
\text { ÉXITO }\end{array}$ & $\begin{array}{l}\text { - Proveedores proactivos } \\
\text { conocerdores del target y } \\
\text { las tendencias. }\end{array}$ & $\begin{array}{l}\text { - Cobertura óptima de } \\
\text { número de profeores } \\
\text { para garantizar } \\
\text { disponibilidad horaria } \\
\text { - Interfaz amigable y } \\
\text { práctica con programa de } \\
\text { soporte sólido. }\end{array}$ & $\begin{array}{l}\text { - WOM para } \\
\text { recomendaciones de } \\
\text { servicio. } \\
\text { - Community manager } \\
\text { que conecta con } \\
\text { padres y estudiantes }\end{array}$ & \begin{tabular}{|l|} 
- Óptima gestión \\
financiera en \\
operaciones, recurso \\
humano y marketing
\end{tabular} & $\begin{array}{l}\text { - Innovación constante } \\
\text { según necesidades del } \\
\text { target. } \\
\text { - Fast followers en } \\
\text { tendencias digitales en } \\
\text { escolares }\end{array}$ & $\begin{array}{l}\text { - Profesores conectan con } \\
\text { necesidades de estudiantes } \\
\text { y padres. } \\
\text { - Calidad de profesores }\end{array}$ \\
\hline $\begin{array}{l}\text { ESTRATEGIA } \\
\text { FUNCIONAL }\end{array}$ & $\begin{array}{l}\text { - Servicio digital con } \\
\text { mantenimiento, } \\
\text { actualización y mejora } \\
\text { contínua aplicando } \\
\text { tendencias del target }\end{array}$ & $\begin{array}{l}\text { - Mantenimiento } \\
\text { constante de la aplicación } \\
\text { para un servicio digital de } \\
\text { calida. } \\
\text {-Adminstración de } \\
\text { disponibilidad de } \\
\text { profesores versus } \\
\text { necesidades. } \\
\text { - Desarrollo Agile para } \\
\text { mejora contínua e } \\
\text { innvoadora. }\end{array}$ & \begin{tabular}{|l|} 
- Generar contenidos \\
en Redes Sociales para \\
generar \\
recomendación.
\end{tabular} & \begin{tabular}{|l|} 
- Pagos OPEX con \\
proveedores \\
- Asesoría financiera y \\
contable-tributaria
\end{tabular} & $\begin{array}{l}\text { - Seguimiento constante } \\
\text { de tendencias digitales } \\
\text { para juegos y procesos } \\
\text { educativos. }\end{array}$ & $\begin{array}{l}\text { - Óptima selección, } \\
\text { inducción y seguimiento de } \\
\text { profesores que transmita } \\
\text { diferencial del servicio } \\
\text { - Programa de } \\
\text { endomarketing }\end{array}$ \\
\hline
\end{tabular}

Fuente: Elaboración propia 


\subsubsection{Matriz FODA}

Tabla 4

\section{FODA Klaz}

\begin{tabular}{|c|c|c|}
\hline & FORTALEZAS & DEBILIDADES \\
\hline Factores Externos & $\begin{array}{l}\text { F1 Entorno web práctico y amigable. } \\
\text { F2 Proveedores digitales expertos en target. } \\
\text { F3 Profesores conocen metodologías de varios } \\
\text { colegios. } \\
\text { F4 Experiencia de socias en enseñanza en entorno } \\
\text { de alta exigencia e innovación UPC. } \\
\text { F5 Experiencia en servicio de tutoria para escolares } \\
\text { como usuarias v madres. } \\
\text { F6 Exclusivo metodología pedagógica virtual. } \\
\text { F7 Programa endomarketing. } \\
\text { F8 Pago online. } \\
\text { F9 Capital disponible para invertir en proyecto. } \\
\text { F10 Análisis cuantitativo de proyecto por expertise } \\
\text { MBA UPC. } \\
\text { F11 Bajos costos de inversión. } \\
\text { F12 Pioneros en el mercado. } \\
\text { F13 Disponibilidad de profesores para óptima } \\
\text { cobertura de clases. } \\
\text { F14 Profesores seleccionados por competencias. } \\
\text { F15 Profesores con verificación de seguridad. } \\
\text { F16 Óptima comunicación en redes sociales. } \\
\text { F17 Expertise en innovación, marketing y ventas. }\end{array}$ & $\begin{array}{l}\text { D1 Servicio fácil de imitar. } \\
\text { D2 Complejo manejo de tributación. } \\
\text { D3 Posiblidad de falta de lealtad de profesores por } \\
\text { negociación por fuera con alumnos. }\end{array}$ \\
\hline OPORTUNIDADES & ESTRATEGIAS DE ATAQUE FO & ESTRATEGIAS DE REFUERZO DO \\
\hline & Explote & Busque \\
\hline $\begin{array}{l}\text { O1 Crece valoración de la educación y } \\
\text { requerimiento clases particulares. } \\
\text { O2 Mejor calidad de crecimiento económico. } \\
\text { O3 Crece confianza en comentarios en redes. } \\
\text { O4 Ingreso preferente con altos promedios a } \\
\text { Universidades. } \\
\text { O5 Tendencia a contar con segundo idioma. } \\
\text { O6 Crecimiento uso digital en vida cotidiana. } \\
\text { O7 Crecimiento aplicaciones digitales en } \\
\text { educación. } \\
\text { O8 Positivo para medio ambiente por menor } \\
\text { uso de papel. } \\
\text { O9 Opción de contratos por locación de } \\
\text { servicios. } \\
\text { O10 Alta preocupación por nivel de seguridad } \\
\text { ciudadana. } \\
\text { O11 Crece número de madres que trabajan } \\
\text { fuera de casa. } \\
\text { O12 Actividades extracurriculares crecen. } \\
\text { O13 Alta tasa de desempleo en Lima. }\end{array}$ & $\begin{array}{l}\text { F101 Enfatizar comunicación de uso práctico a } \\
\text { estudiantes y padres. } \\
\text { F10306 Generar contenidos para compartir en } \\
\text { redes. } \\
\text { F103 Mostrar facilidad de uso a profesores } \\
\text { potenciales } \\
\text { F104 Comunicar promedios para ingreso a } \\
\text { Universidades } \\
\text { F2O6 Aplicar Gaming para incentivar aprendizaje } \\
\text { F301 Reclutamiento de profesores con variedad de } \\
\text { perfiles } \\
\text { F3010 Alianzas con colegios para reclutamiento de } \\
\text { ex-alumnos } \\
\text { F407 Participación activa en foros, seminarios, } \\
\text { medios. } \\
\text { F407 Aplicar metodologías Agile para acelerar } \\
\text { modernizaciones de aplicativo } \\
\text { F607 Renovar y comunicar método exclusivo } \\
\text { pedagógico virtual } \\
\text { F1208 Incluir preocupación por medio ambiente al } \\
\text { minimizar uso de papel }\end{array}$ & $\begin{array}{l}\text { D106 Publicidad que construya valor de marca } \\
\text { D209 Contar con proveedores proactivos. }\end{array}$ \\
\hline AMENAZAS & ESTRATEGIAS DE DEFENSA FA & ESTRATEGIAS DE PREVENCION DA \\
\hline $\begin{array}{l}\text { A1 Retención por recibos por honorarios a } \\
\text { profesores. } \\
\text { A2 Decrece número de hijos por mujer. } \\
\text { A3 Barreras culturales contra clases virtuales. } \\
\text { A4 Alta competencia presencial de todo precio. } \\
\text { A5 Videos tutoriales online gratis. }\end{array}$ & $\begin{array}{l}\text { Confronte } \\
\text { F1F2A1 Cobertura que garantice a profesores } \\
\text { mayores o iguales ingresos que particulares. } \\
\text { F2A3 Comunicación de monitoreo en tiempo real y } \\
\text { grabado. } \\
\text { F3A4 Contar con } 3 \text { niveles de precio según perfil de } \\
\text { profesores. } \\
\text { F5A3 Desarrollar capacitación a profesores en } \\
\text { aprendizaje para entornos digitales. }\end{array}$ & $\begin{array}{l}\text { Evite } \\
\text { D2A1 Asesoría financiera y contable. } \\
\text { D3A1 Asesoría legal para contratos con profesores con } \\
\text { cláusulas claras de seguridad y tributación. } \\
\text { D3A3 Desarrollar y comunicar capacitación profesores } \\
\text { en aprendizaje entorno digital. }\end{array}$ \\
\hline
\end{tabular}

Fuente: Elaboración propia 


\subsection{Estrategia genérica competitiva}

La estrategia genérica que va a desarrollar Klaz para enfrentar las cinco fuerzas competitivas, y así poder obtener la productividad deseada es la de enfoque por diferenciación. Este servicio posee cualidades especiales e importantes para el consumidor y que la harán diferente frente a las ofertas de las otras opciones de asesorías existentes. Por este motivo no abarcamos todo el mercado sino sólo el segmento de estudiantes escolares.

Es así, que la estrategia de enfoque por diferenciación, se basará en implementar un servicio de tutoría online en tiempo real, con una plataforma práctica y amigable que responda a las necesidades de los estudiantes (de 2do grado de primaria a 11vo de secundaria) que requieran reforzar un curso. Se contará con una metodología pedagógica exclusiva brindada por profesores capacitados y empáticos que respondan a las tendencias digitales y educativas.

Según el estudio de Ipsos, perfil del internauta 2016, la frecuencia y el uso de dispositivos de conexión a internet cambian de acuerdo al ciclo de vida. Nuestros potenciales consumidores, niños de 8 a 11 años se conectan en promedio unas cuatro veces a la semana a internet, a través de sus PC's o tablets, de igual manera los adolescentes de 12 a 17 años acceden en promedio 5 o 6 veces a la semana y usan principalmente sus smartphones.

Podemos observar entonces, que sus estilos de vida están centrados en la tecnología, es una generación que no concibe vivir sin internet, no conocieron la vida antes de las redes sociales, por ello procesan más rápido la información digital.

Por lo tanto, los modos de aprendizaje online son los más adecuados para ellos, sienten gran atracción por la información visual debido a su familiaridad con los dispositivos digitales y su facilidad para llevar a cabo diversas actividades simultáneamente. Además, diversos estudios señalan que los estudiantes virtuales tienden a ser auto-motivados, autodisciplinados y auto-dirigidos. 
La estrategia de enfoque por diferenciación protege a nuestra empresa de las cinco fuerzas competitivas, de la siguiente forma: ante los competidores directos, la diferenciación reduce el carácter sustituible del servicio, aumentando la fidelidad y disminuyendo la sensibilidad al precio, por esta razón se mejora la rentabilidad. Por otro lado, la fidelidad de los clientes hace que sea más difícil la entrada de nuevos competidores. Asimismo, teniendo una rentabilidad elevada, se aumenta la capacidad de resistencia de la organización frente a aumentos de coste impuestos por un eventual proveedor fuerte. Finalmente, las características especiales del servicio sumado a la fidelidad de los clientes, conformarán una defensa frente a los servicios alternativos.

Para que esta estrategia sea exitosa, es sumamente importante la inversión en comunicación, para dar a conocer este servicio innovador que satisface las necesidades de nuestro target.

\section{Ventajas competitivas}

- Klaz es el primer servicio de tutorías online en tiempo real. Dada la relevancia de la tendencia digital, el transformar la manera de ofrecer clases de tutorías, genera un diferencial.

- La empresa cuenta con un servicio riguroso de reclutamiento y selección de profesores. Asimismo se validan y rectifican antecedentes policiales, laborales y títulos de los mismos. Todo esto con el fin de garantizar una óptima experiencia de los estudiantes con respecto al servicio.

- Contamos con una metodología pedagógica exclusiva basada en las competencias relevantes para los profesores y sobretodo en la empatía que es clave para lograr una conexión con el estudiante.

\subsection{Objetivos estratégicos y específicos}

\subsubsection{Objetivos estratégicos}

Orientación hacia el cliente

Klaz identificará las necesidades de cada usuario para poder apoyar en las dificultades académicas de manera personalizada utilizando tecnología innovadora y una metodología pedagógica centrada en el estudiante. 
Crecimiento

Se busca garantizar un crecimiento sostenido pudiendo abarcar en un mediano y largo plazo, más colegios de NSE B- y C así como también ciudades en provincias. En el futuro también se considera desarrollar un negocio complementario apuntando a universidades y programas de postgrado.

\section{Rentabilidad}

Alcanzar una rentabilidad del 9\% para el segundo año en el escenario esperado y mantener niveles de rentabilidad de $13 \%, 15 \%$ y $16 \%$ para el año 3 , año 4 y año 5 respectivamente.

\subsubsection{Objetivos específicos}

- Lograr una aceptación positiva en la introducción de nuestro servicio alcanzando el 5\% del mercado de tutorías escolares.

- Captar cada año un incremental de 5\% de participación del mercado.

- Reclutar y capacitar profesores en un incremental de $100 \%$ en el segundo año, $50 \%$ en el tercer año, $33 \%$ en el 4 to y $25 \%$ en el 5 to año, para poder asegurar una óptima cobertura y disponibilidad horaria de tutorías.

- Lograr una puntuación de 4 (de máximo 5) en la evaluación de "Customer Satisfaction"

- Lograr una puntuación de 4.5 en la evaluación "Recomendación" del servicio. 


\section{PLAN DE MARKETING}

\subsection{Objetivos y posicionamiento}

\subsubsection{Objetivos}

Para el desarrollo exitoso del proyecto, se han establecido objetivos a corto, mediano y largo plazo, los cuales pasamos a detallar a continuación.

Estamos señalando 3 objetivos a corto plazo que establecen las metas para el primer año de operaciones desde su lanzamiento en marzo del 2020, mes en que se inicia el año escolar.

- Como primer objetivo se proyecta capturar el 5\% del mercado potencial objetivo de tutorías escolares del NSE AB de Lima.

Para estimar el universo de tutorías posibles se ha considerado que el 30\% de los alumnos de colegios $\mathrm{AB}$ requieren apoyo extra escolar. Esta proyección se basa en cálculos de expertos entrevistados como son directores y educadores de amplia experiencia en la docencia escolar. El estudio cuantitativo realizado para el presente plan de negocio tuvo como respuesta un $55.3 \%$ como uso de profesores particulares, es decir, un porcentaje mucho mayor, lo que indica que el $30 \%$ es un número bastante seguro.

En cuanto al promedio de horas por sesión, se consideró una duración de 1.5 horas y 2 veces por semana, tomando en cuenta el estudio cuantitativo realizado por el equipo

- El segundo objetivo a corto plazo proyecta alcanzar a 350 profesores registrados activamente incluyendo 270 necesarios más cobertura por rotación, al termino del primer año.

Este nivel de cobertura permitirá brindar la variedad de horarios requerido por los estudiantes, a la vez de responder a la disponibilidad indicada por los profesores haciendo posible que tengan un ingreso salarial igual o mayor que el actual, donde dictan clases particulares a domicilio, con la ventaja de poder hacerlo desde la comodidad del lugar elegido.

- El tercer objetivo está orientado a destinar el 3\% de las ventas al presupuesto de marketing para dar a conocer Klaz y generar alta verbalización y WOM. 
Este objetivo equilibra la rentabilidad de la empresa con la difusión publicitaria para ayudar a alcanzar los 2 primeros objetivos.

Los objetivos a mediano plazo se orientan a las metas señaladas para el 2 do al 5 to año de operaciones, donde ya habremos ingresado a provincias y contaremos con un conocimiento más sólido por parte del mercado. Para este efecto, estamos señalando 4 objetivos, los cuales son los siguientes:

- El primer objetivo a mediano plazo se enfoca en incrementar las ventas en $234 \%$ para el segundo año, $50 \%$ para el tercer año y $33 \%$ para el 4to año Estos objetivos se lograrán al incorporar principales ciudades de provincias en el segundo año y aumentar la participación de mercado paulatinamente..

- El segundo objetivo a mediano plazo establece que se incrementará la participación de mercado de tutorías de 5 a 10\% para el segundo año, 15\% en el tercer año y $20 \%$ en el cuarto año en Lima. En el caso de provincias los objetivos son los mismos y, se ha calculado un tamaño de mercado en base a indagaciones mediante entrevistas sin rigurosidad estadística tomando en cuenta un promedio de 10 colegios de NSE AB en las ciudades de Piura, Trujillo, Chiclayo, Huancayo, Cuzco, Arequipa e Ica-Chincha.

- El tercer objetivo se orienta a mantener una cobertura de profesores adecuada para responder a la demanda futura. Se espera tener contratados a 600 profesores en Lima y 370 en provincias para el 2 do año de operaciones. En el 3er, 4to y 5 to año proyectamos contar con 1,050 y 1,400, 1,750 profesores en Lima. En el caso de provincias el objetivo de profesores para los años 3,4 y 5 apunta a tener contratados a 740, 1,100 y 1,477 . Estos objetivos incluyen una cobertura del $30 \%$ como seguridad frente a la posible rotación de profesores.

- Finalmente, como objetivo de marketing se apunta a que Klaz esté posicionado como top of mind con respecto a los servicios de tutorías.

El futuro de Klaz se evidencia mediante los objetivos a largo plazo.

- Ser reconocidos como la marca No.1 en ventas dentro del mercado de servicios de tutorías online. 
- Ampliar cobertura de servicio a más provincias llegando a todo el Perú.

De otro lado se pretende capturar otros mercados, como apoyo universitario, post grados y otros idiomas. Se considera que para alcanzar este crecimiento, se debe establecer otra marca en paralelo a Klaz y no aplicarlo como extensión de línea. Las razones son varias; en primer lugar se ha podido observar que en muchos servicios similares a nivel internacional la atención a apoyo post secundaria aparece como un servicio menor al ser parte de la gran marca de tutoría escolar, reduciendo su protagonismo. De otro lado, el target es distinto, pues los decisores son los mismos estudiantes universitarios o de postgrado, por lo que la propuesta de valor y la personalidad de marca deberán construirse teniendo en cuenta a este target.

\subsubsection{Posicionamiento}

Para plantear el enfoque que guiará a la estrategia de marketing para el presente Plan de Negocio se propone la siguiente Declaración de Posicionamiento.

Para madres y padres de escolares entre 2do grado primaria y 11vo grado secundaria de colegios de NSE AB de Lima metropolitana que necesitan ayuda para reforzar materias donde presentan dificultad, Klaz es un servicio de tutoría escolar online en tiempo real, que permite solucionar las dificultades académicas de cada usuario a medida, a través de una plataforma innovadora y práctica con el apoyo de profesores capacitados que puedan generar una conexión con el estudiante.

El posicionamiento apunta al target de padres como público objetivo principal, dado que ellos serán los decisores finales de la adquisición del servicio, aunque contará con la influencia de sus hijos y amigos.

\subsection{Estrategia de producto}

Klaz es un servicio de tutoría escolar online en tiempo real, que permite solucionar las dificultades académicas de cada usuario a medida, a través de una plataforma innovadora y práctica con el apoyo de profesores capacitados que generan una conexión con el estudiante; asimismo este servicio permitirá monitorear la clase en tiempo real desde otro dispositivo o, 
con videos grabados, además de reportes generados por los profesores terminada cada sesión.

La plataforma digital tendrá constante mantenimiento y actualización para mantenerse operativa y moderna de manera permanente.

La marca Klaz ha sido seleccionada por cumplir con características que la hacen memorable y relacionada con el concepto.

Es un nombre corto y fácil de recordar. Este factor es muy importante dada la proliferación de marcas actual. Esta marca apunta a lograr un Top of Mind y Awareness importantes.

Además, el nombre Klaz es una adaptación del término anglosajón “class” que significa "clase" por lo que transmite el significado del servicio con estilo. El iniciar la marca con la letra " $\mathrm{K}$ " construye imagen de modernidad y tecnología.

El nombre Klaz con 3 consonantes y una vocal, cumple con las características del habla electrónica de los jóvenes como lo explican Juan Biondi y Eduardo Zapata (2017) en "Nómades electronales":

Una primera observación nos pone ante la evidencia de que estamos frente a una consonantización de la escritura. Las vocales - como entidades independientes - son consideradas prescindibles porque la articulación misma de la consonante las supone. (p.45).

La tipografía Impact de Klaz es sólida, consistente y de tono negro, que en conjunto, aporta la modernidad necesaria para el público al que nos dirigimos incluyendo padres y jóvenes usuarios. El isotipo está compuesto por un conjunto de colores brillantes que dan vida a un símbolo "call out" que connota movimiento y nos conecta a un público más joven porque está apoyado en unos píxels negros, que tienen un lenguaje de chat totalmente reconocido por el mundo.

Este símbolo gráfico complementa la comunicación del concepto de Klaz pues como indican Biondi y Zapata (2017) al referirse a los discursos electrónicos: "Son discursos en que se recurre simultáneamente también al código iconográfico...”(p.45) 
Los colores azul, rojo, amarillo y naranja son colores de brillo pleno, son intensos y atraen la atención. Los colores brillantes son perfectos para ser utilizados en envases, moda y publicidad. El verde pantone $809 \mathrm{C}$ es un color asociado a la tecnología y el verde pantone 375C es el utilizado por apps como Whats App y Spotify por lo que construyen la percepción de modernidad tecnológica al usar códigos ya reconocidos en este mundo.

La marca Klaz ha ingresado a búsqueda para registro en Indecopi, obteniendo el calificativo de Riesgo Bajo en el Perú, por lo que es altamente factible que se pueda registrar.
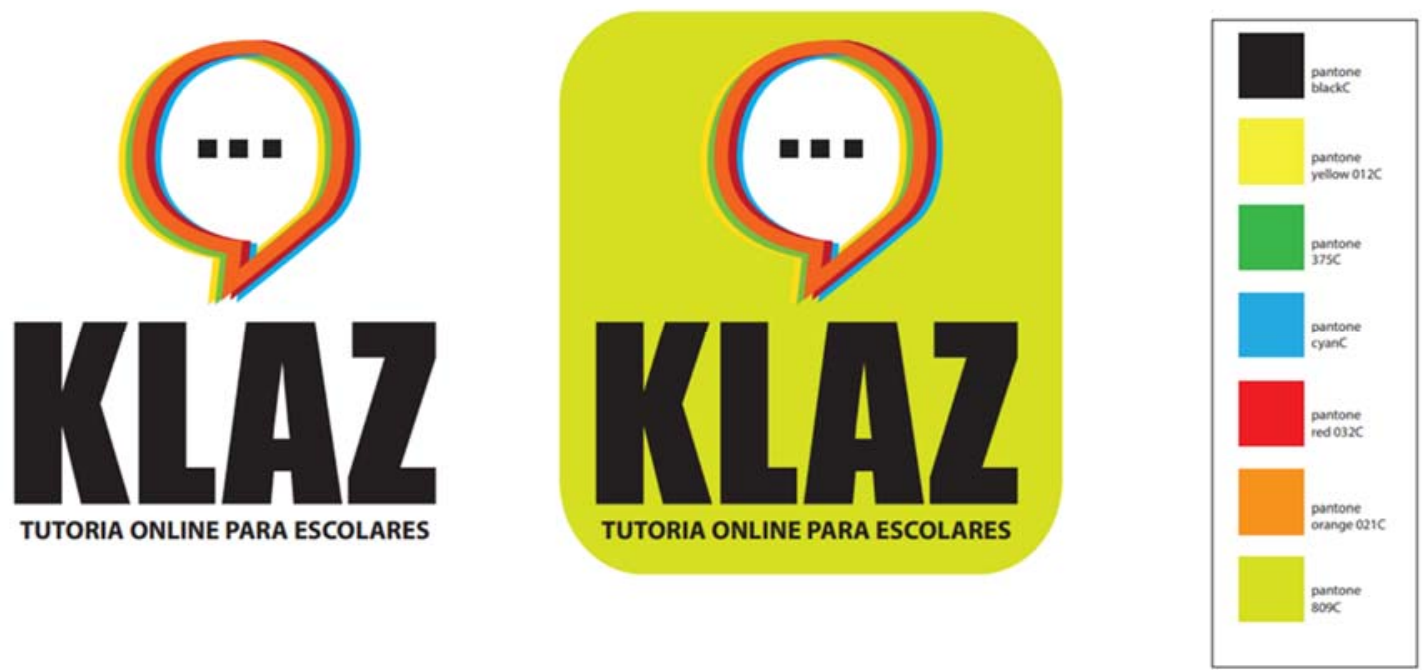

Figura 4. Logotipo Klaz

Fuente: Elaboración de diseñadora Claudia Artadi para JER SA.

Los roles de decisión en relación al servicio Klaz son varios según su impacto en su influencia, decisión, compra y consumo. De esta manera, el público objetivo tiene como usuarios o consumidores a los escolares de 2 do grado de primaria a 11vo grado de secundaria de colegios de NSE AB de Lima Metropolitana. Por otro lado, los decisores y compradores los conforman los padres de los escolares. En el caso de influyentes, estos pueden ser amistades o usuarios que han hecho comentarios del servicio sobretodo en el caso de padres de hijos pequeños. En el caso de niños de secundaria, ellos pueden ser los influyentes de la decisión de compra, y luego convertirse en consumidores. 
Klaz cambiará la forma de tomar tutorías mediante un concepto innovador y disruptivo, frente a la manera tradicional de clases particulares a domicilio ofreciéndole al usuario una mayor disponibilidad de horarios, surtido de profesores empáticos $\mathrm{y}$, el poder conectarse para tomar la clase en el lugar que quieran cómodamente. Se contará con una metodología pedagógica exclusiva para poder brindar la clase de manera virtual.

Las características del servicio de tutoría virtual Klaz se evidencian a través de su plataforma digital, la cual será desarrollada por un equipo experto y de acuerdo al brief entregado por las socias. Dentro de este pedido están considerados algunos requerimientos como los siguientes:

- La aplicación tanto web como móvil, tendrá un uso amigable, es decir, será fácil de manejar, de uso intuitivo, con un diseño simple, moderno y de pocos pasos. Contará con herramientas de compartir pantalla, archivos y pizarra interactiva para facilitar interacción y verificación del aprendizaje.

- Para la selección de profesores, la búsqueda será sencilla y se detallará el perfil de cada profesor con su foto, así como su conocimiento de metodologías de los colegios que dominan.

- En cuanto a la calificación, el alumno/padre de familia/apoderado podrá calificar el desempeño del profesor y la experiencia del servicio. Se incluirán las 5 estrellas para marcación y espacios para comentarios/sugerencias.

- Los padres podrán hacer seguimiento de las clases de sus hijos, puesto que se podrá monitorear la tutoría en tiempo real desde cualquier dispositivo. Asimismo, finalizada la clase el profesor llenará el reporte, el cual se enviará automáticamente al email o Whatsapp registrado del padre de familia. De otro lado, las grabaciones de las clases quedarán disponibles para su visualización hasta un mes después de la sesión.

- La practicidad es un atributo muy ventajoso pues tanto el profesor como el alumno podrán conectarse desde cualquier dispositivo móvil, tablet o laptop y, desde cualquier lugar que le acomode al estudiante en función a la disponibilidad horaria escogida. 
- Se otorgarán incentivos al alumno tipo video juegos o Gaming para acumular puntos y ascender de niveles según los avances en el aprendizaje o muestras de esfuerzo.

- Klaz es de fácil accesibilidad pues el servicio se ofrecerá como aplicativo de App Store de Apple y de Google Play de Android para los dispositivos móviles y tablets. De igual manera, se podrá acceder por internet vía login con un usuario (Windows, IOS, Android). Se ha desarrollado un isotipo para el App alineado al logotipo.

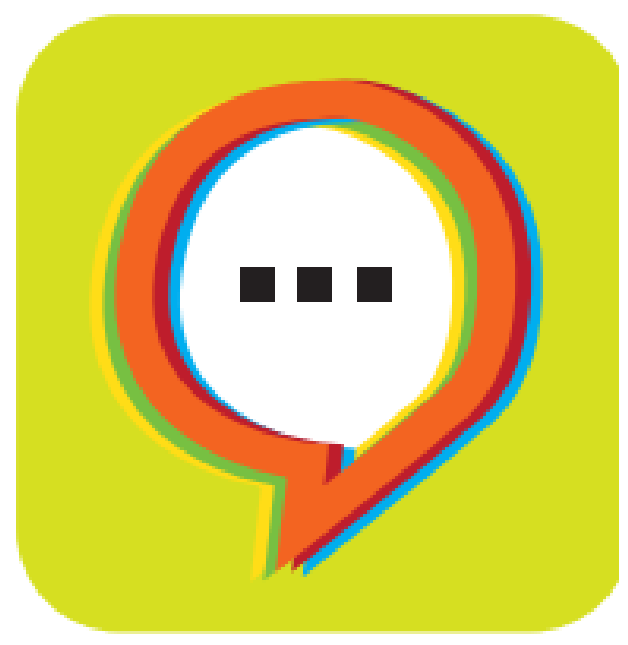

Figura 5. Isotipo de aplicativo Klaz - APP

Fuente: Elaboración diseñadora Claudia Artadi para JER SA

- En cuanto al precio, las tarifas estarán segmentadas en 3 niveles, de acuerdo al perfil del profesor. Klaz emitirá boletas electrónicas o facturas a los padres incluyendo el IGV dentro de la tarifa. Los tutores tendrán un pago por hora, de tal manera que la diferencia versus la tarifa cobrada al padre cubre el IGV y la ganancia para la empresa.

- Se diseñará una metodología de enseñanza-aprendizaje virtual exclusiva bajo una marca registrada, con la cual se capacitará a todos los profesores.

- Todos los datos e información que se registren estarán protegidos por un sistema de seguridad.

- Para efectuar el pago del servicio, los medios de pago serán aplicados online con Visa o Mastercard vía tarjeta débito o crédito ingresada al momento de registro. Se podrán pagar clases de 1 hora, 1 hora y media o de 2 horas. 
- El alcance del servicio irá de menos a más, se lanzará inicialmente en Lima Metropolitana para los colegios de NSE AB. Luego del primer año, se espera abarcar colegios de NSE B- y C y provincias como Arequipa, Chiclayo, Piura, Trujillo, Huancayo, Ica-Chincha y Cuzco.

- En cuanto al servicio de post venta, se contará con un número de Whatsapp de respuesta rápida, así como también un chat online (chatbot) en la página web y un formato de consultas, sugerencias y/o reclamos.

- KlaZ contará con medios propios a través de cuentas fan page de Facebook, página web, Instagram y, canal YouTube.

\subsection{Estrategia de precio}

Se ha definido la estrategia de precios con un enfoque desde el cliente, basado en la investigación de mercado realizada, con lo que se ha determinado la variedad de precios aceptado por el target según las características del profesor a domicilio. Se ha considerado el servicio a domicilio por no contarse en la actualidad con un servicio online como el propuesto.

Se ha aplicado el método de fijación de precios en relación a la competencia considerando plantear las tarifas al mismo nivel de la competencia con 3 tipos de tarifas segmentadas de acuerdo al perfil del profesor, al igual que se da con el servicio de tutoría a domicilio actual en Lima. El mismo criterio ha sido aplicado para la estimación de tarifas para provincias, la cual se dará a partir del 2do año de operaciones de Klaz

- El nivel 1 de precio será para los profesores conformados por alumnos universitarios de primeros ciclos cuya tarifa por hora será de 35 soles.

- En el nivel 2 de precio están considerados los profesores regulares, es decir docentes de colegio, cuya tarifa por hora será de 60 soles. Este será el grueso de profesores de acuerdo al resultado del estudio de mercado. 
- En el nivel 3 de precio están los profesores premium conformados por docentes de cursos para el programa IB o Bachillerato Internacional, los cuales son generalmente dictados en inglés u otro idioma. La tarifa para este nivel será de 80 soles.

Esta segmentación de precios, nos permite satisfacer la demanda diferenciada que el mercado de Lima presenta.

\subsection{Estrategia de distribución}

La estrategia de distribución está conformada por las actividades que colocan el servicio de tutoría virtual on line a disposición de los escolares.

El alcance geográfico en una primera etapa será a nivel de Lima metropolitana y, a mediano plazo se proyecta un crecimiento llegando a las principales ciudades como Trujillo, Piura, Chiclayo, Arequipa, Cuzco, Huancayo, Ica, Chincha, de acuerdo a las estimaciones de la demanda.

Nuestra estrategia se basará en utilizar un canal de distribución directo para tener mejor control sobre el servicio; la intensidad del canal será exclusivo, pues nos contactaremos en forma directa con el consumidor final, no utilizaremos intermediarios.

Basándonos en el perfil de los estudiantes, el canal adecuado para que conecte a nuestra web para iniciar la clase de tutoría, será una interfaz, ingresando su login al igual que el profesor, es en este momento que se brinda el servicio en tiempo real, a través de un dispositivo móvil, tablet, laptop o PC.

La versión web estará disponible a través de internet y será compatible con tablet y laptop. Asimismo, se usará la aplicación móvil disponible de App Store o Google Play de Android. 
En esta primera etapa tendremos 270 profesores de variados cursos y provenientes de distintos colegios de Lima, así como de universidades. Este número de profesores contratados está de acuerdo a la proyección de la demanda de horas y sesiones del primer año.

\subsection{Estrategia de promoción}

\subsubsection{Segmentación y target de comunicación}

El target o público objetivo para la comunicación de la estrategia de marketing y publicitaria ha sido definido según los roles de decisión y una estrategia de segmentación diferenciada. Se ofrecen tutorías escolares para los diferentes cursos de cada grado desde 2 do de primaria hasta 11 vo de secundaria

Para la primera etapa el target estará conformado por madres y padres de niños que cursan de 2do grado de primaria hasta 11vo grado ó 5to de secundaria, NSE AB de Lima metropolitana, principalmente de los distritos: San Isidro, Miraflores, Surco, San Borja, La Molina, Chorrillos (Villa), Barranco, Magdalena, Jesús María, San Miguel y Lince. Una vez el servicio esté consolidado, a partir del 2 do año, nos podremos expandir a otros distritos y ciudades principales del Perú.

De acuerdo a los estilos de vida de Arellano, los padres de familia a los que nos dirigimos son Sofisticados, Progresistas y Modernas. Los sofisticados utilizan el servicio porque son los primeros en utilizar las nuevas tecnologías, están a la vanguardia de los nuevos productos y servicios y buscan productos que les dan status. Para las modernas y progresistas la educación es sumamente importante y buscan este servicio confiando en que les dará a sus hijos un apoyo para mejorar en su rendimiento escolar y por lo tanto tendrán un mejor futuro. Todos estos grupos son abiertos a las innovaciones y tienen bajo rechazo a los usos de la tecnología por lo que estarán interesados en probar a Klaz.

Muchas de las madres trabajan fuera del hogar y monitorean las actividades de sus hijos vía el Smartphone durante el día para sentirse conectadas. Klaz les dará la oportunidad de 
solucionar no sólo la necesidad de contar con un profesor particular de confianza, sino además, tener reportes de avances e incluso presenciar la clase en remoto, lo que les da la satisfacción de cumplir con el rol de buena madre que a veces genera inseguridades en ellas Las madres que no trabajan también tienen temores al no poder ayudar a sus hijos con las tareas o mejorar su rendimiento, al no dominar las nuevas metodologías educativas o no recordar lo aprendido en su etapa escolar.

Hay un público secundario que no debe ser ignorado conformado por los usuarios o consumidores del servicio, los cuales se dividen en 2 sub grupos. Por un lado están los niños de 2do grado hasta 6to grado de primaria y, por el otro, los niños mayores que cursan entre 7 mo y 11vo grado de secundaria. El primer grupo depende de la decisión de los padres para la selección de tutorías escolares, sin embargo, dependerá de su avance académico y su satisfacción con el servicio el que sean leales a KIaz puesto que es importante para los padres ver que sus hijos están mejorando en su performance escolar, a la vez de que comentan la experiencia positiva con sus tutores.

El segundo grupo conformado por los niños más grandes, sí pueden traer a casa la sugerencia de usar Klaz por el atractivo del entorno digital y sentirse más independientes y "grandes" dado que no está viniendo a casa un profesor sino que tienen la clase por internet.

Como parte de la investigación para poder diseñar un servicio que satisfaga las necesidades de padres e hijos, encontramos Insights de las madres y de los hijos. Cabe destacar que en varios casos son ambos, padres e hijos, los que toman la decisión sobre las tutorías escolares, sin embargo, vimos que en la mayoría de los casos recae sobre la mamá esta decisión. Es por esto que priorizamos el Insight de la madre y lo describimos así:

Yo quiero ayudar a mi hija/o a que le vaya bien en el colegio porque así ella y yo estaremos más tranquilas sin preocuparnos por pasar los cursos o malograrnos el verano, sin embargo, no sé cómo ayudarla/o pues me es muy difícil encontrar al tutor ideal para ella. 
En el caso de los hijos, nos enfocamos en el Insight de los adolescentes 7mo a 11vo dado que ellos serán de gran influencia en la decisión de toma del servicio Klaz.

Yo quiero sacarme notas más o menos buenas porque quiero tener tiempo para otras actividades que me gustan aparte del colegio, sin embargo, me da pereza tener que esperar al profesor que venga a la casa, y me incomoda no poder vestirme relajado hasta que se vaya.

\subsubsection{Personalidad de la marca}

Para lograr persuadir al target, debemos conectarnos con ellos entendiendo sus creencias y valores tanto racionales como emocionales. Para ser entendidos $\mathrm{y}$, como parte de la construcción de la esencia de marca, desarrollaremos su personalidad como joven, innovador, moderno, tecnológico, alegre, amigable, práctico, inteligente, solucionador de problemas, siempre disponible y empático.

El Arquetipo seleccionado para transmitir esta personalidad es el tipo común. Klaz busca conexión con los estudiantes hablando su mismo idioma a través de la tecnología con una actitud empática, cercana y amigable. Klaz busca ayudar con respuestas realistas apoyándote en el día a día, a la vez que se preocupa por detectar oportunidades de mejora más profundas que se pueden trabajar a largo plazo. Con actitud cercana y la empatía de los profesores se desarrolla confianza en los estudiantes y sus padres.

\subsubsection{Estrategia de publicidad}

La comunicación publicitaria para el primer año se dará en 3 fases: pre lanzamiento y lanzamiento para la etapa del ciclo de vida de igual nombre y, mantenimiento para la etapa de crecimiento.

\section{- Pre-Lanzamiento: 2 meses}

Se realizará un piloto del servicio o marcha blanca, con una comunicación de target limitado y controlado para ir de la mano con el inicio de operaciones y prueba iterativa del Producto Mínimo Viable (PMV), donde se podría presentar alguna falla que debe ser rápidamente corregida para no impactar negativamente en el negocio. 
Objetivo de comunicación: generar prueba.

Se trabajará la comunicación con foco en pocos distritos aplicando la geolocalización y complementado con la base de datos o Friends \& Family de las socias a nivel Fan Page, Página Web e Instagram. Se informará que es un nuevo servicio de tutoría online escolar en Lima donde el beneficio principal o Key Brand Benefit será la practicidad de tomar las clases desde cualquier lugar y en cualquier momento con profesores verificados y evaluados. Este beneficio debe generar el deseo y luego dar like, compartir, o entrar a la página web para buscar mayor información del servicio.

- Lanzamiento: 4 meses

La comunicación abarca al target total de comunicación, el servicio ya está mejorado con los ajustes necesarios detectados en el pre-lanzamiento.

Objetivo de comunicación: construir Awareness.

Con un alcance de padres de 60 colegios de Lima $\mathrm{AB}$, se atrae al público y se informa que es un nuevo servicio de tutoría escolar online en Lima donde el beneficio principal o Key Brand Benefit será la practicidad de tomar las clases desde cualquier lugar y en cualquier momento. Este beneficio debe también generar el deseo y luego el dar like, compartir, o entrar a la página web para buscar mayor información del servicio.

El público empieza a compartir vía WOM el lanzamiento del servicio, se dan las primeras pruebas y comentarios positivos, así como shares de las publicaciones. Los clientes potenciales empiezan a ver los comentarios y se animan a pedir el servicio.

- Mantenimiento: 8 meses

La red de contactos se ha incrementado a nivel de seguidores en las redes sociales, visualizaciones en You Tube y visitas a la página Web. Ya se pueden observar más comentarios en la Fan Page y en los perfiles de los profesores. 


\section{Objetivo de comunicación: Engagement}

El público da sus testimonios, genera contenidos, el término Klaz empieza a ser parte del lenguaje coloquial, incluso con memes: “aquí Klazeando”. Para lograr este objetivo se generan acciones que invitan a la participación en los contenidos con respecto a la marca y así los clientes y usuarios invitan a otros a formar parte de la comunidad Klaz.

\section{Estrategia anual de medios:}

La revolución de internet, la tecnología y los cambios en el comportamiento del consumidor; hacen que hoy sea cada vez más necesario aplicar la publicidad como una conversación de dos vías buscando acercarnos al cliente. La idea no es sólo llegar a ellos con nuestros mensajes sino que ellos lleguen a nosotros con consultas, comentarios. Además, los usuarios de las redes crean y comparten contenidos que otros potenciales clientes ven y valoran.

Esta comunicación de los usuarios nos permite conocer cómo evolucionan sus necesidades $\mathrm{y}$ son fuente de nuevas ideas que pueden aplicarse para mejorar nuestro servicio y sus procesos.

Raúl Díaz Miranda, especialista en gestión de marcas en entornos digitales indica que según un estudio de Nielsen, el 83\% de las personas confía 'completamente' o 'en algo' en las recomendaciones de las personas a las que conocen. Y, que el $66 \%$ de las personas confían en las opiniones que las personas publican en línea. (Mercado Negro, junio 2018).

Los medios seleccionados serán básicamente digitales compuestos principalmente por las redes sociales.

El ecosistema de medios manejará de forma coordinada los medios propios, comprados y ganados, estando compuesto por Facebook, página Web, Instagram y YouTube y, utilizando 
bases de datos propias de la empresa y adquiridas y aplicando búsquedas SEO, SEM de los usuarios en internet relacionadas con nuestro servicio.

Se utilizarán las Redes Sociales de mayor influencia en nuestros targets, como son Facebook, Instagram y YouTube.

- En el caso de Facebook, este medio tiene alto alcance (97\%) siendo la red social más utilizada desde Smartphones para el rango de 18-35 años y desde laptop de 36 a 45 años según CCR (CCR, 2018). Ellos podrán compartir la publicación con sus contactos, usar reacciones en sus diversos formatos (me gusta, me encanta, me divierte, no me gusta), escribir comentarios y al dar click en la publicación se re-direccionará a la página Web. Facebook es un medio ideal para responder consultas sobre el servicio y también es útil para compartir comentarios positivos y generar leads a través de las preguntas que los potenciales clientes hacen buscando información. A este nivel es clave contar con el rol de Community Manager que promueva la prueba y feedback del servicio.

- Por su parte Instagram alcanza a un público más moderno de madres y padres así como de jóvenes alfa y centenials por lo que otorgará modernidad a la marca. Se utilizará desde el pre lanzamiento. Este medio genera engagement con el target.

En las etapas de lanzamiento, y mantenimiento, los contratos con Facebook e Instagram son dirigidos al target de hombre y mujeres 33 a 55 años, Lima, distritos $\mathrm{AB}$. El número de apariciones se hará con una frecuencia semanal de 3 a más veces y un alcance no menor al $60 \%$ para generar recordación.

- Se recomienda el uso de Youtube puesto que este medio es el segundo en participación y se usará para llegar en mayor medida a niños y jóvenes, los cuales entran a esta plataforma con frecuencia a ver videos. Se utilizarán videos cortos con mensajes impactantes y ágiles para poder viralizar el servicio. De igual manera se buscarán youtubers influencers para hacer conocido el servicio. 
Los objetivos de las redes sociales se dividen de la siguiente manera:

- Etapa de pre-lanzamiento: adquirir seguidores y rápidamente retener mediante comentarios, shares.

- Etapas de lanzamiento y mantenimiento: retener con interacciones (shares, comentarios, visualizaciones).

Además de las redes sociales, se plantean utilizar otras tácticas digitales a través de la página web, búsquedas SEO-SEM y banners.

- El plan integrado de medios incluye el uso de la Página Web de Klaz, con un diseño atractivo, con colores vivos, y con un desarrollo que aplica User Experience (UX) para facilitar el viaje del potencial y actual cliente en la búsqueda de información como es: perfil de profesores y entendimiento del proceso de adquisición y uso del servicio. El objetivo de la página web es producir a través de la información y conversión, es decir, compra del servicio.

La página Web estará activa desde el pre-lanzamiento y será actualizada de manera permanente. El "qué decir" del mensaje es: KlaZ, nuevo servicio escolar tutorial online en tiempo real, en cualquier momento y lugar. Este mensaje se enfoca en la ventaja diferencial versus profesor a domicilio.

Una vez lograda la atracción hacia el mensaje, el interesado busca información donde encontrará:

- Quiénes somos: información de la empresa.

- Perfil de los profesores: foto, experiencia, conocimiento de metodologías de colegio, idiomas, cursos, precios por hora. Los filtros pueden darse por niveles de precio, perfil de profesor, o por curso.

- Demo corto del servicio. 
- Cómo se usa el servicio: sólo necesitas una laptop, tablet, celular y señal internet. Incluye tecnologías usadas en Klaz para interacción profesor alumno.

- Método exclusivo "xxx", para enseñanza online.

- Proceso y pago online.

- Contáctanos.

- Preguntas frecuentes (con sus respuestas)

- Se trabajarán estrategias SEO y SEM Google. En primer lugar es importante contar con una estrategia fuerte SEO friendly para estar en los primeros resultados de búsqueda y captar los prospectos a través de palabras claves y meta descripciones. Se aplicará SEM en la etapa de mantenimiento. Para esto, se utilizan palabras clave en los contenidos de la web y se compra posición en Google.

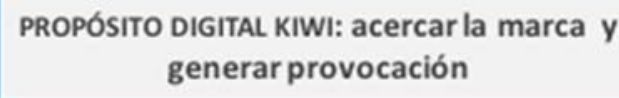

OBJETIVO: 1. Retener y 2 Producir

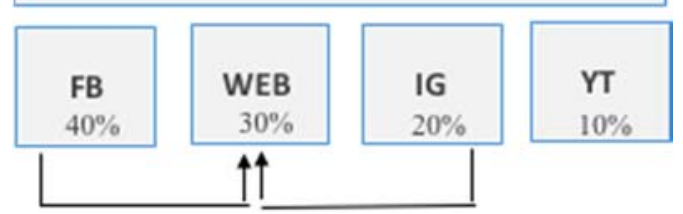

Figura 6. Ecosistema digital

Fuente: Elaboración propia

\section{- Banners y avisos en páginas e emails.}

Se utilizarán en la etapa de mantenimiento como refuerzo.

\section{- Paneles OOH}

En el segundo año para complementar el alcance de los medios digitales, se ubicarán paneles publicitarios en muros cercanos a colegios del target en Lima y provincias. 


\subsubsection{Estrategia de relaciones públicas}

El rol de las relaciones públicas es vincular comunicacionalmente a Klaz con sus públicos internos y externos, es decir, con sus Stakeholders. Se debe adecuar un solo mensaje para cada uno de ellos y lograr una retroalimentación positiva de su parte.

Se trabajarán los ejes estratégicos Business y Marketing Support orientados hacia el target y público en general a través de entrevistas en medios tradicionales y online $\mathrm{y}$, auspicios de eventos como foros educativos, congresos, kermesses, y ferias escolares.

Se propone desarrollar un open day online a manera de webinar para presentar al staff de profesores, metodología, responder preguntas, absolver dudas y hacer una pequeña demo del servicio. De igual manera se contactará con líderes de opinión e influencers relevantes para el negocio.

\subsection{Estrategia de procesos}

Integrada por los elementos utilizados en la prestación del servicio y que afectan a la calidad percibida del mismo.

En este caso, se realizará a través de un sitio web. Nuestra aplicación será amigable y práctica, aplicando User Experience (UX), de esta manera nuestros clientes y usuarios se sentirán cómodos usando Klaz para inscribirse, solicitar clases y tener record del avance del estudiante. 


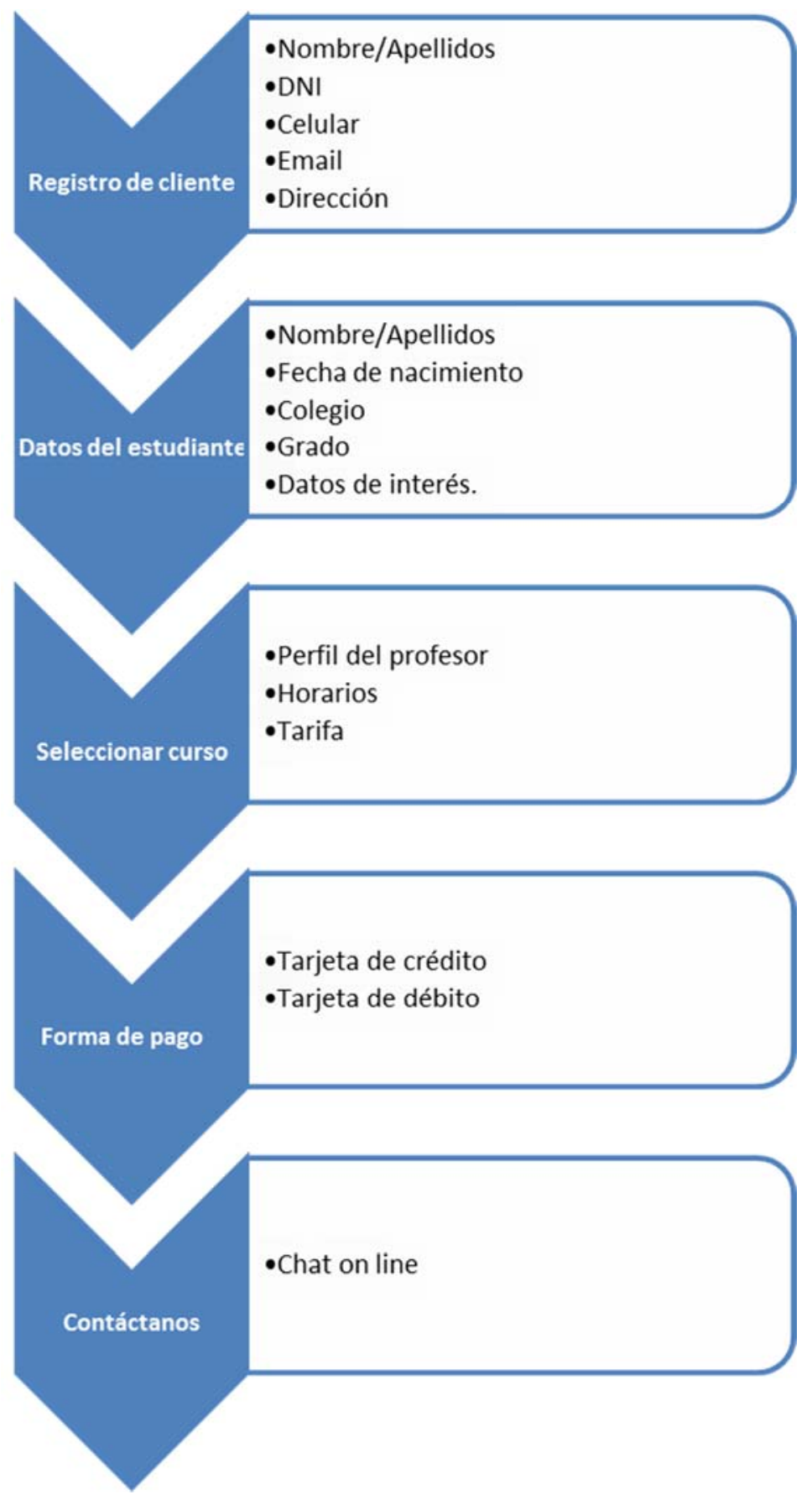

Figura 7. Pasos para solicitar servicio

Fuente: Elaboración propia. 


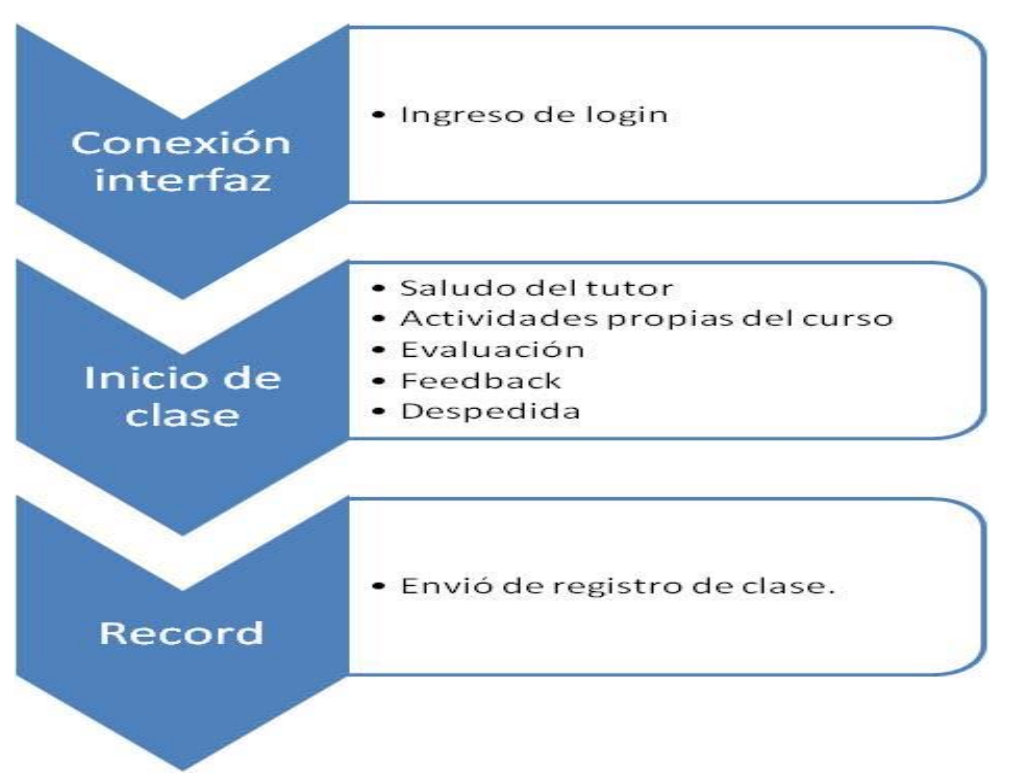

Figura 8. Pasos para tomar servicio de tutoría.

Fuente: Elaboración propia.

\subsection{Estrategia de prueba (evidencia física)}

Esta $\mathrm{P}$ viene del inglés Presence o evidencia física, y se aplica en el caso de servicios a las estructuras arquitectónicas y espaciales de las marcas que buscan por ejemplo transmitir solidez o, la personalidad de la marca. En el caso de servicios digitales, no vemos una construcción como evidencia física por lo que la página web y/o aplicación es la principal evidencia o prueba de existencia del servicio y, los testimonios y comentarios en redes sociales y página web son el respaldo por la experiencia de uso. Los testimonios de los padres y alumnos serán las pruebas para los nuevos clientes. De otro lado, las evaluaciones de los profesores son prueba de que los servicios fueron otorgados.

\subsection{Estrategia de personas}

El equipo de trabajo en Klaz estará conformado por las 3 socias con responsabilidades asignadas a cada una, los profesores, y otros servicios tercerizados como son: diseño, tecnología, contabilidad, finanzas, legal, RRHH y publicidad digital que incluye al community manager.

Por lo antes expuesto, las acciones de endomarketing se enfocarán hacia los profesores a través de: 
- Notificaciones digitales al dispositivo registrado: informando de una manera amigable sobre novedades, cambios, bienvenidas, logros, cumpleaños, capacitaciones y eventos corporativos.

- Premiaciones por alcance de metas de los estudiantes, referidos, cumplimiento de actividades y KPI's (ejemplo cumplimiento horarios, envió de reportes a tiempo).

\subsection{Estrategia de ventas}

Dado que el poder de decisión lo tienen los padres de familia, nuestra estrategia de ventas se enfocará en brindarles la información necesaria sobre el servicio, forma de pago e informe sobre avance de la tutoría.

La fuerza de ventas es interna. Desde la etapa de pre lanzamiento, se contará con una persona capacitada para atender las consultas vía chat o en los formatos de consultas de nuestra página web.

La estrategia de ventas apunta a lograr la proyección de ventas, la cual se ha basado en evaluación del mercado, considerando trabajar con alumnos de colegios NSE AB, estimando que serían en una primera etapa 60 colegios. De acuerdo con las entrevistas sostenidas con los directores de los colegios, el promedio de alumnos (as) que reciben tutorías después del horario escolar asciende al 30\% del total de los alumnos de cada colegio. De acuerdo al estudio cuantitativo se llegó al promedio de 1.5 horas por sesión de clase, 2 veces por semana. 
Tabla 5

Proyección de ventas Klaz

LIMA Met AB

\begin{tabular}{|l|c|c|c|c|c|}
\hline Ventas & er año & 2do año & 3er año & 4to año & 5to año \\
\hline Universo & 13,320 & 13,320 & 13,320 & 13,320 & 13,320 \\
\hline Y anual potencial & $60,281,418$ & $65,304,870$ & $65,304,870$ & $65,304,870$ & $65,304,870$ \\
\hline$\%$ captación & 5 & 10 & 15 & 20 & 25 \\
\hline Y anual & $3,014,071$ & $6,530,487$ & $9,795,730$ & $13,060,974$ & $16,326,217$ \\
\hline Variación & & $117 \%$ & $50 \%$ & $33 \%$ & $25 \%$ \\
\hline
\end{tabular}

Provincias

\begin{tabular}{|l|c|c|c|c|c|}
\hline Ventas & 1er año & 2do año & 3er año & 4to año & 5to año \\
\hline Universo & & 14,030 & 14,030 & 14,030 & 14,030 \\
\hline Y anual potencial & & $35,457,627$ & $35,457,627$ & $35,457,627$ & $35,457,627$ \\
\hline \% captación & & 5 & 10 & 15 & 20 \\
\hline Y anual & & $1,772,881$ & $3,545,763$ & $5,318,644$ & $7,091,525$ \\
\hline Variación & & & $100 \%$ & $50 \%$ & $33 \%$ \\
\hline
\end{tabular}

Total PERÚ

\begin{tabular}{|l|c|c|c|c|c|}
\hline Ventas & 1er año & 2do año & 3er año & 4to año & 5to año \\
\hline Universo & 13,320 & 27,350 & 27,350 & 27,350 & 27,350 \\
\hline Y anual potencial & $60,281,418$ & $100,762,497$ & $100,762,497$ & $100,762,497$ & $100,762,497$ \\
\hline$\%$ captación & 5 & 10 & 15 & 20 & 30 \\
\hline Y anual & $3,014,071$ & $10,076,250$ & $15,114,374$ & $20,152,499$ & $30,228,749$ \\
\hline Variación & & $234 \%$ & $50 \%$ & $33 \%$ & $50 \%$ \\
\hline
\end{tabular}

Fuente: Elaboración propia.

En cuanto al servicio al cliente la estrategia se centra en generar una excelente atención para que la experiencia sea positiva y se construya lealtad.

- Se capacitará a todos los profesores, para que brinden un servicio de calidad

- Mantener una constante comunicación con los clientes para poder actualizar el servicio de acuerdo a sus necesidades. Usaremos encuestas de satisfacción digitales (Questionpro).

- Contratar a profesores que entiendan las necesidades de nuestro target y sepan tratarlos bien, y que sean empáticos.

- Recompensar y reconocer por el buen trato a nuestros clientes. 
De otro lado, el servicio post venta es parte del Customer Journey y también genera lealtad. En este sentido, la estrategia es la siguiente:

- Terminada la clase tutorial, se solicita una calificación, y al no obtener el puntaje máximo se le hará algunas preguntas al usuario para conocer las oportunidades de mejora.

- Cualquier consulta, reclamo o sugerencia se podrá canalizar a través del chat on line, Whatsapp o formatos digitales incluidos en la web en la sección de "contáctanos".

El proceso de venta del servicio tutorial Klaz es así:

La transacción se realiza cuando el padre de familia, ingresa a nuestra web para registrar a su hijo (a), selecciona el curso, el tutor que desee brinde la clase, y finalmente realiza el pago por las clases elegidas. El servicio se entrega en el día y hora señalada en la inscripción. 


\section{PLAN DE OPERACIONES}

\subsection{Estrategia de operaciones}

La estrategia de operaciones debe estar alineada con la estrategia genérica de la empresa, que en este caso hemos optado por la de diferenciación como se mencionó anteriormente.

El objetivo de la estrategia de operaciones es el de encontrar una ventaja competitiva sostenible para la empresa.

Hemos optado priorizar las estrategias de calidad y de servicio. Con respecto a la estrategia de calidad, esta es indispensable para poder lograr la satisfacción de nuestros estudiantes y profesores. Para ello todo el proceso productivo está diseñado de tal manera que responda a las necesidades académicas del alumno y a la disponibilidad horaria de los profesores, rigiéndose por normas, estándares y metodología pedagógica que enmarquen todo el proceso.

Por el lado de la estrategia de servicio, se incluyen dentro del diseño de la plataforma diversos aspectos que generarán una experiencia de usuario de avanzada de tal forma que en cada uno de los momentos de la verdad tanto el estudiante como el profesor se sientan satisfechos con el journey.

Para garantizar esta estrategia, se contará con una evaluación periódica con respecto a la satisfacción de la plataforma; asimismo se contará con un chat online, chatbots y formatos de consultas para poder absolver dudas, problemas e inquietudes, manteniendo en todo momento un contacto con el cliente. La plataforma además contará con un socio estratégico digital que asegurará el mantenimiento constante a nivel de la interfaz, capacidad de servidores, arquitectura de la información, diseño visual y todo aquel aspecto que haga que la experiencia digital sea placentera para clientes, consumidores y profesores.

\subsection{Gestión de operaciones}

\subsubsection{Diseño de servicio}

Nuestra plataforma, contará con funciones generales para que cualquier persona, ya sea un visitante esporádico, un usuario registrado, o un administrador de contenidos pueda obtener la información de manera fácil y amigable sólo navegando por nuestra web. 
Nuestra portada, será atractiva y amigable para que en 15 segundos vean la información relevante del servicio y, contará con un deslizador para que puedan ver un demo (video) de cómo se brindan las clases online. Nuestra portada se adaptará y podrá ser visto en varios dispositivos como tablets, celulares, laptops y PC's.

Los menús, serán claros, vistosos y mostrarán las secciones del sitio web. El encabezado contendrá el menú principal, nuestro logotipo y nombre de la empresa. El tamaño será de pantalla completa.

Dentro del contenido de la página web se comunicarán los beneficios de nuestros tutores como son:

- Los tutores conocen las metodologías de variedad de colegios y apoyan con cursos desde 2 do grado de primaria hasta 11vo de secundaria.

- Contamos con tutores que son estudiantes universitarios, docentes escolares y docentes de programas IB, y bilingües.

- Los tutores han pasado por filtros de verificación de identidad, académica, laboral y de antecedentes penales, policiales y judiciales.

- Los tutores han sido evaluados sicológicamente para prevenir riesgos de seguridad con los estudiantes.

Los tutores han sido seleccionados pasando evaluaciones de competencias.

Otro contenido de la página web será el relacionado con las características tecnológicas del servicio y las ventajas frente a profesores a domicilio como son:

- Las clases pueden ser tomadas desde cualquier lugar y en el horario que más se acomode al estudiante, así, podrá mantener sin problema otras actividades de su agrado.

- Las clases pueden ser tomadas desde cualquier dispositivo móvil o PC, es decir, celular, laptop, Tablet o PC. Es necesario contar con una cámara web y se recomienda contar con un mínimo de velocidad de internet. 
- La plataforma permite tener la clase en tiempo real, con uso de tecnologías que permiten compartir pantalla, archivos, pizarra interactiva.

- Klaz cuenta con un método exclusivo de enseñanza-aprendizaje online que hará que la clase sea más efectiva.

- Las clases pueden ser monitoreadas por los padres en tiempo real desde otro dispositivo o, las pueden ver en otro momento pues quedarán grabadas hasta por un mes después de concluida la sesión de clase.

- Los profesores enviarán un reporte de la clase a los padres al finalizar la sesión.

- El pago es online.

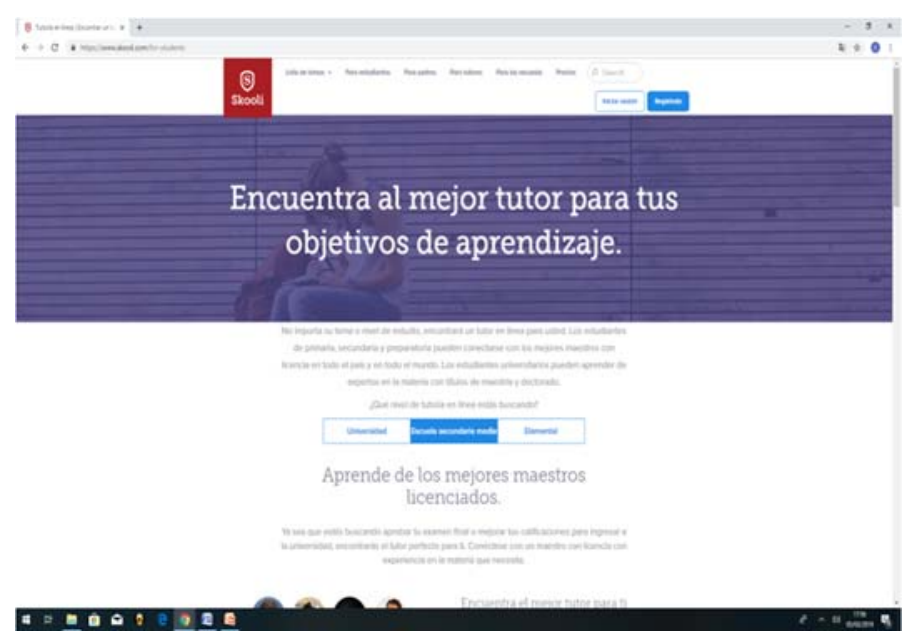

Figura 9. Ejemplo de pantalla de servicio

Fuente: https://www.skooli.com/

El pie de página, mostrará los enlaces a las redes sociales de nuestra empresa, el acceso a contacto vía chat, y enlaces obligatorios por ley, como la política de privacidad, cookies y condiciones de uso. 
Nuestra portada se organizará en secciones bien tituladas (etiquetas HTML, para mejorar resultados SEO), accesibles desde los menús. Los contenidos serán claros y precisos. Se mostrarán fotos e imágenes de las clases online.

Con el fin de conocer siempre la opinión de nuestros usuarios, proporcionaremos un mecanismo para que conecten con nosotros, esta sección es la de "contacto" donde podrán enviarnos preguntas y sugerencias, mediante el chat o whatsapp.

El diseño de esta plataforma estará a cargo de una empresa digital experta en User Experience $(U X)$ de tal manera que sea amigable y práctica.

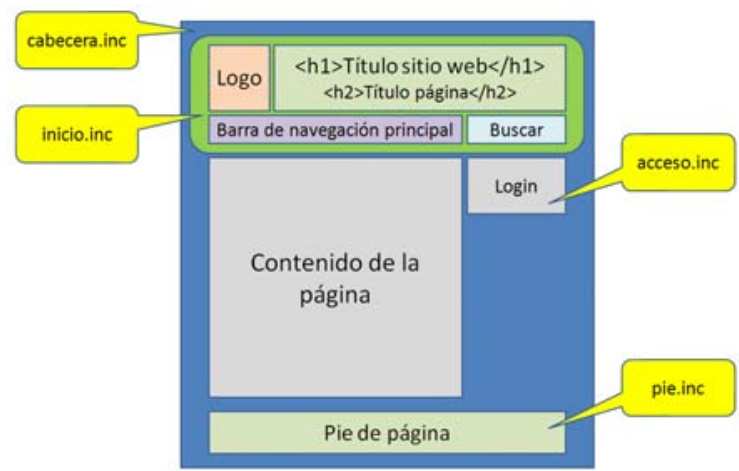

Figura 10. Ejemplo de diseño de portada

Fuente: http://desarrolloweb.dlsi.ua.es/desarrollo-aplicaciones-web-18-19/practicas/06/

\subsubsection{Proceso de adquisición de servicio}

La plataforma contará en la parte superior con botones para seleccionar de acuerdo al perfil del usuario: padre, estudiante o profesor.

Al ser los padres de familia, los decisores de la compra, al ingresar al botón "padres", encontrarán una pantalla amigable, que les describirá los principales atributos que hacen de Klaz la mejor opción tutorial.

De igual manera, al ser un canal nuevo de enseñanza-aprendizaje, se incluirá un video demo que mostrará cómo se brindarán las clases contando con las herramientas como video 
conferencia, chat on line, compartiendo pantalla, interactive whiteboard o pizarra interactiva y google drive, simulando así la tutoría personalizada cara a cara.

Asimismo, el video indicará que terminada la clase, el sistema les enviará un estatus de la clase recibida a la dirección email o al número whatsapp registrado.

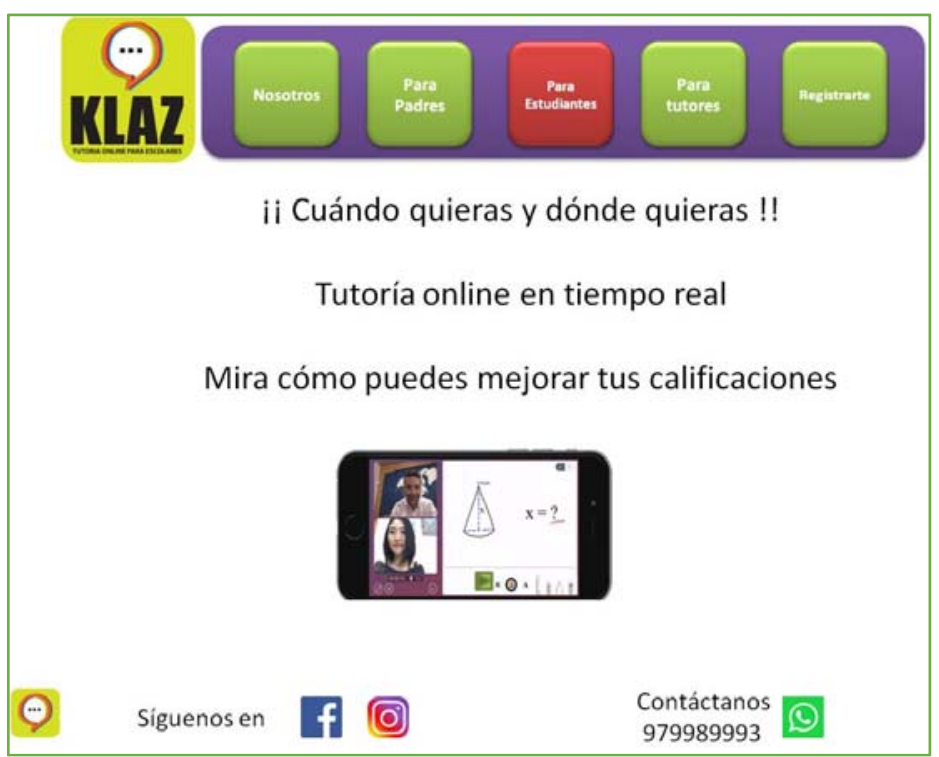

Figura 11. Ejemplo pantallazo de video demo Klaz

Fuente: Elaboración propia.

Seguidamente, se les invitará a registrarse, para que puedan acceder al servicio, y es en este momento donde se inicia el proceso de adquisición del servicio. A continuación pasamos a detallar los pasos para el registro de los usuarios.

Paso 1: El padre o madre ingresa su nombre y apellidos, DNI, celular, email, dirección de domicilio. El sistema les brindará un login, con el cual pueden matricular a sus hijos en el curso que necesitan.

Paso 2: El padre de familia, al ingresar con el login brindado, verá un menú donde le indica "registrar estudiante", es así que el sistema le solicitará datos del alumno (a), por lo que debe ingresar la siguiente información de su hija (o): nombre /apellidos, fecha de nacimiento, colegio, grado que cursa y, para contar con mayor información del perfil del alumno deben 
llenar un cuestionario pedagógico para que el tutor tenga más información de cómo debe apoyar. Luego que llena esa información, podrá seleccionar curso y tutor.

Paso 3: Se selecciona el curso de interés.

Paso 4: Aparecerá el menú con el perfil de profesores, donde encontrará información relevante de su trayectoria, metodología, fotografía.

Paso 5: Se seleccionar profesor/a.

Paso 6: Con el profesor seleccionado, aparecerán sus horarios disponibles, la tarifa para el tutor, asimismo podrá fijar un plan de estudio (semanal, mensual, anual). Se podrán seleccionar turnos de 1 hora, 1.5 horas y hasta 2 horas por día.

Paso 7: Podrá seleccionar y procesar su opción de pago con tarjeta de crédito o débito.

Paso 8: El sistema confirma pago e inscripción.

Paso 9: El sistema envía un mail de confirmación. 
Tabla 6

Proceso de adquisición del servicio

\section{Padre Familia}

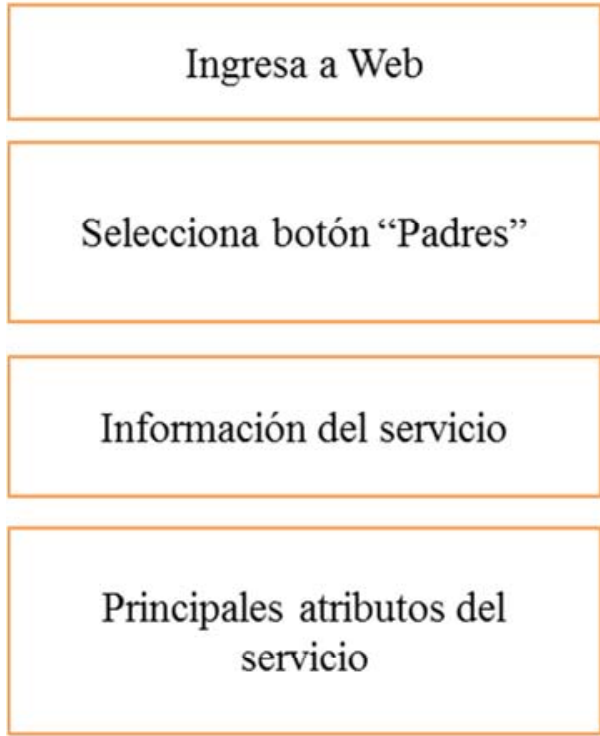

Video demo clase on line

Invitación a registrarse cuenta de padre (ingreso de datos personales)
Sistema brinda login a padre de familia.

Ingresa datos del estudiante

Selecciona curso

Vista de perfil de profesores

Selecciona al profesor

Vista horarios y tarifa del profesor

Selecciona

profesor/horario/tarifa/plan de servicio.

Selecciona forma de pago y paga servicio TC o TD

Sistema confirma pago e inscripción

Log off

Fuente: Elaboración propia. 


\subsubsection{Proceso de uso del servicio}

El uso del servicio consiste en el espacio virtual en el que el estudiante toma la clase particular de acuerdo al horario pactado y profesor seleccionado previamente. El estudiante y el profesor estarán situados físicamente en un lugar conveniente. El estudiante puede estar cómodamente vestido y conectarse desde cualquier lugar de su casa, ya sea en el comedor, family room, su dormitorio o en otro lugar.

A continuación se detallan las actividades para utilizar el servicio desde los puntos de vista del profesor y alumno/a:

- El profesor realizará las siguientes actividades:

Paso 1: Ingresa a la página Web de Klaz y en el recuadro de "Estudiante", "Profesor", Padre/madre", hace click en "Profesor".

Paso 2: el profesor coloca su usuario y contraseña.

Paso 3: se abre conexión con alumno donde ambos se pueden ver y escuchar. El profesor saluda con energía al estudiante, se inicia corta conversación.

Paso 4: el profesor plantea los temas a revisar en clase según lo conversado minutos antes o en sesión anterior.

Paso 5: se desarrolla la clase utilizando las herramientas digitales como pizarra interactiva o interactive whiteboard, compartir pantalla para revisar ejercicios, tareas o envío de archivos, ingreso a links, entre otros.

Paso 6: el profesor comprueba que el estudiante ha adquirido las estrategias o conocimientos planteados.

Paso 7: el profesor prepara un corto informe de lo visto en clase que incluye opinión del avance y recomendación a los padres si es necesario. También puede incluir algún comentario confidencial y lo envía a padres.

Paso 8. el profesor se despide del estudiante y lo motiva a seguir practicando, o le da seguridad para siguiente prueba.

Paso 9: el profesor entra a sección Log off y sale de la sesión. 
- Por su parte, en paralelo, el estudiante realizará las siguientes actividades:

Paso 1: ingresa a la página Web de Klaz y en el recuadro de "Estudiante", "Profesor", Padre/madre", hace click en "Estudiante".

Paso 2: el estudiante coloca su usuario y contraseña.

Paso 3: se abre conexión con profesor donde ambos se pueden ver y escuchar. Conversan y el alumno comparte sus necesidades escolares con el/la profesor.

Paso 4: el estudiante entiende y está de acuerdo con los temas a revisar en clase según lo conversado minutos antes o en sesión anterior.

Paso 5: el estudiante participa en la clase utilizando las herramientas digitales para revisar ejercicios o tareas como: compartir pantalla, pizarra interactiva, envío de archivos, ingreso a links, entre otros.

Paso 6: el estudiante demuestra que ha adquirido las estrategias o conocimientos planteados de acuerdo a lo evaluado por el/la tutor/a.

Paso 7: el estudiante participa con comentarios en el informe del profesor de lo visto en clase, opinión del avance, recomendación a los padres. No ve necesariamente todo lo escrito por el profesor.

Paso 8: una vez que el profesor se despidió, ingresa a ventana de "califica la clase". Puede marcar de 1 a 5 estrellas y escribir comentarios.

Paso 9: el estudiante entra a sección Log off y sale de la sesión. 
Tabla 7

Proceso de uso del servicio
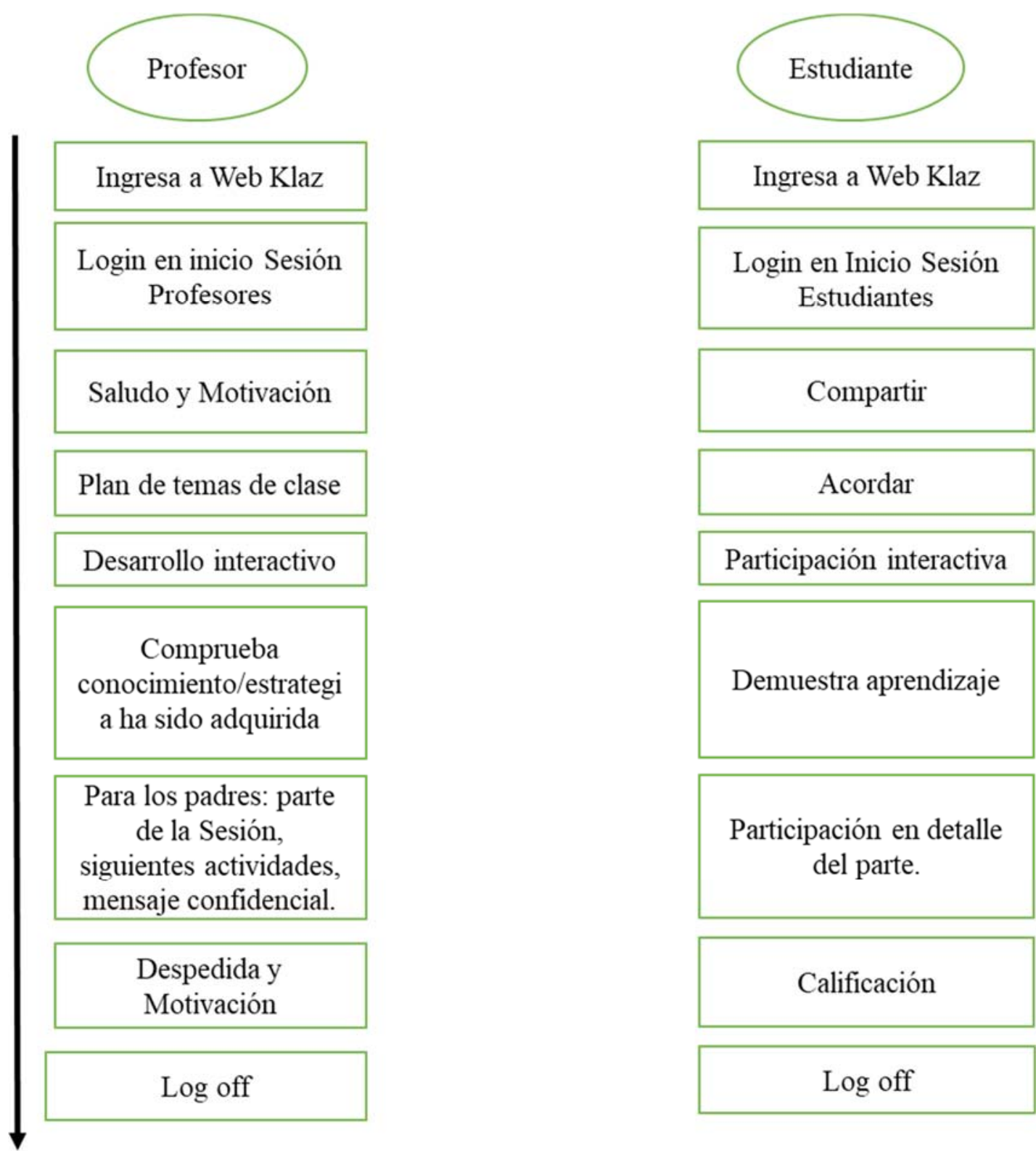

Fuente: Elaboración propia. 
5.3 Cadena de Valor

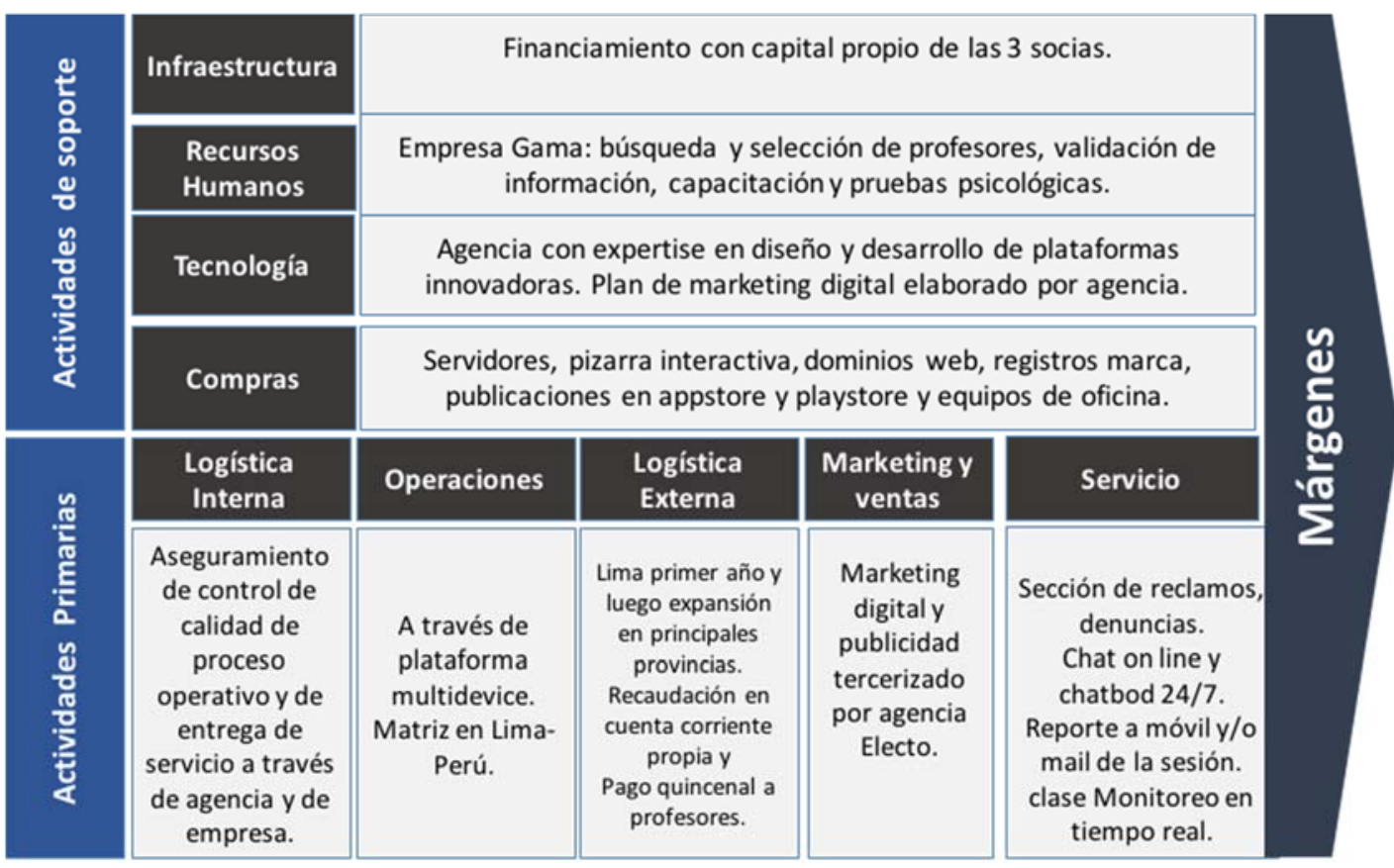

Figura 12. Cadena de Valor

Fuente: Elaboración propia

\subsection{Plan de Implementación}

De acuerdo al cronograma de actividades, se proyecta que la implementación del servicio tome un tiempo de 215 días teniendo como fecha proyectada para el lanzamiento el 1ro de marzo del 2020. El plan de implementación del servicio Klaz contempla diversas actividades pre-operativas como son:

- El desarrollo e implementación de la plataforma digital del servicio incluyendo pruebas beta, página web y fan page, la cual estará a cargo de una empresa especializada y experimentada en diseños y desarrollos similares. La empresa Electo nos acompañará desde el planteamiento del pedido hasta el lanzamiento y luego dará el servicio de mantenimiento de la plataforma para garantizar el correcto funcionamiento y proveerá además de las actualizaciones pertinentes para modernizar la experiencia según tendencias y solicitudes de los usuarios. Ver tabla 8.

- La atracción, evaluación, selección e inducción de los profesores, la cual se llevará a cabo con apoyo de una empresa consultora de Gestión Humana. Luego de la convocatoria, los candidatos firmarán un acuerdo de permiso de validación de su 
información para poder verificar sus datos, información académica, laboral, así como también sus antecedentes policiales, judiciales y penales. También se realizará un rastreo de motores de búsqueda de internet. Esta consultoría estará a cargo de las empresas Gama Consulting y Targo. Ver tabla 9.

- La contratación y entrenamiento del coordinador administrativo estará a cargo de Gama Consulting. Sus funciones están detalladas en el capítulo 6. Ver tabla 9

- Registro de marca, logotipo, constitución de la empresa. El trámite de registro marcario ya cuenta con la búsqueda de viabilidad preliminar en clase 41 de Indecopi, donde se ha encontrado que el riesgo de rechazo es bajo para la solicitud de registro. En cuanto al logotipo, este ya ha sido aprobado por las socias. Finalmente, la constitución de empresa se llevará a cabo con la asesoría de la Notaría Bartra. Ver tabla 9.

- Las asesorías legales, contables y de gestión humana son necesarias para dar seguridad a que las actividades cumplen no solo con los requisitos de ley sino que además se dan de la manera más eficiente posible buscando ahorro de costos sin perjudicar la calidad de la entrega del servicio. En el caso de legal, la asesoría laboral-tributaria incluye la redacción del contrato de locación de servicios a ser firmado por los docentes así como también recomendaciones del orden tributario. La asesoría legal estará a cargo del estudio Elías Medrano. Ver tabla 9.

- El desarrollo de contenidos publicitarios que se comunicarán desde el lanzamiento de Klaz quedan a cargo de Electo. El diseño de paneles se hará con creativos free lance y la negociación de tarifas y colocación de avisos vía Central Media. Ver tabla 9.

- La contratación y adecuación de la oficina contempla una ubicación Co-working en Chacarilla con la empresa Zona de Mejora. Se trata de un espacio para 3 personas que puede crecer hasta albergar 6 personas. Cuenta con áreas comunes para capacitaciones y conferencias equipadas para videoconferencias, kitchenette, servicios higiénicos. Además brinda apoyo secretarial y servicios de luz, internet, agua dentro del contrato. Ver tabla 9.

A continuación detallamos los cronogramas digital y operativo con sus actividades y subactividades. 
Tabla 8

Cronograma de implementación de plataforma digital

\begin{tabular}{|c|c|c|c|c|c|c|c|c|c|}
\hline Desarrollo e Implementación plataforma Klaz & Dias & Mes 1 & Mes 2 & Mes 3 & Mes 4 & Mes 5 & Mes 6 & Mes 7 & Mes 8 \\
\hline Etapa de planificación y diseño & 30 & & & & & & & & \\
\hline \multicolumn{10}{|l|}{ Coordinación de proyecto } \\
\hline \multicolumn{10}{|l|}{ Diseño de Wireframes UX } \\
\hline \multicolumn{10}{|l|}{ Propuesta de diseño de interfaces } \\
\hline \multicolumn{10}{|l|}{ Diagrama de base de datos } \\
\hline \multicolumn{10}{|l|}{ Análisis de dependencias } \\
\hline \multicolumn{10}{|l|}{ Configuración de servidores AWS } \\
\hline Etapa de desarrollo e integración web & 80 & & & & & & & & \\
\hline \multicolumn{10}{|l|}{ Desarrollo front-end de aplicación web } \\
\hline \multicolumn{10}{|l|}{ Integración con firebase } \\
\hline \multicolumn{10}{|l|}{ Creación de tablas de base de datos } \\
\hline \multicolumn{10}{|l|}{ Registro de usuarios e inicio de sesión } \\
\hline \multicolumn{10}{|l|}{ Páginas informativas } \\
\hline \multicolumn{10}{|l|}{ Notificaciones } \\
\hline \multicolumn{10}{|l|}{ Paneles de administración y de usuarios } \\
\hline \multicolumn{10}{|l|}{ Chat y mensajería instantánea } \\
\hline \multicolumn{10}{|l|}{ Bandeja de entrada } \\
\hline \multicolumn{10}{|l|}{ Pizarra interactiva } \\
\hline \multicolumn{10}{|l|}{ Videollamadas o sala reuniones online } \\
\hline \multicolumn{10}{|l|}{ Caja comentarios/valoraciones } \\
\hline \multicolumn{10}{|l|}{ Backups de videollamadas } \\
\hline \multicolumn{10}{|l|}{ Reserva de tutorías } \\
\hline Grid de tutores & & & & & & & & & \\
\hline Pasarela de pagos & & & & & & & & & \\
\hline Integración con servicios de Amazon & & & & & & & & & \\
\hline Etapa de desarrollo e integración móvil & 45 & & & & & & & & \\
\hline Instalación y uso del framework react native & & & & & & & & & \\
\hline Desarrollo de interfaz & & & & & & & & & \\
\hline Integración con la aplicación web desarrollada & & & & & & & & & \\
\hline Integración con base de datos & & & & & & & & & \\
\hline Integración con herramientas de análisis & & & & & & & & & \\
\hline Pruebas & & & & & & & & & \\
\hline Etapa aprobación y de publicación & 25 & & & & & & & & \\
\hline Integración de herramientas de marketing digital: & & & & & & & & & \\
\hline Google Analytics & & & & & & & & & \\
\hline Google tag manager & & & & & & & & & \\
\hline Facebook pixel & & & & & & & & & \\
\hline Google Adwords remarketing & & & & & & & & & \\
\hline Aprobación y publicación de aplicación móvil en: & & & & & & & & & \\
\hline Appstore (iOS) & & & & & & & & & \\
\hline Playstore (Android) & & & & & & & & & \\
\hline Monitoreo y correcciones en línea & 35 & & & & & & & & \\
\hline Beta 1 (friends \& family) & & & & & & & & & \\
\hline Ajustes Beta 1 & & & & & & & & & \\
\hline Beta 2 (entorno controlado) & & & & & & & & & \\
\hline Ajustes Beta 2 & & & & & & & & & \\
\hline Total dias & 215 & & & & & & & & \\
\hline Lanzamiento & & & & & & & & & \\
\hline
\end{tabular}

Fuente: Elaboración propia. 
Tabla 9

Cronograma de implementación de operaciones

\begin{tabular}{|c|c|c|c|c|c|c|c|c|c|}
\hline Implementación de operaciones & Dias & Mes 1 & Mes 2 & Mes 3 & Mes 4 & Mes 5 & Mes 6 & Mes 7 & Mes 8 \\
\hline Asesorias legales, contables, de gestión humana & 15 & & & & & & & & \\
\hline Registro de marca, logotipo, constitución de la empresa. & 30 & & & & & & & & \\
\hline Validación de mercado y desarrollo metodología & 75 & & & & & & & & \\
\hline Contratación y adecuación de oficina & 45 & & & & & & & & \\
\hline $\begin{array}{l}\text { Contratación y entrenamiento del coordinador } \\
\text { administrativo }\end{array}$ & 25 & & & & & & & & \\
\hline $\begin{array}{l}\text { Atracción, evaluación, selección e inducción de } \\
\text { primeros profesores. }\end{array}$ & 60 & & & & & & & & \\
\hline Pruebas Pilotos Beta & 30 & & & & & & & & \\
\hline Desarrollo de contenidos publicitarios & 30 & & & & & & & & \\
\hline Lanzamiento & & & & & & & & & \\
\hline
\end{tabular}

Fuente: Elaboración propia. 


\section{ORGANIZACIÓN Y PLAN DE RECURSOS HUMANOS}

\subsection{Diseño organizacional}

\subsubsection{Elementos y parámetros del diseño}

La empresa JER SAC representa las siglas de las iniciales de los nombres de las 3 socias y nace con Klaz como primer proyecto. Sin embargo, se espera desarrollar otros negocios que hagan sinergia con Klaz en el futuro.

El directorio por lo tanto, está conformado por las 3 socias con los siguientes roles y funciones:

La gerencia general liderará la organización haciéndose cargo de manera particular de las áreas contables, finanzas y legal, así como también la supervisión de los pagos a proveedores, profesores y otros colaboradores.

La gerencia comercial tendrá a su cargo las funciones relacionadas al marketing, agencia digital y relaciones públicas. Además de las acciones de comunicación se encargará de la relación con la empresa digital tanto a nivel de publicidad, como de los procesos de cara a los padres, alumnos y profesores.

La gerencia de operaciones lidera la gestión de operaciones y recursos humanos. Dentro de sus funciones estará el reclutamiento, inducciones, control de calidad así como el proceso de ventas y las necesidades digitales en relación a los procesos de cara a los profesores.

Los salarios para estas 3 gerencias serán determinados a partir del segundo año de funcionamiento del negocio, de acuerdo a las necesidades del negocio.

Se contará desde el inicio de las operaciones de la empresa con un coordinador administrativo que organizará la ejecución de firma de contratos, administración de pagos a proveedores, profesores y servicios. Apoyará también labor de ventas. El salario de esta persona será inicialmente de $\mathrm{S} / 2,500$. Se buscará un bachiller en administración con mínimo un año de experiencia. Se observará la productividad del colaborador a fin de detectar con tiempo la necesidad de incrementar el staff de apoyo. . 
De acuerdo a lo antes expuesto, la empresa inicia su etapa pre-operativa con 4 personas: las 3 gerencias y la coordinadora administrativa quien estará en planilla. De otro lado, los tutores contratados, estarán laborando bajo el régimen de locación de servicios con pagos por hora dictada con recibos por honorarios profesionales. Las retenciones de ley se harán según notificación de los tutores cuando ellos alcancen el ingreso anual sujeto a tributación.

La empresa iniciará sus servicios en Lima con una base de 60 profesores, debiendo contar con 140 tutores disponibles a los 6 meses de operaciones. Este número de profesores permitirá cubrir la demanda sin contratiempos considerándose una rotación del 30\%. Ver anexo 7: estimado cálculo de profesores

Hemos considerado que los salarios se deben de dar de acuerdo a tres niveles, privilegiando la función docente y el valor agregado que puedan dar en función de algún conocimiento complementario. Basados en estas premisas, dividiremos a los profesores en estudiantes universitarios, docentes de colegios particulares y nacionales, y docentes de colegios que puedan asumir otro idioma en el dictado. Rn función de ellos tenemos los siguientes niveles de salarios:

- Los alumnos universitarios dedicados a la tutoría recibirán un salario de S/ 25.00 la hora.

- Los docentes de colegios tendrán un salario de S/ 45.00 la hora.

- Un nivel Premium de profesores que dicta cursos en otro idioma y para Bachillerato Internacional (IB) con un salario de S/ 60.00 la hora

Cada 15 días se abonará a la cuenta de los tutores el monto correspondiente a sus horas trabajadas en función a su tarifa.

Para poder implementar el negocio, hemos visto necesario contratar los servicios de una empresa de servicios digitales que genere y desarrolle la aplicación web y móvil para la plataforma, así como también los contenidos y pauta digital publicitaria. Además asesore a JER en las inversiones que se debe realizar a nivel de tecnología. Por esta razón, la empresa Electo nos acompañará desde el planteamiento del pedido hasta el lanzamiento y luego dará el servicio de mantenimiento de la plataforma para garantizar el correcto funcionamiento y proveerá además de las actualizaciones pertinentes para modernizar la experiencia según tendencias y solicitudes de los usuarios. 
Por otro lado, el tema de contar con tutores y personal administrativo idóneos en el aspecto personal y profesional, será garantizado por una consultora de gestión humana, quien se encargará de la convocatoria, evaluación, selección e inducción, además de la verificación de antecedentes policiales, judiciales y penales. Para este trabajo contrataremos a las consultoras Gama Consulting y Targo.

Asimismo, para una correcta aplicación del derecho laboral, contaremos con la asesoría del estudio de abogados Elías \& Medrano, quienes desarrollarán inicialmente el contrato de locación de servicios para los tutores y brindarán asesoría en reducción de costos laborales, así como de fiscalizaciones en materia laboral y tributario.

El aspecto contable y tributario de Klaz, estará a cargo de la contadora Lola Rocha. El pago por sus servicios será por recibo por honorarios profesionales.

En cuanto a la ubicación física de nuestra oficina, hemos decidido trabajar en esta primera etapa, en una oficina alquilada para tres personas bajo la modalidad de coworking, estará ubicada en el centro empresarial Chacarilla. Este alquiler cuenta con varios beneficios, entre ellos acceso a sala de reuniones, espacio para talleres, servicio networking y capacitación entre otros.

En cuanto a las remuneraciones de los tutores, estarán en promedio con el mercado para lo cual se deberá monitorear constantemente este aspecto. En cuanto al personal administrativo, éste contará con empoderamiento y delegación de funciones que permitan un desarrollo en la organización y a nivel profesional del colaborador.

La estructura de la compañía es horizontal donde se compartirán las decisiones tomadas buscando la agilidad y progreso de la compañía. 


\subsubsection{Configuración organizacional}

La organización se presenta como una línea horizontal entre las 3 gerencias de las socias, un apoyo administrativo y una relación de no subordinación con los profesores.

Por lo tanto, el organigrama para el proyecto desarrollado es el siguiente:

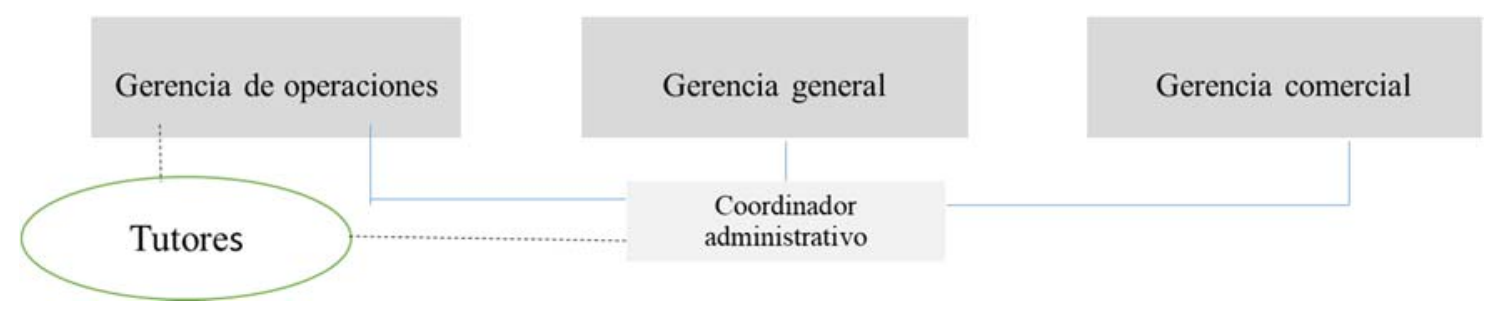

Figura 13. Organigrama JER

Fuente: Elaboración propia.

\subsection{Gestión de Recursos humanos}

El principal activo de la empresa son las personas, y sin su apoyo no sería posible la existencia de la organización, por esta razón basaremos la gestión de recursos humanos en el modelo por competencias.

El objetivo de esta gestión es asegurar que los profesores y personal administrativo asignados sean los más idóneos para cumplir con las funciones. Así tenemos que, los componentes de las competencias son:

- Saber (conocimientos): Esta competencia abarcaría el conjunto de conocimientos que posee cada colaborador.

- Saber hacer (habilidades / destrezas): Esta competencia implica que la persona sea capaz de aplicar los conocimientos que posee para solucionar los problemas que le plantea su trabajo.

- Saber estar (actitudes / intereses): Esta competencia comprende que los comportamientos de los colaboradores se ajusten a las normas y reglas de la organización. 
- Querer hacer (motivación): Esta competencia busca confirmar que los esfuerzos del colaborador por conseguir una utilización más eficaz del tiempo se valoren, y así decida que merece la pena esforzarse por hacerlo.

- Poder hacer (medios y recursos): Comprende los medios y recursos necesarios que debe tener un colaborador para llevar a cabo los comportamientos incluidos en la competencia que necesita la organización.

Con el fin de fomentar una cultura organizacional orientada hacia el cliente, donde tutores y personal administrativo tengan la capacidad de aprender y adaptarse a los constates cambios sociales y tecnológicos, hemos decidido que las competencias para Klaz se estructurarán de acuerdo a la siguiente clasificación.

Las competencias estratégicas, son aquellas que se encuentran vinculadas a la misión y valores de la organización, por lo que se buscará que los tutores tengan las siguientes características: orientación al estudiante, empatía, innovación y mejora continua, personas integras con comprobado sentido ético y practicidad en la enseñanza.

Las competencias personales, incluyen aspectos que son propios de los colaboradores tanto a nivel individual como en su interacción con otros, por lo que buscaremos que sean personas con madurez y equilibrio emocional, iniciativa y profesionalidad, gusten del aprendizaje y desarrollo individual. Adicionalmente a los tutores se les demandará que busquen desarrollar a sus alumnos, mantengan comunicación y escucha activa, les guste el trabajo en equipo y tengan resistencia al estrés. Además es importante incluir en este punto la gestión de relaciones con los usuarios.

Las competencias funcionales, son las vinculadas con la operatividad y los procesos del día a día de Klaz, por lo tanto privilegiaremos el buen manejo de herramientas tecnológicas, organización y planificación del trabajo, gestión de recursos, orientación a objetivos y resultados. 


\section{Políticas de recursos humanos}

- En lo que se refiere a reclutamiento, Klaz tendrá como política convocar para el puesto de tutores a personas con comprobados conocimientos sobre la materia a dictar, y que respondan a las competencias exigidas en el perfil del puesto. De manera adicional buscaremos promover el desarrollo de empleo en las provincias donde nos demanden. Esta función se la encargaremos a la consultora de RRHH Gama Consulting, quienes serán los encargados de la convocatoria y evaluación.

- La selección se iniciará cuando el prospecto responda a la convocatoria a través de los medios que utilice la empresa consultora de RRHH, luego de llenar la información respectiva y dar consentimiento a la verificación de datos, se procederá con dicha verificación y se aplicarán las pruebas psicológicas y de competencia. La empresa consultora filtrará a los candidatos de acuerdo al pedido de Klaz y nos enviara lista de postulantes que responden al perfil solicitado. El directorio de Klaz evaluará la propuesta y hará la selección final. La evaluación incluirá la visualización de una clase modelo de 5 minutos grabada por el candidato.

- La contratación se hará a través de la firma de un contrato de locación de servicios modelo desarrollado por un abogado laboralista, de acuerdo al régimen Pyme. Este contrato especifica que el pago de haberes se realizará con la presentación de un recibo por honorarios (4ta categoría). En el contrato se especificará la tarifa por hora de acuerdo al perfil del tutor, la cual habrá sido acordada previamente con el candidato.

- En la etapa de integración, la responsable del área de RRHH de Klaz, dará la bienvenida al nuevo personal dentro de las comunicaciones internas online. La integración incluye la coordinación de la inducción y capacitación virtual.

- La inducción consiste en un video institucional de la empresa.

- La capacitación consiste en un video tutorial de uso de la plataforma, herramientas, lineamientos generales del servicio, procedimientos en cuanto a temas éticos y morales, metodología de clase, preguntas frecuentes y responsabilidades. 
- En lo que se refiere a la evaluación de desempeño, esta considerará el puntaje obtenido por la evaluación de padres de familia y usuarios, asistencia a capacitaciones, control y registros de asistencia y puntualidad. La plataforma Klaz, contemplará un control de cada docente en donde se registrarán hora de inicio y término de clase y reporte.

- De acuerdo a la experiencia y resultados de las evaluaciones a largo plazo, se evaluará crear el puesto de coordinador por área de enseñanza.

\section{Esquema de incentivos}

Como bien señala Peter Drucker, "lo que no se puede medir, no se puede gestionar", es por ello, que los profesores serán evaluados a través del modelo por competencias de Klaz, mediante encuestas a los padres y alumnos.

Estas evaluaciones serán utilizadas como base para los incentivos de motivación orientados a generar la lealtad de los profesores hacia la marca. Las evaluaciones se complementan con el compromiso del tutor relacionado a la asistencia, puntualidad, calidad y envío de reportes.

El sistema de incentivos buscará atraer a potenciales tutores y retener a los mejores y, desarrollar un buen clima laboral, haciendo que la organización sea competitiva y que evolucione de acuerdo a los objetivos estratégicos.

\section{Endomarketing.}

Nuestra empresa buscará siempre desarrollar un ambiente positivo y gratificante para conseguir el compromiso de nuestros tutores. De acuerdo a lo señalado por Harvard Business Review "las relaciones laborales a largo plazo son la clave para un alto rendimiento y niveles duraderos de motivación de los empleados".

Para lograr este objetivo, periódicamente aplicaremos una encuesta a los tutores vía Survey Monkey (Freemium), donde se evaluará su satisfacción con respecto a laborar en Klaz y de 
acuerdo al resultado se preparará un plan de endomarketing considerando temas como capacitaciones, día de integración, merchandising entre otros.

El servicio definitivamente se centra más en las personas que los números, por eso es muy importante convertir a nuestra empresa en un motor de buen servicio con el apoyo de tutores comprometidos con su trabajo.

Se elegirá mensualmente al "tutor del mes", quien será el que alcanzó las metas trazadas para un periodo determinado. Ellos recibirán incentivos económicos vía gift cards o vales de compra. De igual manera habrá una comunicación constante entre Klaz y los tutores dando la bienvenida a los nuevos integrantes, saludos por fechas especiales como cumpleaños, día del maestro, navidad entre otros, y asimismo se propone implementar Facebook workplace para motivar la integración y comunicación entre los docentes. 


\section{ANÁLISIS ECONÓMICO Y FINANCIERO}

\subsection{Plan financiero}

Para el caso de Klaz, nuestro análisis económico y financiero comienza con la presentación de datos y supuestos sobre los cuales hemos basado nuestras proyecciones de ventas, flujo de caja y estado de resultados.

Como se trata de una start up nueva, actualmente no se cuenta con data histórica, sin embargo, para suplir esta información, hemos basado nuestras proyecciones en la investigación de mercado realizada mediante: encuestas, entrevistas a profundidad y opinión de expertos. Asimismo hemos revisado información pertinente al sector e incluido cotizaciones formales de empresas que trabajarán de la mano con Klaz.

\subsection{Proyecciones}

Si bien es cierto en otros países existe ya un servicio de tutorías online, en el Perú no contamos con este servicio. El modelo de negocio presentado es el de un servicio online que opera mediante una plataforma digital multidevice, por lo tanto, se ha podido tomar como referencias modelos de negocio similares. No es posible saber con certeza si lo proyectado se cumplirá, sin embargo, una vez lanzado el servicio, las estimaciones se irán revisando una vez al mes para ajustarlas con la realidad.

\subsubsection{Supuestos y políticas financieras}

Hemos considerado para el presente negocio, los siguientes supuestos:

- Para el mes de diciembre, las ventas corresponden a la mitad de lo estimado en un mes típico, mientras que para los meses de verano: Enero y Febrero, las ventas corresponden a la tercera parte. 
- Estamos considerando que el tipo de cambio será el mismo para los 5 años de proyección: 3.35 soles.

- Para la proyección de ventas en provincias, hemos asumido como las ciudades más atractivas para las tutorías escolares a: Trujillo, Chiclayo, Piura, Arequipa, Cusco, Chincha, Ica y Huancayo. Asimismo hemos asumido el mismo porcentaje promedio de alumnos que necesitan refuerzo en edad escolar de Lima Metropolitana para aplicarlo en provincias como mercado potencial.

- Cada año se captará un 5\% adicional del mercado potencial estimado (1er año 5\%, 2 do año $10 \%$, 3er año $15 \%$ 4to año $20 \%$, 5to año $25 \%$ ).

- Estamos asumiendo para el escenario pesimista una comisión del 15\% y que la captación del mercado para cada uno de los 5 años sea de 3\%, 5\%, 10\%, 15\% y 20\% respectivamente.

- Estamos asumiendo para el escenario optimista una comisión del 30\% y que la captación del mercado para cada uno de los 5 años sea de $7 \%, 12 \%, 17 \%, 22 \%$ y $27 \%$ respectivamente.

Con respecto a las políticas financieras se ha considerado lo siguiente:

- El pago a los profesores se realizará quincenalmente mediante depósito al banco de preferencia. Los profesores emitirán un recibo por honorarios.

- El cobro a los clientes será por adelantado por cada servicio de clase reservado en el sistema. Se cobrará mediante una pasarela de pago online donde se registrará la tarjeta de crédito o débito. Se emitirá una boleta de pago electrónica que llegará al correo registrado.

- Se le pagará mensualmente con factura a nuestro proveedor socio estratégico Electo por los servicios de marketing digital y plataforma digital.

- Se le pagará mensualmente con factura a nuestro proveedor Gama Consulting por los servicios de reclutamiento, selección de profesores y validaciòn de datos. 
- Se le pagará mensualmente al contador, por sus servicios de asesoría legal mediante recibo por honorarios.

\subsubsection{Inversión}

- Con respecto al plan de inversiones, se estuvieron evaluando diversas alternativas y se decidió que la inversión para este negocio se realizará con capital propio de las 3 socias de la siguiente manera: un capital inicial de $\mathrm{S} / 100,000$ soles en el mes de agosto del presente año para poder comenzar a desarrollar la plataforma, en enero del siguiente año se aportará S/ 70,000 soles previos al lanzamiento de Klaz y finalmente, en mayo se aportarían, S/ 100,000 soles para capital de trabajo. La inversión total para este plan de negocio sería de S/ 270,000 soles.

- Dado que Klaz alquilará oficinas en un coworking, no cuenta con un local propio y al ser un negocio online, sus activos fijos estarían conformados por equipos como laptops, impresoras y celulares y para el caso de los intangibles, se considerará el valor de la marca en un futuro.

- Para los gastos pre-operativos, se están considerando: gastos legales, registro de marca, dominio de web, constitución de empresa y diseño de logo.

- Para la inversión de la plataforma digital, como se mencionó anteriormente, se contratarán los servicios de la agencia Electo quien se encargará de su diseño y desarrollo. Se considera un tiempo de 6 meses con un costo de \$3,200 dólares americanos por cada mes hasta las pruebas beta y lanzamiento.

\subsubsection{Proyección de ventas}

- Dado que Klaz es un servicio nuevo, para proyectar las ventas, se utilizaron los datos obtenidos de la investigación de mercado y del análisis del sector. Esta proyección se ha hecho en soles.

- Para el modelo de negocio planteado, las ventas corresponden a los ingresos generados por el pago de cada clase virtual de una hora (la cual será considerada como la unidad). Se cuenta con 3 tarifas de S/ 35, S/ 60 y S/ 80 soles en función al perfil del docente. 
- Para poder proyectar las ventas, en primer lugar, se calculó el mercado potencial objetivo con 60 colegios de NSE AB de Lima Metropolitana, tomando como promedio 1,000 alumnos por los 10 años desde 2 do grado de primaria hasta 11 vo grado de secundaria.

- Sobre ese número se aplicó el 30\%, porcentaje obtenido en la investigación de mercado, que refiere a los alumnos que en promedio necesitan refuerzo académico y a su vez restándole el porcentaje de padres que rechazan el concepto de una tutoría online (21\%) y el porcentaje de escolares con déficit de atención (5\%).

Tabla 10

Población alumnos en Lima

\section{Total población de alumnos en LIMA AB}

$\%$ alumnos con necesidad de refuerzo

total alumnos con necesidad de refuerzo

$\%$ padres rechazan tutoría online

total alumnos con padres que rechazan la tutoria online

$\%$ escolares con déficit atención

total escolares con déficit atención

\section{0,000}

$30 \%$

18,0001

$21 \%$

3,7802

$5 \%$

9003

Mercado potencial objetivo

Fuente: Elaboración propia.

En segundo lugar, se calcularon las horas estimadas mensuales tomando en cuenta dos tipos de clases: $62 \%$ con refuerzo en cursos y $38 \%$ por un objetivo específico. Para el primer caso se multiplicó el porcentaje correspondiente sobre el mercado potencial y éste a su vez se multiplicó por las horas promedio mensual solicitadas: 12 horas (sesión promedio de 1.5 horas por 2 veces por semana por 4 semanas, según dato de investigación de mercado). Para el segundo caso, se utilizó la misma lógica, solo que esta vez se multiplicó por 6 horas promedio mensual (sesión promedio de 1.5 horas por 1 vez por semana por 4 semanas, según dato de investigación de mercado) de esta forma se obtuvo el total de horas estimadas mensuales, sumando ambos rubros. 
Tabla 11

Mercado Potencial

Mercado potencial objetivo

$13,3201-2-3$

\begin{tabular}{|c|c|c|}
\hline$\%$ alumnos con refuerzo en cursos & $62 \%$ & \\
\hline Total alumnos con refuerzo & 8,258 & \\
\hline Horas promedio mensual solicitadas & 12 & $1.5 \mathrm{hrs}$ promedio $\mathrm{x}$ clase \\
\hline Total horas estimadas mensuales & 99,101 & $A$ \\
\hline$\%$ alumnos con objetivo específico & $38 \%$ & \\
\hline Total alumnos con objetivo específico & 5061.6 & \\
\hline Horas promedio mensual solicitadas & 6 & $1.5 \mathrm{hrs}$ promedio $\mathrm{x}$ clase \\
\hline Total horas estimadas mensuales & 30,370 & \\
\hline
\end{tabular}

\begin{tabular}{lll}
\hline Total horas estimadas mensuales mercado potencial en Lima $\quad 129,470$ & $A+B$
\end{tabular}

Fuente: Elaboración propia.

Por último, en tercer lugar, se calcularon los ingresos mensuales potenciales como la suma de los tres tipos de ingresos determinados por sus respectivas tarifas: universitario, regular y premium. Cada tipo de ingreso se calculó multiplicando su porcentaje obtenido de la investigación de mercado por el total de horas mensuales estimadas y por la tarifa.

Tabla 12

Ingresos mensuales potenciales

\begin{tabular}{|c|c|}
\hline$\%$ horas pagadas tarifa universitario & $28 \%$ \\
\hline Tarifa universitario & 35 \\
\hline Total Ingresos con tarifa universitario & $1,268,810$ \\
\hline$\%$ horas pagadas tarifa regular & $39 \%$ \\
\hline Tarifa regular & 60 \\
\hline Total Ingresos con tarifa regular & $3,029,607$ \\
\hline$\%$ horas pagadas tarifa Premium & $33 \%$ \\
\hline Tarifa Premium & 80 \\
\hline Total Ingresos con tarifa Premium & $3,418,019$ \\
\hline Ingresos mensuales potenciales & $7,716,436$ \\
\hline
\end{tabular}

Fuente: Elaboración propia. 
Finalmente, para la proyección mensual de ventas, se multiplicó los ingresos mensuales potenciales por el porcentaje de captación de mercado esperado cada año.

Cabe resaltar que este mismo ejercicio se aplicó para el cálculo de ingresos en provincias, tomando en cuenta su respectiva población de alumnos estimada y considerando solo 2 tarifas: regular y premium.

\subsubsection{Proyección de costos}

Para la proyección de costos, se ha considerado datos propios de cotizaciones formales con los proveedores que se contratarán para la empresa.

Con respecto al costo de ventas, este incluye las remuneraciones de los profesores tanto de Lima como de provincia y significa el $75 \%$ de los ingresos puesto que la comisión para la empresa es del $25 \%$ para el escenario esperado.

También está incluido el servicio de Gama Consulting, puesto que se trata de la empresa que se encargará del reclutamiento y selección de docentes además de la verificación de antecedentes y CV. Este monto asciende para el primer año a S/ 5,800 soles más IGV y aumentará en los siguientes años, en un $20 \%, 35 \%, 50 \%$ y $65 \%$ sobre el monto inicial, en proporción a la cantidad de docentes estimada.

Otro ítem a considerar son todos los pagos mensuales escalables relacionados con el servidor para la plataforma como: notificaciones en tiempo real y almacenaje de información, servidor para aplicación web, servidor para alojamiento de videos back up y los pagos anuales para la publicación de las aplicaciones en iOS y Android, así como el dominio de web.

Para el caso de los gastos de ventas, está conformado básicamente por la comisión mensual de la agencia Electo por el concepto de mantenimiento de plataforma $(\$ 2,500)$ y marketing digital $(\$ 2,500)$. Este último aumentará en un $10 \%$ cada año.

El pago de la comisión visa/mastercard, es considerado un gasto financiero y corresponde al $3.99 \%$ sobre los ingresos mensuales. 
Por último, con respecto a los gastos administrativos, estos incluyen el alquiler de oficinas en Coworking, el servicio de un asesor contable y la planilla de un coordinador administrativo. El sueldo de las 3 socias recién se asignará a partir del segundo año.

\subsection{Análisis económico y financiero}

Para poder evaluar la rentabilidad del negocio, utilizamos algunas herramientas como: Estado de pérdidas y ganancias, Balance General, Flujo de caja económico, punto de equilibrio, VAN, TIR y análisis de sensibilidad.

\section{Flujo de caja económico}

Esta herramienta nos enseña los ingresos que el negocio proyecta tener durante los 5 años de evaluación y cuánto dinero en efectivo y en qué momento la empresa necesita para poder cubrir los gastos que se requieren.

Al evaluar el flujo de caja esperado, podemos determinar que necesitaremos $\mathrm{S} / 100,000$ soles para iniciar operaciones y poder comenzar con el diseño y desarrollo de la plataforma digital que tomará 6 meses. Luego de este tiempo, se requerirán $\mathrm{S} / 70,000$ soles previo al lanzamiento del negocio ( 2 meses antes) como capital de trabajo. Finalmente, en mayo del ler año, se necesitará $\mathrm{S} / 100,000$ soles para poder seguir cubriendo necesidades operativas. Adicionalmente se está considerando un gasto de S/ 20,000 en Febrero, previo al lanzamiento, por concepto de marcha blanca, donde se probará gratis el servicio para los escolares, no obstante se le pagará a los profesores su sueldo.

Para el escenario esperado, en el año 0 y año 1 , se tendrá una caja final negativa de $\mathrm{S} / 78,652$ y S/ 235,762 respectivamente. A partir del año 2 se contará con cajas finales positivas de: S/ $754,761, \mathrm{~S} / 3,152,236, \mathrm{~S} / 6,908,137$ y S/ 12,021,384 respectivamente.

Ver anexo 8: Flujo de caja económico.

\section{Estado de pérdidas y ganancias}

Este estado financiero muestra la rentabilidad de la empresa para los 5 años de evaluación. Nos enseña los ingresos y egresos operativos del negocio.

Para el caso de Klaz, los ingresos corresponden a las ventas generadas por el pago de cada clase virtual de una hora dependiendo de cada una de las 3 tarifas (de S/ 35, S/ 60 y S/ 80 
soles) que se escoja en función al perfil del docente. La venta se genera en el momento y se carga automáticamente en la tarjeta registrada, por lo tanto no se cuenta con transacciones realizadas a crédito.

Con respecto a los egresos, los gastos de ventas corresponden a la comisión de mantenimiento de marketing que se le paga mensualmente a la empresa Electo por concepto de marketing digital y mantenimiento de cuenta por la plataforma digital desarrollada.

Los gastos administrativos engloban al alquiler de oficinas (Coworking), outsourcing de asesoría contable, planilla del coordinador administrativo y las gerencias general, comercial y de operaciones y servicios generales. Cabe resaltar que el sueldo de las 3 gerencias, recién se percibirá en el año 2 .

Para los gastos pre-operativos, se han considerado los gastos legales de apertura de negocio, registro de marca, dominio web, diseño de logo, constitución de empresa y equipos (laptops, celulares).

Se puede observar que el negocio es rentable a partir del segundo año donde ya se percibe utilidad neta.

Ver anexo 9: Estado de pérdidas y ganancias.

\section{Balance general}

El balance general muestra los activos que posee la empresa, los pasivos, es decir sus deudas y su patrimonio neto, la diferencia entre estos.

Para el presente plan de negocio, no se cuenta con inventarios dado que se trata de un negocio online, asimismo tampoco se cuenta con activos fijos de grandes dimensiones, ya que el servicio de tutorías se presta mediante una plataforma digital.

Las cuentas por cobrar, corresponden a los días que quedan pendientes al final del año y que serán abonados luego de unos días por Visa.

Con respecto a las cuentas por pagar comerciales, estas refieren a los cargos ya contabilizados pero pendientes de ser cancelados a Visa. 
Los activos intangibles, corresponden al monto de diseño y desarrollo de la plataforma multidevice.

Ver anexo 10: Balance general.

\section{Análisis de sensibilidad}

Esta herramienta nos ayudará a tomar decisiones de inversión al considerar el impacto de los cambios en algunas variables relevantes para el negocio sobre las utilidades de la empresa. Las variables consideradas son la captación de mercado y el porcentaje de comisión que gana la empresa por hora dictada.

Se consideraron 3 escenarios: esperado, optimista y pesimista.

Tabla 13

Análisis de sensibilidad

\begin{tabular}{|c|c|c|c|c|c|}
\hline Esperado & Año 1 & Año 2 & Año 3 & Año 4 & Año 5 \\
\hline Captación de mercado & $5 \%$ & $10 \%$ & $15 \%$ & $20 \%$ & $25 \%$ \\
\hline Utilidad Neta & $-125,176$ & 773,865 & $1,801,180$ & $2,786,685$ & $3,771,428$ \\
\hline \% comisión & $25 \%$ & & & & \\
\hline Optimista & Año 1 & Año 2 & Año 3 & Año 4 & Año 5 \\
\hline Captación de mercado & $7 \%$ & $12 \%$ & $17 \%$ & $22 \%$ & $27 \%$ \\
\hline Utilidad Neta & 183,527 & $1,097,625$ & $2,182,079$ & $3,229,656$ & $4,276,470$ \\
\hline \% comisión & $30 \%$ & & & & \\
\hline Pesimista & Año 1 & Año 2 & Año 3 & Año 4 & Año 5 \\
\hline Captación de mercado & $3 \%$ & $5 \%$ & $10 \%$ & $15 \%$ & $20 \%$ \\
\hline Utilidad Neta & $-465,305$ & 478,476 & $1,391,512$ & $2,252,874$ & $3,113,474$ \\
\hline \% comisión & $15 \%$ & & & & \\
\hline
\end{tabular}

Fuente: Elaboración propia.

El porcentaje de comisión variará en función a la aceptación de los profesores con respecto a su ganancia. Es importante resaltar que se analizaron modelos de negocio similares y por ejemplo en Cabify la comisión de ganancia de la empresa es del $25 \%$, esto significa que los choferes de taxis ganan el $75 \%$ de la tarifa.

Vale la pena mencionar, que el presente modelo de negocio promueve a que los profesores abarquen más horas de clases dadas las facilidades y practicidad de manejar el sistema online, por lo tanto, si bien la tarifa ganada por hora podría ser menor que la tarifa cobrada por clases presenciales, como volumen total generarían más ingresos. 
Con respecto al porcentaje de captación de mercado, este podría variar dependiendo de la acogida del concepto. Cabe destacar que nos estamos basando en el mercado potencial objetivo del $30 \%$ de los escolares que requieren refuerzo de acuerdo a los estimados de expertos en educación. Sin embargo, con los resultados de investigación de mercado cuantitativa, se obtuvo un porcentaje más alto de uso de profesores particulares llegando al $55.3 \%$ s. Pero por otro lado, todavía se cuenta con un público conservador que se resiste a los cambios de paradigmas, el cual podría recaer en un escenario pesimista.

\section{Valor actual neto y tasa interna de retorno}

El VAN, valor actual neto, se utiliza para estimar el valor del negocio en el presente. Pudimos conversar con algunos financistas para poder determinar la tasa COK con la que descontaríamos los flujos.

Para el presente negocio hemos considerado una tasa del 12\%, que correspondería a la tasa fija de un fondo mutuo como otra opción de inversión.

Para el escenario esperado, el VAN arroja un resultado positivo de S/ 4,795,869. Esta cifra es mayor que cero, por lo tanto el dinero por recuperar de las socias será superior a lo invertido y el negocio rentable y viable.

La TIR, tasa interna de retorno permite conocer la rentabilidad de un proyecto. En este caso la TIR para el negocio es de 106\%, tasa cuyo valor es mayor que la COK (12\%), por lo tanto, sí es conveniente invertir dinero en el proyecto.

Tabla 14

VAN Y TIR

\begin{tabular}{|c|c|c|c|c|c|c|c|c|}
\hline Escenario Esperado & Inversión & Año 0 & Año 1 & Año 2 & Año 3 & Año 4 & Año 5 & VAN \\
\hline \multirow{2}{*}{$\begin{array}{l}\text { VAN } \\
\text { COK }\end{array}$} & $-270,000$ & $-21,809$ & $-99,789$ & 550,822 & $1,144,683$ & $1,581,240$ & $1,910,723$ & $4,795,869$ \\
\hline & $12 \%$ & & & & & & & \\
\hline Escenario Esperado & Inversión & Año 0 & Año 1 & Año 2 & Año 3 & Año 4 & Año 5 & \\
\hline \multirow[b]{2}{*}{ TIR } & $-270,000$ & $-11,842$ & $-29,420$ & 88,176 & 99,495 & 74,627 & 48,964 & 0 \\
\hline & $106 \%$ & & & & & & & \\
\hline
\end{tabular}

Fuente: Elaboración propia. 


\section{Punto de equilibrio}

El punto de equilibrio es importante para poder determinar en qué punto los ingresos totales equivalen a los egresos y por lo tanto no hay ganancia ni pérdida.

Para efectos del cálculo, se requiere hallar los costos fijos totales, que consideran las siguientes cuentas: servicio Gama Consulting, notificaciones y almacenaje, servidores, publicaciones de apps y dominio web. Se han considerado como gastos: endomarketing de profesores, comisión de marketing digital y los gastos administrativos. El resultado para el CFT es de $\mathrm{S} / 28,009$.

Para el cálculo del precio de venta, se ha considerado el total de ingresos potenciales entre el total de horas potenciales, multiplicadas ambas por el 5\% de captación inicial de mercado. Cabe destacar que en estos ingresos se encuentran ponderadas las 3 tarifas por hora según investigación de mercado. El resultado para este PV es S/ 59.60.

Para el cálculo del CVU, se consideró el PV menos el 25\% de comisión y menos el 3.99\% de pasarela de pago Visa. El resultado para este CVU es de S/ 47.01.

Por lo tanto, se pudo obtener que el punto de equilibrio es alcanzando 7,996 horas o el equivalente en soles de S/ 476,553. (CFT/(PV-CVU). Este punto se alcanza, capturando el $6,18 \%$ de cuota del mercado.

\subsection{Métricas de marketing}

Para las métricas de marketing, se han evaluado las siguientes:

- ROI de marketing, que se refiere al retorno de la inversión en las acciones de marketing.

- Contribución neta del marketing, que mide la rentabilidad del marketing.

- Rendimiento de marketing sobre las ventas, es decir cuánto aporta cada sol vendido a la contribución neta de marketing. 
Tabla 15

Métricas de marketing

\begin{tabular}{|l|c|c|c|c|c|}
\hline Escenario Esperado & Año 1 & Año 2 & Año 3 & Año 4 & Año 5 \\
\hline ROI de marketing & $141 \%$ & $1324 \%$ & $2440 \%$ & $3314 \%$ & $4030 \%$ \\
\hline Contribucion neta del marketing & 146,319 & $1,729,007$ & $3,455,229$ & $5,096,103$ & $6,735,704$ \\
\hline Rendimiento de marketing sobre ventas & $5 \%$ & $21 \%$ & $25 \%$ & $27 \%$ & $28 \%$ \\
\hline
\end{tabular}

Fuente: Elaboración propia. 


\section{CONCLUSIONES Y RECOMENDACIONES}

\subsection{Conclusiones}

- Luego de analizar las diferentes aristas para el presente plan de negocio concluimos que el servicio tutorial online para escolares de 2do a 11vo grado de colegios de NSE AB de Lima Metropolitana y principales provincias, es atractivo y viable. Adicionalmente, en función a los estudios realizados, cubre la necesidad latente del mercado escolar peruano.

- Hemos observado, que de acuerdo a la investigación de mercado, la empatía es considerada como principal atributo diferenciador y un factor crítico del éxito, al hacer posible una conexión segura entre profesores y estudiantes. La plataforma escogida contribuye a potenciar la empatía que es nuestro principal diferenciador.

- Luego de la investigación de mercado, reafirmamos la importancia de la evolución del mundo al mundo digital, donde nuestro proyecto toma vigencia. La evolución al mundo digital lleva a que servicios que se han brindado de manera tradicional en forma presencial enrumben a ser parte de la interacción digital por lo que se deben replantear modelos de negocios que hoy conocemos adaptándolos a la nueva era digital y del Big Data.

- Nos enfrentamos a 2 mundos frente a la tecnología, por un lado los padres que son inmigrantes digitales y los hijos que son los nativos. La oportunidad se da en entrar en lo que es la tendencia natural online de acuerdo al estilo de vida de los estudiantes de hoy rompiendo los paradigmas de los padres en cuanto al servicio de tutorías escolares.

- Las tutorías online pueden traer resultados o beneficios nuevos y sorprendentes frente a la versión tradicional dado que los estudiantes se sienten más cómodos por diversas razones, por ejemplo, ellos estarán hablando en su idioma natural en las pantallas, incluso con símbolos relevantes. También, se sienten más cómodos al no tener personas extrañas que invaden su espacio privado. 
- La idea de Klaz es una propuesta innovadora y beneficiosa para los profesores dado que les brindará mayor flexibilidad en su labor complementaria económica y les permitirá obtener mayores ingresos con menores gastos por la mayor cantidad de clases que podrían abarcar.

\subsection{Recomendaciones}

- Este modelo de negocio puede ampliarse a otras ramas como son la de clases para universitarios y postgrado. En el caso de universitarios es común, que los estudiantes acudan a pequeñas academias cercanas a sus centros de estudios buscando refuerzo en materias en las que tienen dificultad como cálculo, estadística, etc.

- Klaz, podría adaptarse a otros países de la región realizando las investigaciones de mercado respectivas.

- Se podría evaluar la inclusión de otros cursos relevantes como Microsoft Office: excel, power point, word, tablas dinámicas, incorporar otros idiomas, entre otros. 


\section{REFERENCIAS}

Arbaiza, L. (2016). Cómo elaborar un plan de negocio, Lima: ESAN ediciones.

Agencia Peruana de Noticias. (22 de octubre de 2018). Moody's: crecimiento económico del Perú en 2018 es de mejor calidad que en los últimos dos años. Diario América economía. Recuperado de $\quad$ https://www.americaeconomia.com/economiamercados/finanzas/moodys-crecimiento-economico-del-peru-en-2018-es-de-mejorcalidad-que-en [Consulta: 5 de noviembre de 2018]

Biondi, J., Zapata, E., (2017). Nómades electronales, Lima: UPC.

BBC News Mundo. (10 de febrero de 2016). Los países de América Latina "con peor rendimiento académico". Recuperado de https://www.bbc.com/mundo/noticias/2016/02/160210_paises_bajo_rendimiento_e ducacion_informe_ocde_bm [Consulta: 25 de setiembre 2018].

Ecured. (12 de febrero de 2014). Educación Virtual. Recuperado de https://www.ecured.cu/Educaci\%C3\%B3n_Virtual. [Consulta: 10 de enero de 2019].

Falck, D., Kluttig, M. \& Peirano C. (2013). Informe TIC y Educación, la experiencia de los mejores: Corea, Finlandia y Singapur. Santillana. Recuperado de http://conocimientoeducativo.com/wp-content/uploads/2014/11/Final-BAJA-GEEstudio-Educaci\%C3\%B3n-y-Tecnolog\%C3\%ADa1-1.pdf. [Consulta: 20 de enero de 2019].

Fundación Romero. (12 de abril de 2018). Demanda de profesores particulares aumenta por más colegios con Bachillerato Internacional. Portal PQS. Recuperado de https://www.pqs.pe/economia/demanda-profesores-particulares-aumenta-porbachillerato-internacional. [Consulta: 10 de agosto de 2018].

IPSOS (2016), Perfil del Internauta, Lima: Ipsos Perú

IPSOS (2018). Estadística poblacional. Lima: Ipsos Perú

IPSOS (14 de febrero de 2019). Generaciones en el Perú. Recuperado de: https://www.ipsos.com/es-pe/generaciones-en-el-peru [Consulta: 28 de febrero de 2019]. 
IPSOS Perú (31 de diciembre de 2018). Encuesta Nacional Urbano Rural. Del 12 al 14 de diciembre de 2018. Recuperado de https://elcomercio.pe/noticias/encuesta-elcomercio-ipsos [Consultado: 20 de enero de 2019].

Lambin, J.(1995). Marketing estratégico. Chile: McGraw-Hill

Ministerio de Economía y Finanzas.(2019).Proyecto de Ley de Presupuesto del Sector $\begin{array}{lllll}\text { Público para el } & \text { año fiscal }\end{array}$ https://www.mef.gob.pe/contenidos/presu_publ/sectr_publ/proye 2019/EM PL_Pr esupuesto_2019.pdf. [Consulta: 15 de febrero de 2019].

Oppenheimer,A., (2015). Crear o Morir, Buenos Aires: Debate.

Page,B.,Duffy,B.,Shrimpton,H., Whyte-Smith,H.,Abboud,T.,Clemence,M.\&Thomas,F. (2018). Traspasando los límites del binarismo El estilo de vida y las decisiones de la Generación Z. IPSOS VIEWS. Recuperado de https://www.ipsos.com/sites/default/files/ct/publication/documents/201901/gen_z_0.pdf [Consulta: 17 de febrero de 2019].

Redacción Gestión.(06 de febrero de 2018). Economía. Ipsos: Tasa de crecimiento anual de población peruana es de 1.01\%. Diario Gestión. Recuperado de https://gestion.pe/economia/ipsos-tasa-crecimiento-anual-poblacion-peruana-1-01226591 [Consulta: 6 de Noviembre de 2018].

Redacción Gestión. (15 de octubre de 2018). Economía. INEI: Empleo adecuado en Lima se elevó en $1.2 \%$ en tercer trimestre. Diario Gestión. Recuperado de https://gestion.pe/economia/inei-adecuado-lima-elevo-1-2-tercer-trimestre-247143. [Consulta: 10 de diciembre de 2018].

Revista Semana económica.(12 de diciembre de 2018). Citibank: PBI del Perú crecerá 4\% en el 2019, la cifra más alta de la región. Recuperado de http://semanaeconomica.com/article/economia/macroeconomia/323273-citibankpbi-del-peru-crecera-4-en-el-2019-la-cifra-mas-alta-de-la-region/?ref=f-lmvd [Consulta: 24 enero 2019].

Universidad de Lima. (2018). Admisión. Recuperado de http://www.ulima.edu.pe/admision/tercio-superior-de-colegios-acreditados.

[Consulta: 10 de noviembre de 2018]. 
UPC. (2018). Recuperado de: https://pregrado.upc.edu.pe/. [Consulta: 16 diciembre de 2018].

Yamada, G.\& Martínez, J., (31 de enero de 2016). ¿Universidad o instituto? La hora de la reforma de la educación. Diario el Comercio. Recuperado: https://elcomercio.pe/economia/peru/universidad-instituto-hora-reforma-educacion209625. [Consulta:25 de noviembre de 2018]. 


\section{ANEXOS}

Anexo 1: guía entrevista exploratoria a madres/padres de escolares

\section{Guía encuesta mamás/papás estudiantes}

Edad Mamá:

Edad hijos(as):

Grado:

Distrito:

Colegio hijos:

Nos encontramos desarrollando nuestra tesis sobre un servicio de tutoría escolar virtual, mediante la cual el alumno podrá acceder por una aplicación a una sesión de clases del curso en el que tenga dificultades o para algún tema específico o tarea del momento, interactuando con el profesor en línea a tiempo real, a través de un dispositivo móvil, tablet o laptop.

Para ello, les pedimos su colaboración con esta encuesta:

1. ¿Usted contrata o ha contratado los servicios de un profesor particular a domicilio? a. Sí.

b. No.

2. ¿Con qué frecuencia contrata (o contrataría) los servicios de un profesor particular para sus hijos?
a. 1 o 2 veces por semana.
b. 1,2 o 3 veces cada quince días.
c. Mensualmente (indicar frecuencia
d. Otro:

3. ¿Cuánto paga por cada clase de profesor particular? 
Rpta:

4. ¿En qué materias suele necesitar refuerzo?

Área de Comunicación

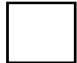

Área de Matemática

Área Ciencias y tecnología

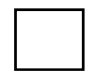

Área de inglés o idiomas

5. ¿Para qué grados suele contratar los servicios de profesor particular?

a. Primaria:

b. Secundaria:

6. ¿Cuál es la razón principal por la cual contrataría un profesor particular?

a. Quiero reforzar las materias aprendidas.

b. Quiero lograr un objetivo concreto (Ej. pasar un examen, lograr una certificación, tareas, etc).

c. Deficiencia en aprendizaje de un curso específico.

Otro:

7. Para contratar un profesor particular a domicilio, ¿cuáles son los tres criterios que usted considera los más importantes? (puede marcar más de uno).

a. Recomendación de amigos y/o familiares.

b. Que tenga educación universitaria.

c. Que tenga un certificado que demuestre su conocimiento en el tema.

d. El costo por hora más económico.

e. Que sea puntual, respetuoso y cordial.

F. Que tenga empatía y paciencia.

8. Según tu experiencia, ¿qué problemas dificultades has tenido con los profesores particulares? 
9 ¿Estaría dispuesto a utilizar esta nueva aplicación para tener la clase y/o tutoría on line a tiempo real con el profesor?

a. Sí.

b. No, motivo

10. De acuerdo a la idea propuesta de la tesis, ¿Por qué preferiría contratar un profesor particular on line en lugar de uno a domicilio o de academia? (puede marcar más de una respuesta).

a. Quiero ahorrarme el tiempo de viaje, mucho tráfico.

b. Seguridad al no tener un extraño en casa.

c. Disponibilidad para el momento en que justo se necesita, sin mayor planificación.

d. Me resulta más económico.

e. Otro:

11. ¿Qué desventajas, o dificultades crees que podría tener este servicio?

12. ¿Qué ventajas crees que tendría este servicio?

13. ¿Cuáles serían los tres principales atributos que le gustaría que tenga la aplicación?

a. Perfil del profesor.

b. Ranking y comentarios de profesores.

c. Pago on line por pay pal, tarjeta débito y crédito.

d. Reporte de avance de clase y evaluación del hijo culminada la clase.

e. Link seguimiento en línea de clase a tiempo real.

14. Considerando que pagas $x \times x$ por tu profesor particular hoy, ¿cuánto estarías dispuesto a pagar por una hora de tutoría virtual? ¿Por qué?

15. ¿Algo que me quieras comentar?

Muchas Gracias por tu colaboración. 
Anexo 2: guía entrevista exploratoria a expertos en educación.

1. De acuerdo a su experiencia profesional, ¿cuáles son los cursos de mayor dificultad para los alumnos? Por favor ordene de forma descendente donde 1 es el de mayor dificultad y 4 el de menor dificultad.

\begin{tabular}{|l|l|}
\hline & Orden \\
\hline Área de matemática & \\
\hline Área de inglés & \\
\hline Área de comunicación & \\
\hline Área de ciencias & \\
\hline Área de tecnología & \\
\hline
\end{tabular}

2. ¿Piensa que los entornos virtuales generados por las TIC (tecnologías de información y comunicación) ayudan a optimizar el aprendizaje de los alumnos? ¿Por qué?

3. ¿Tiene conocimiento de algunos cursos que actualmente están utilizando las TIC en primaria o secundaria? ¿Cuáles son esos cursos?

4. ¿Considera que un servicio de tutoría virtual (después del colegio) para los alumnos que presentan dificultad en su aprendizaje, (sin ninguna complicación de fondo cognitivo) sería efectivo? ¿Por qué?

5. ¿Cuáles son los principales atributos que debería incluir este servicio?

6. ¿Qué perfil debería tener el tutor virtual?

7. ¿Cuál es la duración debería tener este servicio tutorial virtual?

8. ¿Recomendaría este servicio? ¿Por qué?

9. ¿Tiene algún comentario que crea será de utilidad para nuestro proyecto?

10. De su experiencia, por favor estime el porcentaje de necesidad de apoyo extra escolar. 
Muchas gracias por querer participar en esta entrevista, la cual nos ayudará a desarrollar mejor nuestro proyecto de Plan de Negocio para una Tesis de grado.

Nombre:

Edad:

Profesión:

1. Usted es profesor de tutoría para escolares; ¿lo hace de manera particular directa y/o a través de alguna empresa?
a. Particular online
b. Particular a domicilio
c. Empresa online
d. ¿Cuál?
e. Empresa a domicilio
f. ¿Cuál?

2. ¿Qué cursos dicta?
a. Matemática
b. Comunicación integral, lenguaje
c. Inglés
d. Ciencias (especificar): Física Química Biología
e. Otro:

3. ¿A qué grados dicta?
a. Primaria: $1^{\circ}$ $2^{\circ}$ $3^{\circ}$ $4^{\circ}$ 5 $6^{\circ}$
b. Secundaria: $1^{\circ}$ $2^{\circ}$ $3^{\circ}$ $4^{\circ}$ $5^{\circ}$ $6^{\circ}$

4. ¿Cómo verificas el avance en el aprendizaje de tus alumnos?

a)

b. ¿Lo reportas? $\mathrm{Si}$ No

c. ¿A quién? 
5. ¿Quiénes te contratan?
a. Mamá
b. Papá
c. Otro, especificar

6. ¿Cómo consigues alumnos?

a. Anuncio en internet

b. Anuncio en tiendas

c. Referidos por alumnos

d. Otros

7. ¿Consideras que es fácil conseguir alumnos particulares?

a. $\mathrm{Si}$

b. No

c. ¿Por qué?

8. Queremos ofrecer un aplicativo para conectar profesores con alumnos para el dictado de clases particulares de manera virtual (online), ¿estarías interesado en dictar clases por este aplicativo?
a. Sí
b. No

9. Por favor indica el rango de tarifa que cobras actualmente por hora en soles.
a. Menos de 35
b. 35 a 44
c. 45 a 54
d. 55 a 64
e. 65 a 74
f. 75 a 84
g. 85 a más
Especifica:

10. Para la respuesta anterior, ¿qué porcentaje de tu tarifa por hora estarías dispuesto/a a pagar para ser parte de este aplicativo?

Valor: 
11. Sólo sí trabajas actualmente para una empresa, ¿qué comisión te cobran?

12. ¿Conoce alguna aplicación y/o página web que ofrezca algo similar?

Sí No

Cuál/cuáles:

13. ¿Qué ventajas le ves a este servicio?

14. ¿Qué desventajas le ves a este servicio? (dudas del servicio, en cuanto a materias, edad...)

Muchas gracias 


\section{Formato encuesta mamás/papás alumnos}

Nos encontramos desarrollando nuestra tesis de maestría sobre un servicio de tutoría escolar virtual, mediante la cual el alumno podrá acceder a una sesión de clases del curso en el que tenga dificultades o para algún tema específico o tarea del momento, interactuando con el profesor en línea a tiempo real, a través de un dispositivo móvil, tablet, laptop o PC. Las clases podrán tener una duración entre 1 a 2 horas. Al final de la sesión se entregará un reporte o status de la sesión a los padres. El pago será on line por débito o crédito. El servicio permite seleccionar al profesor/a de acuerdo al perfil mostrado el cual indicará sus estudios y experiencia; así como también sus rating y comentarios.

Para ello, te pedimos su colaboración con esta encuesta:

1. ¿Actualmente contratas o has contratado los servicios de un profesor particular a domicilio?

a. Sí.

b. No. Gracias, fin de la encuesta

2. ¿Con qué frecuencia contratas o has contratado los servicios de un profesor particular para tu hijo/a?

a. 1 o 2 veces por semana.

b. 3 veces a más por semana.

c. Esporádicamente para casos puntuales.

3. La Duración de cada sesión de clase es:

a. 1 hora

b. 1.5 horas

c. 2 horas

4. ¿Cuánto pagas en promedio por la hora de clase de profesor particular? 

a. S/.30-39.
b. S/. $40-49$
c. $\mathrm{S} / .50-59$
d. S/. $60-69$
e. S/. $70-79$
f. S/. 80 a más

5. ¿En qué materias suele tener mayor dificultad tus hijos?. Puedes marcar más de uno

a. Área de Comunicación

b. Área de Matemática

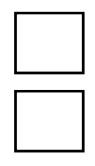

c. Área Ciencias

d. Área de inglés o idiomas

6. Para qué grados has contratado los servicios de profesor particular? Puedes marcar más de una opción:

Primaria: 23456

Secundaria 7891011

7. Ordena de forma descendente, donde 1 es la razón principal por la cual contratarías un profesor particular y 4 la menos importante

a. Reforzar un curso para mejorar rendimiento 1 2 3 4

b. Reforzar un tema específico de un curso. 1 2 3 4

c. Lograr un objetivo concreto: pasar un examen, lograr una certificación, proyecto, etc. $1 \_2 \_3 \_4$

d. Deficiencia en aprendizaje de un curso específico. 1 2 3 4

8. Cuando contratas un profesor particular a domicilio, ¿cuáles son los tres criterios que consideras más importantes?

a. Recomendación de amigos y/o familiares.

b. Que tenga educación universitaria. 

c. Que conozca la metodología del colegio.
d. El costo por hora más económico.
e. Que sea puntual, respetuoso y cordial.
F. Que tenga empatía y paciencia.

\section{Según tu experiencia, ¿qué problemas o dificultades has tenido con los profesores}

particulares?
a. Que no conozca la metodología del colegio
b. Que no conecte con el estudiante
c. Impuntualidad y/o cambios de horario
d. Disponibilidad restringida del profesor
e. Que no sepa dictar el curso en otro idioma
f. Otro

10. De acuerdo a la idea propuesta de la tesis, ¿Por qué contratarías a un profesor on line ? (puedes marcar más de una).
a. Quiero ahorrarme el tiempo de viaje, mucho tráfico.
b. Seguridad al no tener un extraño en casa.
c. Disponibilidad para el momento en que justo se necesita, de acuerdo a tus horarios.
d. Comodidad y practicidad de tener la clase en cualquier lugar.
e. Otro:

11. ¿Cuáles serían los tres principales atributos que te gustaría tenga este servicio de tutoría online?
a. Perfil del profesor.
b. Ranking y comentarios de profesores.
c. Pago on line por pay pal, tarjeta débito y crédito.
d. Reporte de avance de clase y evaluación del hijo culminada la clase.
e. Link seguimiento en línea de clase a tiempo real.
f. Notificación inmediata de solicitud de servicio
g. Programa de incentivos de recompensa por logros
h. otro 
12. ¿Cuánto estarías dispuesto a pagar por una hora de tutoría virtual?
a. S/. 30-39
b. S/. $40-49$
c. S/. 50-59
d. S/. $60-69$
e. $\mathrm{S} / .70-79$
f. S/. 80 a más

Por favor responde las siguientes preguntas individualmente por cada hijo/hija que esté entre 2 do grado de primaria y 11 vo grado (5to de secundaria).

\section{$\underline{\text { Hijo/hija \#1 }}$}

12.1 Edad hijo/a:

Grado en el que está:

12.2 Primaria: 23456 Secundaria 7891011

12.3 ¿Es hijo? ¿Es hija?

12.4 Colegio:

13 ¿Estarías dispuesta/o a utilizar este nuevo servicio de tutoría online explicado al inicio de esta encuesta?
a. Sí.
b. No, explicar motivo

14. De acuerdo a la idea propuesta de la tesis ¿Qué desventajas, o dificultades crees que podría tu hijo/hija tener con este servicio? (Puedes marcar más de 1 alternativa)
a. Que se pueda distraer o desconcentrar
b. Que el estudiante no pueda explicar el requerimiento con claridad.
c. Menor control del profesor/a hacia el estudiante. 
d. Dificultad en la interacción con el profesor.

e. otro

15. De acuerdo a la idea propuesta de la tesis ¿Qué ventajas crees que tendría este servicio para tu hijo/hija? (Puedes marcar más de una alternativa)

a. Practicidad para conectarte en el horario y momento que necesitas

b. Pago online

c. No invasivo, no vienen a tu casa

d. Servicio Ad Hoc porque son nativos digitales

e. Seguridad al no tener un extraño en casa

f. Comodidad y confort al tomar la clase en el espacio que desees

g. Otro

\section{Hijo/hija \#2}

16.1 Edad hijo/a:

Grado en el que está:

16.2 Primaria: 23456 Secundaria 7891011

16.3 ¿Es hijo? ¿Es hija?

16.4 Colegio:

17 ¿Estarías dispuesta/o a utilizar este nuevo servicio de tutoría online explicado al inicio de esta encuesta?

a. Sí.

b. No, explicar motivo

18. De acuerdo a la idea propuesta de la tesis ¿Qué desventajas, o dificultades crees que podría tu hijo/hija tener con este servicio?
a. Que se pueda distraer o desconcentrar
b. Que el estudiante no pueda explicar el requerimiento con claridad.
d. Menor control del profesor/a hacia el estudiante. 
e. otro

19. De acuerdo a la idea propuesta de la tesis ¿Qué ventajas crees que tendría este servicio para tu hijo/hija?
a. Practicidad para conectarte en el horario y momento que necesitas
b. Pago online
c. No invasivo, no vienen a tu casa
d. Servicio Ad Hoc porque son nativos digitales
e. Seguridad al no tener un extraño en casa
f. Comodidad y confort al tomar la clase en el espacio que desees
g. Otro

\section{Hijo/hija \#3}

20.1 Edad hijo/a:

Grado en el que está:

20.2 Primaria: 23456 Secundaria 7891011

20.3 ¿Es hijo? ¿Es hija?

20.4 Colegio:

21. ¿Estarías dispuesta/o a utilizar este nuevo servicio de tutoría online explicado al inicio de esta encuesta?
a. Sí.
b. No, explicar motivo

22. De acuerdo a la idea propuesta de la tesis ¿Qué desventajas, o dificultades crees que podría tu hijo/hija tener con este servicio?
a. Que se pueda distraer o desconcentrar
b. Que el estudiante no pueda explicar el requerimiento con claridad.
d. Menor control del profesor/a hacia el estudiante.
e. otro 
23. De acuerdo a la idea propuesta de la tesis ¿Qué ventajas crees que tendría este servicio para tu hijo/hija?
a. Practicidad para conectarte en el horario y momento que necesitas
b. Pago online
c. No invasivo, no vienen a tu casa
d. Servicio Ad Hoc porque son nativos digitales
e. Seguridad al no tener un extraño en casa
f. Comodidad y confort al tomar la clase en el espacio que desees
g. Otro

Muchas Gracias por tu colaboración. 


\section{Respuestas a entrevistas educadores expertos}

Nombre: Alberto Melgar. Director colegio

1. De acuerdo a su experiencia profesional, ¿cuáles son los cursos de mayor dificultad en nivel primaria y secundaria para los alumnos. Por favor ordene de forma descendente, 1 es el de mayor dificultad y 4 el de menor dificultad.

\begin{tabular}{|l|c|}
\hline & Orden \\
\hline Área de Matemática & 1 \\
\hline Área de inglés & 4 \\
\hline Área de Comunicación & 3 \\
\hline Área Ciencias & 2 \\
\hline Área tecnología & 0 \\
\hline
\end{tabular}

2.- ¿Piensa que los entornos virtuales generados por las TIC (tecnologías de información y comunicación) ayudan a optimizar el aprendizaje de los alumnos?

Si, ayudan.

¿Por qué?

- Los recursos son más dinámicos, entretenidos, les interesa más y eso ayuda a que aprendan

- Son más reales porque son más cercanos a su día a día.

- También se pueden distraer si no están bien utilizados.

3. ¿Tiene conocimiento de algunos cursos que actualmente están utilizando las TIC en primaria o secundaria? ¿Cuáles son esos cursos?

- Se utilizan para ciencias, programación y otros cursos 
- Se utiliza Google class, Juegos en Línea, Scratch y otros TIC's

- También se utilizan foros para ciencias.

4. ¿Usted cree que un servicio de tutoría virtual después del colegio para los alumnos que presentan dificultad en su aprendizaje, (sin ninguna complicación de fondo cognitivo), sería efectivo?

Sí, es una muy buena idea

\section{¿Por qué?}

- Es algo que se viene ya dando para muchos aspectos de nuestras vidas, incluso ya se buscan profesores por internet aunque luego ellos vayan a casas a dictar las clases

- Hay una clara necesidad de conseguir profesores recomendados y los padres llaman continuamente por referencias para que vayan a sus casas o estudiantes acudan a Nivel A.

- La clase en línea sería lo adecuado para estos tiempos modernos en que se necesita este tipo de soporte. Ya estamos adecuados a buscar datos, servicios, comprar por internet. La búsqueda de información por internet es ya parte natural de todos nosotros y es la primera parte: seleccionar el profesor. La siguiente es el servicio mismo, es decir, la clase

- Creo que es lo que viene en el futuro próximo y es totalmente natural.

- Muchos niños requieren apoyo extraescolar por salones muy grandes, estilos de educación complejos para el alumno. Es normal que requieran un apoyo temporal, incluso se da en el modelo de Finlandia.

\section{5. ¿Cuáles serían los principales atributos que debería incluir este servicio?}

- No falla la disponibilidad del profesor

- La tecnología es amigable y servicio debe también serlo

- Que haya buena retro alimentación hacia los padres.

- Muchas veces los padres se acostumbran a que el niño tenga acompañamiento durante toda su vida escolar y no se preocupan de encontrar la causa raíz y dar 
estrategias para que el niño continúe solo. Idealmente el profesor debe poder determinar las bases que debe corregir o las deficiencias que el niño podría tener ya sea para ser trabajadas con él mismo o con otro especialista. Es natural que en ocasiones se requiera focalizar esfuerzos en pasar el curso, y podrán haber otros momentos para trabajar los fundamentos del curso.

- Encontrar información rica en las necesidades del estudiante para detectar esos nichos por ejemplo: las fijas cuando no hay tiempo y luego profundizar.

\section{6. ¿Cuál es el perfil que debería tener el tutor virtual?}

- Se debe formar vínculos estables entre profesor/alumno, si el vínculo no funciona, si no hay empatía, la clase no será posible, no habrán avances. El mejor profesor no es el que más sabe sino el que genera un "feeling" con el alumno.

- Tutores capaces de encontrar el problema central y proponer estrategias.

- Ser un Asesor.

\section{Duración debería tener este servicio tutorial virtual.}

- En chicos menores 50 minutos.

- Mayores a 5to grado entre una hora y 1.5 horas

\section{8. ¿Recomendaría este servicio?}

$\mathrm{Si}$

¿Por qué?

Sería un buen complemento que da practicidad a una necesidad continua en casi todos los colegios, Incluso en colegios que dan nivelación en las tardes, muchos niños no las quieren tomar. Sería más cómodo para ellos y para los maestros.

\section{9. ¿Tiene algún comentario que crea será de utilidad para nuestro proyecto?}

- Contactarse con los colegios para que sepan del servicio y lo puedan recomendar. 
- Contactarse con colegios para tener profesores con métodos de esos colegios y ahora son alumnos universitarios de primeros ciclos.

- Cuando tengan el proyecto armado me buscan, me interesa.

10. De su experiencia, por favor estime el porcentaje de necesidad de apoyo extra escolar.

- Por lo menos $20 \%$ de los escolares requieren apoyo durante todos los años de colegio 2 veces por semana durante todo el año escolar.

- $20 \%$ de escolares requiere apoyo durante el verano

- $60 \%$ requiere apoyo cerca a exámenes, y luego muchos quedan con el profesor.

- $80 \%$ de estudiantes necesitan apoyo en algún momento de sus años escolares.

\section{Muchas gracias.}


Nombre: Gali Orbegoso Reyes. Director colegio

1.- De acuerdo a su experiencia profesional, ¿cuáles son los cursos de mayor dificultad en nivel primaria para los alumnos?. Por favor ordene de forma descendente, 1 es el de mayor dificultad y 4 el de menor dificultad.

Área de Comunicación

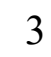

Área de Matemática

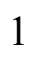

Área Ciencias y tecnología

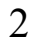

Área de inglés

2.- ¿Piensa que los entornos virtuales generados por las TIC (tecnologías de información y comunicación) ayudan a optimizar el aprendizaje de los alumnos?

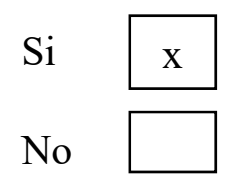

Por qué? Hoy en día, el mundo se desenvuelve en la tecnología y no podemos negarle a las generaciones actuales este mundo. Lo que sí. Hay que sacarle el mejor provecho sin perder algunas cosas esenciales de lo básico. Muchos niños aprenden hasta mejor con estímulos tecnológicos, el reto es encontrar este equilibrio.

3.- Tiene conocimiento de algunos cursos que actualmente están utilizando las TIC en primaria o secundaria, cuáles son esos cursos?

$\underline{\text { Todos los cursos incorporan presentaciones en power point que se muestran a través de las }}$ computadoras de cada salón. Cualquier material del curso es enviado inmediatamente finalizada la clase, a los correos de los alumnos. También se cuenta con intranet y un aplicativo de sianet donde se pueden consultar notas, avances y tareas a tiempo real.

$\underline{\text { Se puede ingresar a cada curso y consultar el rendimiento así como información del profesor. }}$ 
4.i Cree usted que un servicio de tutoría virtual (después del colegio) para los alumnos que presentan dificultad en su aprendizaje, (sin ninguna complicación de fondo cognitivo) seria efectivo?

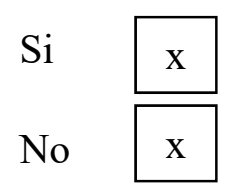

Por qué- Considero que depende. No le veo ninguna barrera a un alumno con dificultades, por el contrario, tal vez sea motivador y más eficiente que aprenda de esta forma y se vea un cambio más rápido y nos sorpenda, insisto, es el lenguaje y el mundo de los alumnos. Habría que probar en todo caso si funciona pero no se lo negaría.

5. ¿Cuáles serían los principales atributos que debería incluir este servicio?

Algún tipo de tecnología para poder explicar la clase.

Monitoreo en tiempo real.

Envío de reporte de clase.

$\underline{\text { Pago en línea. }}$

Perfil de profesores.

\section{6. ¿Qué perfil debería tener el tutor virtual?}

Incluir grado académico, lugar de estudios, experiencia previa y tal vez algo que en una oración lo defina como persona.

\section{7. ¿Qué duración debería tener este servicio tutorial virtual?}

Depende con qué fin uses la tutoría: podría ser entre una hora y una hora y media.

8. ¿Usaría o recomendaría este servicio?

Si $\mathrm{x}$

No

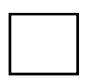


Por qué?Definitivamente funcionaría.

9.- ¿Cuánto pagaría por el servicio de tutoría virtual?

Aproximadamente entre 50 y 60 soles, depende de la complejidad del curso y/o objetivo.

10.- Algún comentario que crea será de utilidad para nuestro proyecto?

Aproximadamente el 30\% de los alumnos de cada promoción necesitan refuerzo para poder entender mejor alguna materia. El curso que generalmente suelen llevar vacacional, es el de Matemáticas seguido por Science.

\section{Muchas gracias}

Janice Roeder McKay. Directora colegio

1. De acuerdo a su experiencia profesional, ¿cuáles son los cursos de mayor dificultad en nivel primaria para los alumnos?. Por favor ordene de forma descendente, 1 es el de mayor dificultad y 4 el de menor dificultad.

\begin{tabular}{|l|c|}
\hline & Orden \\
\hline Área de Matemática & 1 \\
\hline Área de inglés & 3 \\
\hline Área de Comunicación & 2 \\
\hline Área Ciencias & 4 \\
\hline Área tecnología & 0 \\
\hline
\end{tabular}

2.- ¿Piensa que los entornos virtuales generados por las TIC (tecnologías de información y comunicación) ayudan a optimizar el aprendizaje de los alumnos? 
$\mathrm{Si}$, ayudan.

¿Por qué?

Es a lo que los chicos están acostumbrados, es normal para ellos, los saben manejar muy bien.

3. ¿Tiene conocimiento de algunos cursos que actualmente están utilizando las TIC en primaria o secundaria? ¿Cuáles son esos cursos?

Se utilizan en varios cursos, a veces como juegos para matemática, para ciencias y hasta inglés.

4. ¿Usted cree que un servicio de tutoría virtual después del colegio para los alumnos que presentan dificultad en su aprendizaje, (sin ninguna complicación de fondo cognitivo), sería efectivo?

Sí, me parece genial.

¿Por qué?

- Es natural para los alumnos, ellos están en internet muchas horas, les parece entretenido, se divierten y aprenden.

- También a veces juegan mucho rato y se distraen, hay que saber monitorearlos.

- El uso de internet es cada vez mayor en nuestras vidas y más en la de los alumnos.

5. ¿Cuáles serían los principales atributos que debería incluir este servicio?

- Que sea amigable, divertido

- Que no falle el internet

- Que los profesores sean empáticos, hagan click

- Que sea fácil interactuar con el profesor.

- Que entienda la metodología del colegio.

- Que reporte los avances a los padres del alumno o alumna. 
- Que sea como jugar, con premios, incentivos.

6. ¿Cuál es el perfil que debería tener el tutor virtual?

- Saber llegar a los chicos, más que saber mucho, debe ser empático.

- Saber entender la metodología del colegio.

- Amenos, con energía.

\section{7. ¿ Qué duración debería tener este servicio tutorial virtual.}

Entre una hora y 1.5 horas aunque en algunos casos pueden tolerar hasta 2 horas cuando son más grandes, pero es bueno hacer breaks

\section{8. ¿Recomendaría este servicio?}

$\mathrm{Si}$, de todas maneras.

\section{¿Por qué?}

Sería muy práctico para los chicos y para las mamás. Hoy hay mucho tráfico, y a los chicos les molesta a veces tener los profesores que vienen a casa. Estarían más entusiasmados con estas clases, lo sentirían "más normal".

\section{9. ¿Tiene algún comentario que crea será de utilidad para nuestro proyecto?}

- Avisar a los colegios para que los recomienden.

- Contactar a los colegios para que les recomienden exalumnos para tenerlos como profesores.

10. De su experiencia, por favor estime el porcentaje de necesidad de apoyo extra escolar. 
Yo calculo que el 30\% de los alumnos necesitan y tienen clases particulares. Veo además que los chicos que tienen dificultad en matemática desde el comienzo de colegio, lo seguirán teniendo hasta terminar el colegio. Lo he visto en mis 30 años de experiencia en educación.

Muchas gracias.

María Mercedes García de Valenzuela. Directora de Colegio.

1. De acuerdo a su experiencia profesional, ¿cuáles son los cursos de mayor dificultad en nivel primaria para los alumnos? Por favor ordene de forma descendente, 1 es el de mayor dificultad y 4 el de menor dificultad.

\begin{tabular}{|l|c|}
\hline & Orden \\
\hline Área de Matemática & 1 \\
\hline Área de inglés & 2 \\
\hline Área de Comunicación & 3 \\
\hline Área Ciencias & 4 \\
\hline Área tecnología & 0 \\
\hline
\end{tabular}

En tecnología no hay ningún chico que necesite asesoría para aprender algún programa.

2. Piensa que los entornos virtuales generados por las TIC (tecnologías de información y comunicación) ayudan a optimizar el aprendizaje de los alumnos.

$\mathrm{Si}$, ayudan.

¿Por qué? Área con mucho potencial por desarrollar pues se puede personalizar las herramientas, y la interacción, comunicación se da uno a uno, lo que mejora el aprendizaje en los alumnos.

3. ¿Tiene conocimiento de algunos cursos que actualmente están utilizando las TIC en primaria o secundaria, cuáles son esos cursos? 
- Se usa plataformas para el curso de matemáticas. A partir de 5to grado se incrementa el uso de tecnología en las aulas, se interactúa en el aula virtual, donde encuentran ejercicios y tareas e investigaciones que deben desarrollar.

- En secundaria los alumnos (as) crean páginas web, programas etc.

4. ¿Usted cree que un servicio de tutoría virtual (después del colegio) para los alumnos que presentan dificultad en su aprendizaje, (sin ninguna complicación de fondo cognitivo) sería efectivo?

- $\mathrm{Si}$

¿Por qué?

- Con el apoyo de plataformas se puede reproducir la situación en clase, y apoyar en el punto específico que no comprendió el alumno.

- La interacción es de uno a uno por lo que el aprendizaje es mejor.

5. ¿Cuáles son los principales atributos que debería incluir este servicio

- Flexibilidad

- Plataforma dinámica que use el enfoque del colegio (ej. En Matemática se puede guiar del libro). Otras áreas debe coordinar con el profesor del colegio para estar alineados en el contenido y forma.

- Enfocado en preguntas que los alumnos deseen absolver (escucha activa).

6. ¿Cuál es el perfil debería tener el tutor virtual?

- En primaria podría ser un tutor que domine todas las áreas, pero en secundaria NO, se necesita que sean especialistas por áreas.

- En primaria puede ser un liderazgo más directivo, en secundaria debería ser más horizontal, que enganche con el alumno.

- Empatía

- Buen manejo de las herramientas tecnológicas.

7. ¿Qué duración debería tener este servicio tutorial virtual?

- Máximo de una hora.

- Media hora los más pequeños. 


\section{8. ¿Recomendaría este servicio?}

$\mathrm{Si}$

\section{¿Por qué?}

Es la tendencia, la tecnología bien trabajada tiene mucho potencial para desarrollar en materia de educación.

\section{9. ¿Algún comentario que crea será de utilidad para nuestro proyecto?}

- Para poder tener un buen argumento en caso al alumno no le vaya bien después de recibir nuestro servicio, sería bueno poder filmar (grabar) las clases, pues hay muchas quejas de los padres, que individualmente (de acuerdo al reporte del tutor presencial) le va bien en las clases individuales, pero no se plasma en las notas del colegio, esto se debe a que en las clases particulares el profesor está con ellos y les hace indicaciones in situ de como están desarrollando el curso, en el aula es diferente no existe ese acompañamiento.

- Los chicos deben desarrollar hábitos de estudio y estrategias que les ayude a resolver las tareas en forma individual.

- Dejarles trabajos para que desarrollen individualmente.

- Cuestionario de satisfacción de los padres/niños/adolescentes, muy importante pues un profesor puede enseñar a varios niños pero hay uno al que no le va bien.

- Reunirse con los padres y el colegio (profesores) para tener un mejor conocimiento del alumno, alineación para tener impacto en su desempeño escolar.

\section{De su experiencia, por favor estime el porcentaje de necesidad de apoyo extra} escolar.

En primaria, cuando vemos que los niños no están respondiendo en forma adecuada a las evaluaciones, en algún curso en particular, solicitamos asistan a nivelaciones después del horario escolar.

En secundaria es opcional el que asistan a nivelaciones en el colegio, ya que muchos prefieren un profesor personal. 
El número total de alumnos es 1100 , de los cuales aproximadamente el $30 \%$ necesita en algún momento de su etapa escolar, asistir a alguna nivelación.

\section{Muchas gracias}

Fernando Bolaños. Alto ejecutivo de entidad de Naciones Unidas y ex vice ministro Educación.

1. De acuerdo a su experiencia profesional, ¿cuáles son los cursos de mayor dificultad en nivel primaria para los alumnos? Por favor ordene de forma descendente, 1 es el de mayor dificultad y 4 el de menor dificultad.

\begin{tabular}{|l|c|}
\hline & Orden \\
\hline Área de Matemática & 1 \\
\hline Área de inglés & 2 \\
\hline Área de Comunicación & 3 \\
\hline Área Ciencias & 4 \\
\hline Área tecnología & 0 \\
\hline
\end{tabular}

2. ¡Piensa que los entornos virtuales generados por las TIC (tecnologías de información y comunicación) ayudan a optimizar el aprendizaje de los alumnos?

Si, ayudan.

¿Por qué?

- Los chicos son nativos digitales. Aunque hoy en día en su mayoría usan la tecnología para fines recreativos. (ej. Fornite, otros juegos).

- La correcta utilización de las herramientas tecnológicas beneficiara a los alumnos en optimizar sus conocimientos. 
3. ¿Tiene conocimiento de algunos cursos que actualmente están utilizando las TIC en primaria o secundaria, cuáles son esos cursos?

- Se usan tutoriales para enseñar programas de computación.

4. Un servicio de tutoría virtual (después del colegio) para los alumnos que presentan dificultad en su aprendizaje, (sin ninguna complicación de fondo cognitivo) ¿sería efectivo?

- $\mathrm{Si}$

¿Por qué?

- Muy importante que se entienda que el servicio es de acompañamiento, para ayudar a mejorar en algún tema en específico, NO es para hacerles la tarea.

- La interacción es de uno a uno por lo que el aprendizaje es mejor.

5. ¿Cuáles son los principales atributos que debería incluir este servicio?

- Interacción en línea, que los padres puedan ver cómo están estudiando sus hijos.

- Enseñarles estrategias a los alumnos que puedan transferir en el colegio y en el examen.

- Desarrollar hábitos de estudio, rutinas que mejoren el desempeño del alumno.

- Métrica que pueda plasmar los resultados obtenidos por el alumno terminada la clase.

- Programa de incentivos, recompensas.

6. ¿Cuál es el perfil debería tener el tutor virtual?

- Motivador (que sepa escuchar al alumno para apoyarlo en el punto especifico que no entiende).

- Empatía

- Buen manejo de las herramientas tecnológicas. 


\section{7. ¿Qué duración debería tener este servicio tutorial virtual?}

Para chicos menores (primaria) 30 minutos y se le deja una tarea individual, pues en la repetición está el proceso de aprendizaje, una hora de tutoría no va a resolver todo el problema de aprendizaje

\section{8.- ¿Recomendaría este servicio?}

Sí

¿Por qué?

Primero tendría que comprobar la calidad del servicio, las recomendaciones son muy importantes, testimoniales que el servicio funciona.

\section{9. ¿Algún comentario que crea será de utilidad para nuestro proyecto?}

- Cuestionarios de satisfacción de los padres.

- Siempre después de la tutoría virtual, dejarles un trabajo que deban hacerlo individualmente, así van desarrollando hábitos de estudio y autorregulación del mismo alumno.

- Antes de la tutoría virtual, sobre todo en los menores se debe sostener una reunión presencial con padres para que se conozcan y les sea más familiar el tutor.

- Reunirse con profesores del colegio del estudiante para tener un mejor conocimiento del alumno, alineación para tener impacto en su desempeño escolar.

- Primera clase gratis para conocer el sistema.

10.- Porcentaje del total de alumnos que asisten a asesorías.

No aplica esta pregunta pues no es Director de colegio. 
Sara Costa. Profesora y Jefe de Área

1. De acuerdo a su experiencia profesional, ¿cuáles son los cursos de mayor dificultad en nivel primaria para los alumnos? Por favor ordene de forma descendente, 1 es el de mayor dificultad y 4 el de menor dificultad.

\begin{tabular}{|l|c|}
\hline & Orden \\
\hline Área de Matemática & 1 \\
\hline Área de inglés & 3 \\
\hline Área de Comunicación & 2 \\
\hline Área Ciencias & 4 \\
\hline Área tecnología & 0 \\
\hline
\end{tabular}

2.- ¿Piensa que los entornos virtuales generados por las TIC (tecnologías de información y comunicación) ayudan a optimizar el aprendizaje de los alumnos?

Sí por supuesto, son muy necesarios.

¿Por qué?

Permiten que los niños se involucren más y aprendan mejor pues es natural para ellos entender todo en internet, es parte de su vida diaria. Ellos están acostumbrados a acceder a entornos digitales para buscar información.

3. ¿Tiene conocimiento de algunos cursos que actualmente están utilizando las TIC en primaria o secundaria? ¿Cuáles son esos cursos?

Se utilizan en varios cursos, a veces como juegos para matemática, geometría, para ciencias, comunicación, inglés. Los profesores usan programas ya existentes o crean juegos para que los chicos interactúen mejor. Por ejemplo en 8vo grado aprenden geometría con un juego de Pac Man y se divierten aprendiendo.

4. ¿Usted cree que un servicio de tutoría virtual después del colegio para los alumnos que presentan dificultad en su aprendizaje, (sin ninguna complicación de fondo cognitivo), sería efectivo?

Sí, claro. 


\section{¿Por qué?}

- Están muy acostumbrados a la tecnología, Aunque alguno necesitan supervisión por su edad o por tender más tendencia a distraerse. Diría que de 1ro a 3ro requieren supervisión, a partir de 4to grado son más independientes.

- Algunos niños tiene problemas de aprendizaje y necesitan terapia.

\section{5. ¿Cuáles serían los principales atributos que debería incluir este servicio?}

- Que sean particularmente fuertes en tutoría de matemáticas en español e inglés

- Que tengan ejercicios disponibles de acuerdo al tema.

- User friendly.

- Que permita practicar ejercicios según el nivel y vayan avanzando de nivel. Debe haber retroalimentación al niño sobre los errores para que los supere y vaya avanzando.

- Muchos ejercicios de inglés.

\section{6. ¿Cuál es el perfil que debería tener el tutor virtual?}

- Mucha paciencia.

- Bagaje de estrategias para aplicar de acuerdo a las necesidades de los niños.

- Tener referencias de las metodologías del colegio.

- Saber qué esperan los padres de él o ella como profesora.

\section{7. ¿Qué duración debería tener este servicio tutorial virtual?}

Depende del chico, algunos toleran menos tiempo como 45 minutos, otros hasta más de 1.5horas. Se debe tener en cuenta que los chichos tienen más tareas a parte del curso en el que se les está ayudando.

\section{8. ¿Recomendaría este servicio?}

Si.

¿Por qué? 
Están acostumbrados al uso de internet en variados programas, redes.

\section{9. ¿Tiene algún comentario que crea será de utilidad para nuestro proyecto?}

- Tener un curso virtual para los profesores, preparándolos para esta enseñanza.

- En algunos colegios como contamos con programas de apoyo para los estudiantes con problemas de aprendizaje atendiéndolos con estrategias que les permiten suplir sus barreras de desorden o concentración de manera complementaria al tratamiento que pudieran tener de manera personal.

10. De su experiencia, por favor estime el porcentaje de necesidad de apoyo extra escolar.

Es difícil estimar, pero luego de muchos años de experiencia podría considerar que entre 30 y $40 \%$ de los niños requieren ayuda adicional.

\section{Muchas gracias.}


Nombre: Ursula Freundt Edad: 39

Profesión: Educadora de Inicial

1. Usted es profesor de tutoría para escolares; lo hace de manera particular directa y/o a través de alguna empresa?
a. Particular online
b. Particular a domicilio
c. Empresa online
d. ¿Cuál?
e. Empresa a domicilio
f. ¿Cuál?

2. ¿Qué cursos dicta?
a. Matemática
b. Comunicación integral, lenguaje
c. Inglés
d. Ciencias (especificar): Física Química Biología
e. Otro:

3. ¿A qué grados dicta?
a. Primaria: $1^{\circ}$ $2^{\circ}$ $\mathrm{X} \_3^{\circ}-\mathrm{X}$ $4^{\circ}$ 5
b. Secundaria: $1^{\circ}$ $2^{\circ}$ $3^{\circ}$ $4^{\circ}$ $5^{\circ}$ $6^{\circ}$

4. ¿Cómo verificas el avance en el aprendizaje de tus alumnos?

a) Les tomo ejercicios o pruebas una vez terminado el tema o dependiendo si es largo, en la mitad de cada capítulo.

b. $l o$ reportas? $\mathrm{Si} \mathbf{X}_{\text {_ }}$ No

c. ¿A quién? A la mamá o al papá.

5. ¿Quiénes te contratan?
a. Mamá
b. Papá
c. Otro, especificar 

6. ¿Cómo consigues alumnos?
a. Anuncio en internet
b. Anuncio en tiendas
c. Referidos por alumnos
d. Otros

7. ¿Consideras que es fácil conseguir alumnos particulares?

a. $\mathrm{Si}$

b. No

c. ¿Por qué? Hoy en día muchos niños tienden a desconcentrarse en clase, no atienden o no entienden al profesor, son varios que siempre necesitan refuerzo.

8. Queremos ofrecer un aplicativo para conectar profesores con alumnos para el dictado de clases particulares de manera virtual (online), ¿estarías interesado en contratar y dictar clases por este aplicativo?
a. Sí
X
b. No

9. Por favor indica el rango de tarifa que cobras actualmente por hora en soles.
a. Menos de 35
b. 35 a 44
c. 45 a 54
d. 55 a 64
e. $\quad 65$ a 74
f. 75 a 84
g. 85 a más

Especifica:

10. Para la respuesta anterior, ¿qué porcentaje de tu tarifa por hora estarías dispuesto/a a pagar para ser parte de este aplicativo?

Valor: $20 \%$ 
11. Sólo sí trabajas actualmente para una empresa, ¿qué comisión te cobran?

Valor: Soy profesora en el EIC y me descuentan lo concerniente a planilla

12. ¿Conoce alguna aplicación y/o página web que ofrezca algo similar? Por favor indicar.

Sí No $\quad X$

Cuál/cuáles:

13. ¿Qué ventajas le ves a este servicio?

Puedo dictar más horas de clase y hacerlo desde mi casa y no estar preocupándome por mis hijos en casa.

14. ¿Qué desventajas le ves a este servicio? (dudas del servicio, en cuanto a materias, edad...)

No estoy segura si para los niños con déficit de atención, les pueda funcionar

\section{Muchas gracias}

Muchas gracias por querer participar en esta entrevista, la cual nos ayudará a desarrollar mejor nuestro proyecto de Plan de Negocio para una Tesis de grado.

Nombre: Mónica Espantoso Edad: 39

Profesión: Educadora de Inicial

1. Usted es profesor de tutoría para escolares; ¿ lo hace de manera particular directa y/o a través de alguna empresa?
a. Particular online
b. $\quad$ Particular a domicilio
c. Empresa online
d. ¿Cuál? 

e. Empresa a domicilio
f. ¿Cuál?

2. ¿Qué cursos dicta?

a. Matemática

b. Comunicación integral, lenguaje

c. Inglés

d. Ciencias (especificar): Física Química Biología

e. Otro:

3. A qué grados dicta?

a. Primaria: $1^{\circ} 2^{\circ}$ $3^{\circ}-\mathrm{X}$

b. Secundaria: $1^{\circ}$ $2^{\circ}$ $3^{\circ}$ $4^{\circ}$ X 5 X $6^{\circ}$

\section{4. ¿Cómo verificas el avance en el aprendizaje de tus alumnos?}

a) Les tomo ejercicios o pruebas una vez terminado el tema o dependiendo si es largo, en la mitad de cada capítulo.

b. Lo reportas? $\mathrm{Si} \mathrm{X}_{\text {_ }}$ No

c. ¿A quién? A la mamá o al papá.

\section{5. ¿Quiénes te contratan?}

a. Mamá b. Papá X c. Otro, especificar
6. ¿Cómo consigues alumnos?
a. Anuncio en internet
b. Anuncio en tiendas
c. Referidos por alumnos
d. Otros

7. ¿Consideras que es fácil conseguir alumnos particulares?

a. $\mathrm{Si} \_\mathrm{X}$

b. No 
c. ¿Por qué? Hoy en día muchos niños tienden a desconcentrarse en clase, no atienden o no entienden al profesor, son varios que siempre necesitan refuerzo.

8. Queremos ofrecer un aplicativo para conectar profesores con alumnos para el dictado de clases particulares de manera virtual (online), ¿estarías interesado en contratar y dictar clases por este aplicativo?
a. Sí_X
b. No

9. Por favor indica el rango de tarifa que cobras actualmente por hora en soles.
a. Menos de 35
b. 35 a 44
c. 45 a 54
d. 55 a 64
e. $\underline{65 \text { a } 74}$
f. 75 a 84
g. 85 a más
Especifica:

10. Para la respuesta anterior, ¿qué porcentaje de tu tarifa por hora estarías dispuesto/a a pagar para ser parte de este aplicativo?

Valor: $20 \%$

11. Sólo sí trabajas actualmente para una empresa, ¿qué comisión te cobran? Valor: Soy profesora en el EIC y me descuentan lo concerniente a planilla

12. ¿Conoce alguna aplicación y/o página web que ofrezca algo similar? Por favor indicar.

Sí No _

Cuál/cuáles: 
13. ¿Qué ventajas le ves a este servicio?

Que puedo conectarme desde donde yo quiera y poder abarcar más horarios.

14. ¿Qué desventajas le ves a este servicio? (dudas del servicio, en cuanto a materias, edad...)

Depende mucho de la velocidad de la internet lo cual podría ser clave en este negoci.

\section{Muchas gracias}

Muchas gracias por querer participar en esta entrevista, la cual nos ayudará a desarrollar mejor nuestro proyecto de Plan de Negocio para una Tesis de grado.

Nombre: Franco Torres Edad: 27años

Profesión: Sicólogo educativo

1. Usted es profesor de tutoría para escolares; ¿lo hace de manera particular directa y/o a través de alguna empresa?

a. Particular online

b. Particular a domicilio

c. Empresa online

d. ¿Cuál?

e. Empresa a domicilio

f. ¿Cuál? Es Inglés

2. ¿¿Qué cursos dicta?
a. Matemática
b. Comunicación integral, lenguaje
c. Inglés
d. Ciencias (especificar): Física Química Biología
e. Otro: 
3. ¿A qué grados dicta?

a. Primaria: $1^{\circ} \quad 2^{\circ}$ $3^{\circ} \mathrm{X}_{-} 4^{\circ}{ }^{\circ} \mathrm{X} \_5 \ldots \mathrm{X} \_6^{\circ}{ }_{-} \mathrm{X}$

b. Secundaria: $1^{\circ} \mathrm{X} \_2^{\circ} \_\mathrm{X}-3^{\circ}-\mathrm{X} \_4^{\circ}$ $5^{\circ}$ $6^{\circ}$

4. ¿Cómo verificas el avance en el aprendizaje de tus alumnos?

a. Veo cómo les ha ido en sus pruebas b. lo reportas? Si $\mathbf{X}$ No

b. ¿A quién? A padres cuando es particular o a la empresa

5. ¿Quiénes te contratan?

a. Mamá X b. Papá X c. Otro, especificar Clases duran 2 horas. 2 a 3 veces por semana
6. ¿Cómo consigues alumnos?
a. Anuncio en internet
b. Anuncio en tiendas
c. Referidos por alumnos
d. Otros: la empresa me los da

7. ¿Consideras que es fácil conseguir alumnos particulares?

a. Si $\underline{X}$

b. No

c. ¿Por qué? Desde que la empresa ha comenzado a publicitarse por Facebook.

8. Queremos ofrecer un aplicativo para conectar profesores con alumnos para el dictado de clases particulares de manera virtual (online), ¿estarías interesado en contratar y dictar clases por este aplicativo?
a. Sí $\underline{X}$
b. No

9. Por favor indica el rango de tarifa que cobras actualmente por hora en soles.

a. Menos de 35 cuando es por empresa. Si son directos más. 

b. 35 a 44
c. 45 a 54
d. 55 a 64
e. 65 a 74
f. 75 a 84
g. 85 a más

Especifica: Precio también depende de la cantidad de horas.

10. Para la respuesta anterior, ¿qué porcentaje de tu tarifa por hora estarías dispuesto a pagar para ser parte de este aplicativo?

Valor: no veo porcentajes sino monto total.

11. Sólo sí trabajas actualmente para una empresa, ¿qué comisión te cobran? Valor: me pagan $\mathrm{S} / .25$

12. ¿Conoce alguna aplicación y/o página web que ofrezca algo similar? Por favor indicar.

Sí _ No

Cuál/cuáles:

13. ¿Qué ventajas le ves a este servicio?

- Mejora el potencial de los chicos, recomendaría que sea a partir de 3er grado. Creo que en mejores, sería mejor la tutoría presencial. Ya a partir de 3er grado son expertos en manejo de TIC's.

- Por la necesidad de movilizarme a dictar clases a domicilio hoy, me permitiría dar más clases si estresarme por el tráfico de Lima. El profesor y el alumno no llegan tarde. Se optimiza el tiempo.

- Puedo dar las clases desde cualquier lugar, por ejemplo desde el Regatas.

- Podría ser sea competitivo, es decir, se permitan tutorías grupales

- Puede tener muchas imágenes.

- Puede ser muy (friendly) amigable. 
14. ¿Qué desventajas le ves a este servicio? (dudas del servicio, en cuanto a materias, edad...)

- Tener el equivalente a una pizarra, o que los profesores tengan pizarra en para mostrar allí los ejercicios.

- Tener un curso virtual para los profesores, preparándolos para esta enseñanza.

\section{Muchas gracias}

Muchas gracias por querer participar en esta entrevista, la cual nos ayudará a desarrollar mejor nuestro proyecto de Plan de Negocio para una Tesis de grado.

Nombre: Diego Frank Lam Edad: 18años

Profesión: Estudiante de Negocios Internacionales en UPC Monterrico.

1. Tú eres profesor de tutoría para escolares; lo haces de manera particular directa y/o a través de alguna empresa?

a. Particular online

b. Particular a domicilio

c. Empresa online

d. ¿Cuál?

e. Empresa a domicilio

f. ¿Cuál?

2. ¿Qué cursos dictas?

a. Matemática

b. Comunicación integral, lenguaje

c. Inglés

d. Ciencias (especificar): Física Química Biología

e. Otro: 
3. ¿A qué grados dicta?
a. Primaria:
$1^{\circ}$
$2^{\circ}$
$3^{\circ}$ $5 \underline{X}$
$6^{\circ} \underline{X}$
b. Secundaria: $1^{\circ} \underline{X}$
$2^{\circ} \underline{X} 3^{\circ}$
$4^{\circ}$
$5^{\circ}$
$6^{\circ}$

4. ¿Cómo verificas el avance en el aprendizaje de tus alumnos?

a) Me doy cuenta porque les hago seguimiento continuo. Veo cómo están sus bases para enfocarme en ellas. Lo reportas? Si $\underline{X}$ No

c. ¿A quién? A sus padres

5. ¿Quiénes te contratan?

a. Mamá $\underline{X}$ b. Papá $\underline{X}$ c. Otro, especificar Las clases son de 2 horas/ 2 a 3 veces por semana.
6. ¿Cómo consigues alumnos?
a. Anuncio en internet
b. Anuncio en tiendas
c. Referidos por alumnos
d. Otros: la empresa me los da

7. ¿Consideras que es fácil conseguir alumnos particulares?
a. Si $\underline{X}$
b. No
c. ¿Por qué? Ellos mismos recomiendan.

8. Queremos ofrecer un aplicativo para conectar profesores con alumnos para el dictado de clases particulares de manera virtual (online), ¿estarías interesado en contratar y dictar clases por este aplicativo?
a. Sí X
b. No

9. Por favor indica el rango de tarifa que cobras actualmente por hora en soles.

a. Menos de 35 

b. 35 a 44
c. 45 a 54
d. 55 a 64
e. 65 a 74
f. 75 a 84
g. 85 a más

Especifica: S/ 20, también depende de la cantidad de horas.

10. Para la respuesta anterior, ¿qué porcentaje de tu tarifa por hora estarías dispuesto/a pagar para ser parte de este aplicativo?

Valor: depende de la cantidad de horas y alumnos.

11. Sólo sí trabajas actualmente para una empresa, ¿qué comisión te cobran? Valor: N.A.

12. ¿Conoce alguna aplicación y/o página web que ofrezca algo similar? Por favor indicar.

Sí No $\underline{X}$

Cuál/cuáles:

13. ¿Qué ventajas le ves a este servicio?

- El mundo está globalizado y se va dejando lo físico para dar paso a lo virtual, por ejemplo las monedas.

- Más comodidad porque lo puedes hacer desde tu casa

- Multi alumnos.

- Se cortan tiempos al no tener que movilizarte

- Te rinde más el tiempo. Enseño porque no quería depender de pedir plata a mis padres. 
14. ¿Qué desventajas le ves a este servicio? (dudas del servicio, en cuanto a materias, edad...)

- Aún hay padres que no están inmersos en la tecnología y le temen o no confían en ella.

- Alumnos ya entran a You Tube a buscar tutoriales y es gratis.

- Podría haber un primer impacto negativo al no tener la presencia física.

- Que el profesor no logre empatía con los alumnos. Se debe construir relaciones.

- Quizás no ver lo que está haciendo el alumno.

\section{Muchas gracias}

